\title{
LOS CONTEXTOS FUNERARIOS Y LOS MATERIALES AROUEOLÓGICOS DE LA HUACA CONCHA ${ }^{1}$
}

\author{
GORI TUMI ECHEVARRÍA LóPEZ \\ Arqueólogo, Universidad Nacional Mayor de SAN MARcos \\ goritumi@gmail.com \\ ALEX ZÚÑIGA CRIOLLO \\ Aroueólogo, Universidad Nacional Mayor de SAN Marcos \\ alexxxito75@hotmail.com
}

\section{RESUMEN}

A partir de un proyecto de investigación de materiales arqueológicos, los autores desarrollan el inventario, clasificación y ordenamiento de artefactos arqueológicos procedentes de la Huaca Concha, que fueron recuperados desde 1989 hasta 1994, y luego depositados en los ambientes de la Escuela de Arqueología de la Universidad Nacional Mayor de San Marcos.

El objetivo principal del estudio consistió en la identificación y reintegración de los diversos contextos funerarios rescatados de la Huaca Concha, que estaban siendo reorganizados y almacenados por ítems materiales en los depósitos de la Escuela. Esta labor permitió también identificar momentos de levantamiento de colecciones específicas, responsables de las recuperaciones y por sobre todo conjuntos adicionales de materiales culturales con relevancia para la historia del sitio arqueológico y su comprensión histórica.

Palabras Clave: Lima, Huaca Concha, contexto funerario, colección, artefacto arqueológico

1. Este documento fue presentado a la Escuela de Arqueología de la Universidad Nacional Mayor de San Marcos en mayo del año 2005. Aquí se publica con algunas correcciones y modificaciones mínimas. 


\section{AbSTRACT}

Follow a research project of archaeological materials, the authors develop the inventory, classification and ordering of archaeological artifacts from the monument Huaca Concha, that were recovered from 1989 to 1994 and later deposited in the School of Archaeology of the San Marcos University.

The main objective of the study consisted of the identification and reintegration of various funerary contexts rescued from Huaca Concha, that were being reorganized and stored by material items in the deposits of the school of archeology. This work also helped identify moments of material collection, responsible for recoveries and especially additional collections of cultural materials relevant to the history and the historical understanding of this archaeological site.

KEYWORDS: Lima, Huaca Concha, funerary contexts, collection, archaeological artifact

\section{INTRODUCCIÓN}

El presente documento constituye el resultado final del proyecto de investigación "Los Contextos Funerarios y los Materiales Arqueológicos de la Huaca Concha", el mismo que se llevó a cabo en los ambientes de la Escuela de Arqueología de San Marcos entre los años 2003 y 2004, bajo la aprobación y supervisión de la dirección de la misma Escuela.

El proyecto fue diseñado originalmente para reagrupar y estudiar materiales arqueológicos provenientes de la Huaca Concha recuperados en 1993, sin embargo, debido a la cantidad y variedad de los objetos depositados en la Escuela, se logró hacer el registro y reagrupación de artefactos y contextos provenientes de este sitio, mismos que fueron recuperados con intermitencias durante casi una década, entre 1989-1994.

A continuación se expone la forma en que los materiales del sitio fueron recuperados y depositados en los gabinetes de la Escuela de Arqueología; y cómo éstos mismos materiales fueron utilizados, inventariados y re-almacenados en los mismos depósitos. Además se explica y propone la recomposición final de los contextos de procedencia de la mayor parte de la colección y por consiguiente, el ordenamiento definitivo de estos materiales para su uso y estudio científico.

\section{ANTECEDENTES}

Aunque el Proyecto de Investigación presenta un objetivo muy explícito, nuestro interés por documentar los materiales de la Huaca Cocha empieza después de su mismo depósito en los gabinetes de la Escuela de Arqueología el año 1993, luego de ser recuperados de la destrucción parcial que sufrió el sitio ese año. Hasta el 2003 no se realizó una intervención efectiva en estos materiales, debido a la falta de condiciones adecuadas de trabajo en el Gabinete de la Escuela, lo que hizo que estas evidencias se almacenaran caóticamente por muchos años. ${ }^{2}$

Aunque se hicieron intentos por documentar los contextos y materiales recuperados de la Huaca Concha ${ }^{3}$, además de su proceso de destrucción ${ }^{4}$, mucha de la información original referente a estos

2. El Licenciado Daniel Morales Chocano, Director de la Escuela de Arqueología el año 2003, cambió el estado del Gabinete y facilitó el ordenamiento y el estudio de los materiales arqueológicos almacenados allí.

3. ECHEVARRÍA LÓPEZ, Gori Tumi: Catálogo de materiales de la Huaca Concha de 1993. Manuscrito. Lima, 1993; Inventario del material recuperado del Fardo disturbado A. Manuscrito. Lima, 1993; El rescate arqueológico de la Huaca Concha. Actas y Trabajos. V Congreso Nacional de Estudiantes de Arqueología "Luis A. Pardo" Pp. 37-48. UNSAAC. Cusco, 1995; Huaca Concha, Notas y el Catalogo inédito de 1993. Revista de Investigaciones del CEAR 6:55-65. UNMSM. Lima, 2004. 
sucesos permaneció inédita, se dispersó o desapareció irremediablemente, a medida que los sucesos de esta destrucción perdían vigencia y de que los estudiantes que participaron de los rescates egresaban de la universidad sin desarrollar ningún reporte.

En este sentido, la tragedia del sitio arqueológico no sólo corresponde a su extensa destrucción física y material, sino a la pérdida de su documentación; la cual, como se verá más adelante, no sólo comprende los variados rescates que se hicieron en 1993, sino el conjunto de los mismos.

Esta falta de documentación no es de ninguna forma suplida por el presente reporte, quizás exceptuando una de estas intervenciones en 1993, es más que evidente que en todos los casos va a ser necesaria una búsqueda adicional de información y posiblemente, entrevistas con los participantes de las recuperaciones, si es que se quiere entender mejor la historia del sitio.

\section{El proyecto}

La propuesta original de investigación se diseñó para estudiar los materiales arqueológicos que fueron recuperados en el sitio durante las labores de rescate ocurridas entre el 26 y 27 de agosto de 1993, donde los autores del reportve participaron directamente. Dado que este rescate intervino fundamentalmente cuatro contextos funerarios ${ }^{5}$, es que el proyecto se nominó "Los Contextos funerarios y los materiales arqueológicos de la Huaca Concha"6.

La investigación fue inspirada en la exposición temporal llamada "Huaca Concha Diez años después”, la cual se realizó en el auditorio Toribio Mejía Xesspe de la Escuela de Arqueología de San Marcos entre el 2 y 20 de diciembre del año 2002. En esta exposición pudimos comprobar que los materiales del sitio, recuperados en 1993, habían sido objeto de importante manipulación, la cual incluyó además un reordenamiento de su almacenaje en el gabinete.

Una de las razones por la que se decidió proponer esta investigación, fue que la "Comisión de Inventario General del Gabinete de Arqueología”", quienes también organizaron la muestra temporal, desconocían claramente los antecedentes del rescate de parte del material expuesto y especialmente, la forma en que se realizó el almacenaje del mismo; por lo cual supusimos que estos artefactos estaban siendo tratados como un conjunto sin contexto específico.

También advertimos que la manipulación de los objetos, sin la adecuada información de procedencia y almacenaje, podría acarrear problemas futuros si se pretendía dotar a la colección Huaca Concha de connotaciones culturales. Aunque el reordenamiento de estos objetos ha favorecido su conservación, la cual sin duda era crítica, se hacía necesario desarrollar un trabajo que reconstituyera la información de origen de la colección del sitio.

Así, la propuesta original, programada entre el 20 de febrero y 15 de julio del 2003, incluyó dos etapas operativas con los materiales y una de redacción: a. "Reagrupamiento, recuperación y recatalogación del material", b. "Análisis del material"; y c. "Redacción del reporte final". Estas labores debían complementar el trabajo de ordenamiento y catalogación de la Comisión de Inventario designada por la propia Escuela.

4. NARVÁEZ LUNA, José Joaquín: La Huaca Concha y su proceso de destrucción. Manuscrito. Lima, s/f.

5. Contextos funerarios A, C, D y E. Cf. Echevarría 1995.

6. Propuesta de Investigación presentada a la Escuela de Arqueología de San Marcos el 19 de febrero del 2003, y aprobada por el Comité Asesor de la Escuela de Arqueología el 5 de marzo del 2003. Autorización de la Escuela expedida el 10 de marzo del 2003.

7. Compuesta por las estudiantes Maria Ysela Leyva Velasco, Diana Antezana Ruiz y María Díaz. 
Por razones particulares nunca se pudo ejecutar la segunda etapa del trabajo propuesto mientras que la primera fue llevada a cabo hasta donde la Comisión de Inventario permitió, lo que se debió al procedimiento asociado de registro de los materiales. En todo momento trabajamos sobre la base de los progresos de la Comisión puesto que nuestro proyecto debía operar “... sin alterar los registros y procesos de catalogación previamente implementados” (Cf. Propuesta de Investigación, 2003)

Como ya dijimos, la investigación intervino finalmente en materiales que fueron recuperados no sólo en 1993, sino en años anteriores y posteriores; en este sentido el trabajo se complicó por la falta de información adicional relacionada a estos sucesos, lo que hizo necesaria la extensión y el replanteamiento sucesivo de nuestros sistemas de registro y en teoría, nuestra selección de contextos relevantes de estudio.

Hasta nuestra intervención final en la colección Huaca Concha, se trató en lo posible, de mantener una coordinación fluida y directa con los miembros de la Comisión de Inventario, con los que trabajamos la mayor parte del tiempo en forma simultánea, y de complementar la información de nuestro trabajo con entrevistas a algunos participantes directos de los sucesos en el sitio arqueológico; de esta forma el proyecto completó, lo que consideramos constituye la parte más relevante de la propuesta original de trabajo.

\section{El inventario realizado por la Comisión de la Escuela}

Aunque no conocemos los términos del proyecto original presentado por la Comisión de Inventario de la Escuela de Arqueología, sabemos por propia experiencia, la forma en que esta Comisión ejecutó parte de su labor, especialmente con los materiales de Huaca Concha; lo que se debe parcialmente a que nuestra intervención se hizo efectiva cuando la Comisión tenía más de medio año laborando en el gabinete y continuaba con el ordenamiento de los materiales del referido sitio ${ }^{8}$.

Al respecto, hay que reconocer que la Comisión de Inventario tuvo que afrontar un arduo trabajo debido a las caóticas condiciones en que el Gabinete se encontraba, especialmente porque muchos de los materiales recuperados en los "rescates", dentro y fuera del Campus de la Universidad, habían sido depositados arbitrariamente, y en general, sin ninguna referencia contextual adecuada; lo que también se aplica a los materiales de la Huaca Concha recuperados en 1993.

Aunque Huaca Concha recibió un trato especial, lo que se evidencia por la exposición temporal que se hizo de sus objetos, era de esperar que muchas de las colecciones del Gabinete fueran inventariadas de acuerdo únicamente a su sitio de procedencia, siendo almacenadas de forma genérica, como bloques particulares, lo que explica en parte el tipo de manipulación de que fueron objeto después.

Debido a que al momento en que empezamos nuestra intervención en los materiales de Huaca Concha la Comisión de Inventario aún no había presentado ningún informe de actividades, es que tuvimos que entrevistar a la Coordinadora de la Comisión ${ }^{10}$, y luego deducir mediante observación la forma en que se operaba con las colecciones del gabinete, lo cual realizamos mientras duró el trabajo.

8. De acuerdo a la coordinadora de la Comisión de Inventario, sus labores empezaron el 12 de agosto del 2002. Hasta nuestra última intervención (Julio del 2004) parte los materiales de Huaca Concha no habían terminado de ser ordenados y almacenados.

9. La mayoría de estas recuperaciones en realidad, no fueron "rescates" arqueológicos de modo alguno. Se trataron de simples colecciones de objetos arqueológicos recogidos y salvados de destrucciones en progreso, lo que se hicieron en la mayoría de los casos sin ningún control y registro adecuado.

10. Arql. María Ysela Leyva. 
De acuerdo a la Coordinadora de la Comisión, la operación en las colecciones de la Escuela se hizo mediante el ordenamiento progresivo de los materiales depositados en los ambientes del gabinete, muchos de los cuales se encontraron originalmente en desorden, lo que obligó a proceder en relación a su disposición específica ${ }^{11}$. A pesar de esto, cuando fue posible se procedió por conjuntos, interviniéndose primeramente el material excavado en la Huaca San Marcos en $1988^{12}$ y luego el resto de la colección.

Basado en su disposición, todas las colecciones fueron reagrupadas, reordenadas y contabilizadas sobre la premisa de una distinción de categorías de artefactos, para luego ser embolsadas, codificadas y colocadas en nuevas cajas sobre estantería ${ }^{13}$. Los códigos particulares, en las nuevas fichas de registro, se resolvieron de acuerdo a un número arbitrario de conteo para la bolsa específica con material cultural, y al número del sitio arqueológico del campus de San Marcos precedido de la letra $\mathrm{H}^{14}$.

Hasta donde sabemos todos los datos fueron tabulados en una lista cuyo código o número correlativo de inventario antecedía a todas las referencias de procedencia y contextuales. Esta lista englobaba todos los materiales recuperados en el campus de la universidad que incluían los sectores 9, 11, Huaca Concha y Huaca San Marcos ${ }^{15}$, cuando se conocía el origen; y del Complejo Maranga (Ciudad Universitaria - Maranga) cuando no se conocía el mismo. Además también, de materiales recuperados fuera del mismo campus.

Este trabajo sin duda permitió tener, por primera vez, una lista coherente del número de colecciones depositadas en el gabinete y especialmente de la cantidad y variabilidad del material almacenado; y aunque este arreglo con toda probabilidad hubiese cumplido con los objetivos básicos de un inventario, la Comisión intervino adicionalmente la mayoría de los grupos establecidos en el ordenamiento, los que fueron objeto de manipulaciones no relacionadas directamente a su catalogación y almacenaje.

Este tratamiento adicional ${ }^{16}$ incluyó la clasificación y conteo del material cerámico y óseo en categorías complementarias de elementos: “diagnósticos” para la cerámica, y del tipo de pieza ósea

11. Lo que explicaría circunstancialmente por qué parte de la colección de Huaca Concha no se terminó de inventariar hasta marzo del 2003

12. Un proyecto de emergencia en el denominado "Sector Plaza" al este de la Huaca San Marcos. Ejecutado por el "Taller III de Arqueología” bajo la supervisión del profesor Elías Mújica en los primeros meses de 1988. Ver, LOZANO CALDERÓN, Anselmo y José RAMÍREZ ROJAS, Informe de la Excavación efectuada en la Huaca San Marcos. EAP. de Arqueología. UNMSM. Lima, 1988. Ms.

13. Las cajas incluyeron un código numérico adicional seguido de la referencia al material exclusivo que era contenido, así por ejemplo: 3 Cerámica, 5 óseo, etc. Hasta julio del 2004 las cajas con el material de Huaca Concha no tenían un número definitivo.

14. Por ejemplo: 119-H12 (bolsa 119, Huaca Concha). La numeración de sitios se basó en: Canziani, 1987, y Santillana, 1988.

15. El uso de la numeración para identificar los sitios fue caótico, es evidente que la nomenclatura, en el inventario, no ha sido estandarizada a pesar que los sitios del campus de la universidad fueron numerados en una evaluación arqueológica (Santillana, 1988). Para nosotros es claro que la numeración de Canziani, únicamente impuesta en Huaca Concha (ver Gaceta Arqueológica Andina 14: 10, 1987) ha complicado innecesariamente la nomenclatura y esta no debería utilizarse. Ver Informe de la Junta Deliberante Metropolitana de lugares Históricos, Artísticos y Lugares Arqueológicos de Lima Metropolitana (1962-1963), la numeración está vigente, y el número 12 corresponde a otra Huaca demolida en La Victoria.

16. Practicado principalmente en la colección de la Huaca San Marcos. 
para los materiales osteológicos; mismos que fueron almacenados en cajas independientes. Es probable que otros materiales hayan sido también objeto de un tratamiento similar, aunque no tenemos noticias al respecto. No conocemos, salvo información adicional, que una lista extra de artefactos clasificados haya sido elaborada aparte de la lista matriz de inventario.

Independientemente de las connotaciones de esta labor, y a pesar que no sabemos cuales fueron los agrupamientos de materiales de los que se pudo recuperar información contextual, es claro para nosotros que este "ordenamiento" fue derivado de la manipulación del material y de la intención del Comité en facilitar el acceso y el estudio de estas colecciones en la Escuela, colecciones que no habían sido objeto de estudio desde que fueron originalmente almacenadas.

Por otra parte, el caso de Huaca Concha es diferente. De acuerdo a la Coordinadora del inventario, los materiales de este sitio fueron reconocidos como un grupo compacto durante las labores iniciales de organización por lo que se procedió a su reordenamiento inmediatamente después de catalogarse el material de la Huaca San Marcos recuperado en 1988. Lo que diferenciaba a la colección, sin embargo, es que el material reconocido incluía una importante variedad de artefactos arqueológicos, además de contextos funerarios completos.

Debido a que la Comisión de Inventario desconocía el origen de este material, esta se informó someramente de los sucesos que acarrearon su rescate, y que propiciaron su estancia en el gabinete, por la dirección y profesores de la escuela; y eventualmente por algunos estudiantes que participaron de estos acontecimientos. Esta información, no obstante, careció de los datos de contexto y especialmente de toda referencia derivada sobre la manera de almacenaje y organización del material, por lo que se procedió con su catalogación estándar; es decir, por categoría de ítems.

Esta separación estándar por ítems ha sido clave y ha tenido efectos contundentes en el posterior resultado de las labores de reagrupamiento y recatalogación de los materiales arqueológicos del sitio. Sin contar, además, con que la mayoría del material fue objeto de manipulación y estudios adicionales no relacionados al inventario de la Comisión.

Debido a que la Comisión no tenía claras referencias orales o escritas sobre la situación del material en la Escuela, esta falló en notar que una parte considerable de los artefactos habían sido previamente objeto de un registro y catalogación, el cual dejó marcas físicas derivadas de esta labor en la mayoría de los contenedores y bolsas que almacenaban el material recuperado; omisión que, pensamos, se debió al procedimiento mecánico de inventario que se estaba ejerciendo en el gabinete.

Un caso claro es, por ejemplo, el que se hallan registrado materiales sin procedencia o asociación cuando se encontraron sin fichas de registro, a pesar que fueran halladas junto a otros materiales con tales referencias y en los mismos contenedores o cajas, las cuales en la mayoría de los casos correspondían a recuperaciones únicas y presentaban número de catalogación. Muchos de estos materiales fueron disociados de su contenedor, cuyo número nunca fue registrado por la Comisión ${ }^{17}$, siendo registrados particularmente.

Otros materiales sufrieron el deterioro de sus fichas de registro ${ }^{18}$ por lo que no fueron revisadas y se trataron como objetos sin contexto, mientras que en otros casos no se verificó adecuadamente y/o

17. La Coordinadora de la Comisión de Inventario nos mostró fotos de las cajas originales en que se depositó el material de Huaca Concha, donde se pueden observar claramente los números de registro en sus paredes exteriores. Este número lamentablemente jamás fue registrado.

18. Estas fichas fueron muy variadas debido a que fueron hechas por diferentes personas sin seguir un único patrón de registro. 
guardó la ficha original de registro que contenía adendas derivadas de su catalogación temprana; la cual unificaba los apuntes particulares que se efectuaron en los materiales durante los destrozos en el sitio. En ambos casos por simples omisiones se afectó la colección.

Por otra parte y tal como mencionamos anteriormente, también la mayoría de los materiales de la colección fueron objeto de manipulaciones y estudios independientes. Así, de acuerdo a la Coordinadora de la Comisión de Inventario, parte del material textil, ictiológico, malacológico, botánico y lítico fue utilizado particularmente; sin contar la cerámica, óseo y muchos otros artefactos que fueron usados para ser dispuestos en la exposición temporal de diciembre del 2002.

Según la información recabada, el material textil fue hallado en tres cajas diferentes del grupo Huaca Concha siendo preliminarmente limpiados y catalogados hasta el 3 de setiembre del 2002. En algún momento de esta labor, sin embargo, se decidió que estos materiales fueran dispuestos para análisis del curso de textiles de Taller II de arqueología en el mismo año ${ }^{19}$; y aunque algunos textiles se codificaron juntos, se sugirió que el material se individualizara para análisis. Hasta julio del 2004 no se conocían los reportes de esta labor por parte de la Comisión, independientemente del trabajo estudiantil realizado.

Así también se analizó parte de material ictiológico que fue tomado de un mate de la colección, lo cual se hizo en la casona universitaria, y del que no se conoce ningún reporte al respecto hasta julio del 2004. Igualmente pasó con una muestra de restos malacológicos que fueron estudiados en el mismo local ${ }^{20}$ y del que tampoco se sabe de ningún reporte; a lo que hay que añadir que estos materiales fueron rotulados. Y de la misma manera sucedió con parte del material botánico ${ }^{21}$.

Por otro lado el material lítico se examinó en la Escuela de Arqueología, aunque tampoco se conoce ningún reporte de labores. Lo más relevante de esta intervención, siguiendo la información proporcionada por la Coordinadora, es que algunas piezas del conjunto fueron eliminadas de la colección bajo el argumento de que no eran "culturales"22.

Hasta aquí es obvio que estos materiales se analizaron de acuerdo a factores de oportunidad más que a un proyecto consistente y planificado, a pesar que formaron parte de las actividades destinadas a habilitar la exposición temporal de Huaca Concha. Más allá de esto e independientemente de su inventario, es evidente que la colección fue ampliamente usada, y no podemos dejar de mencionar que también se manipuló, y se expuso después, cerámica, óseo, y algunas muestras de artefactos con manufactura, como cestería y escultura en madera.

Aunque tal como hemos mencionado, los procedimientos de registro, catalogación y manipulación del material han tenido y van a tener consecuencias en estudios posteriores, considerando fundamentalmente el desconocimiento del origen y contexto arqueológico de procedencia, reconocemos que la Comisión hizo un esfuerzo extraordinario por verificar adecuadamente todas las colecciones y dotarlas de funcionalidad, pero sobre todo, por conservar y rescatar un material del olvido y la destrucción al que estuvo destinado por más de una década.

19. De acuerdo a la coordinadora de la Comisión, la idea de analizar los textiles de Huaca Concha fue propuesta por Maria Ysela Leyva, Diana Antezana y la profesora Maria Bastiand.

20. Estos materiales fueron analizados por el Sr. Eduardo Rivas.

21. Este material fue analizado por el Sr. J. J. Alegría

22. Este examen y eliminación de piezas fue hecho por la Srta. Claudia Grimaldo. 


\section{El material durante el periodo 2003 y 2004}

Hasta aquí está claro que al momento en que empezamos nuestra intervención en el Gabinete de la Escuela de Arqueología, el grueso del material Huaca Concha se encontró perfectamente almacenado y dotado de sus respectivos códigos de inventario; mientras duró nuestra labor, sin embargo, parte de la colección no había terminado de ser inventariada y catalogada apropiadamente, e incluso materiales que habían sido objeto de estudio y manipulación esperaban ser nuevamente codificados y reintegrados al grupo.

Independientemente de la situación descrita, las condiciones del material y del gabinete eran adecuadas para el trabajo por lo que la labor de reagrupamiento y recatalogación de contextos se hizo con normalidad, básicamente entre el 25 de febrero y 28 de marzo del $2003^{23}$. El trabajo, no obstante, sólo pudo ser completado parcialmente hasta julio del 2004 cuando parte del material textil fue finalmente incorporado a la colección mediante su almacenaje respectivo.

Aunque parte de los materiales de Huaca Concha fueron llevados y traídos de los ambientes del Museo de Arqueología de San Marcos (en la Casona Universitaria), luego de sus análisis respectivos, toda la colección, exceptuando únicamente los fardos funerarios A y B, se encontraron en el gabinete de la Escuela de Arqueología y fueron objeto del inventario. Los fardos funerarios mencionados fueron trasladados a la misma Casona Universitaria para un proyecto particular de investigación el año de $1996^{24}$.

Hasta el año 2005, los fardos no habían sido reincorporados a la colección del gabinete, cosa que es necesario hacer, especialmente porque esto completaría los contextos más relevantes rescatados. Aparte de esto, nuestra intervención en la colección Huaca Concha, llevada a cabo únicamente en el gabinete de Arqueología, ha mantenido la misma disposición y orden con la que estos materiales fueron dotados por la Comisión de Inventario, y así han debido permanecer hasta la actualidad.

\section{Métodos y Procedimientos}

En general, la forma en que el proyecto llevó a cabo sus actividades ya fue expuesta en el informe de la primera etapa de investigación que se presentó a la Dirección de la Escuela de Arqueología en abril del 2003, y el cual se arregló en dos secciones: 1. La revisión de las colecciones materiales y, 2 La recuperación de información sobre los objetos salvados. Este esquema no fue alterado, aunque sufrió modificaciones mientras se completó tardíamente la labor; en este reporte vamos a presentar más detalladamente el procedimiento seguido.

\section{Aspecto metodológico}

Debido a que el objetivo fundamental de la investigación se basó en el reagrupamiento y recuperación de contextos arqueológicos, la principal preocupación del trabajo fue la de determinar cual sería el indicador o los indicadores básicos, en las referencias de los materiales, que permitirían realizar esta labor.

23. Cf. Echevarría López, Gori Tumi y Alex Zúñiga Criollo. Informe de Investigación. Los Contextos Funerarios y Los Materiales Arqueológicos de la Huaca Concha. Primera Etapa, Reagrupamiento, Recuperación y Recatalogación de Materiales. Presentado a la dirección de la Escuela de Arqueología el 10 de abril del 2003.

24. De acuerdo al arql. Flavio Estrada (comunicación Personal), estos fardos fueron formalmente solicitados al Dr. Jorge Silva cuando era Director de la Escuela de Arqueología, y fueron llevados a la Casona Universitaria cuando el Director del Museo de San Marcos era el Dr. Alberto Bueno. Fue a través de la administración de la Casona que se facilitó el transporte de los restos. 
En este sentido, determinar la noción de "contexto" ha sido singularmente relevante antes de intervenir la colección. Así, el concepto se definió de acuerdo a la procedencia y la asociación del material que fue recuperado del sitio, y fundamentalmente, en la combinación de estos con la fecha en que este material fue levantado. El uso de este concepto dio resultados efectivos, aunque hay que decir que este criterio va a diferir de la noción clásica de "contexto" arqueológico, que implica la determinación de la posición del objeto y sus asociaciones relevantes dentro de un mismo sustrato espacial y cronológico ${ }^{25}$.

Debemos enfatizar que el uso de la fecha del levantamiento del material y no una referencia contextual directa del mismo, se usó como un indicador clave en la investigación, por dos razones fundamentales. Primero, porque el material se recuperó sin mediar ninguna investigación, por lo que su situación específica en el yacimiento no es técnicamente conocida. Y segundo, porque la mayoría de los registros fueron redactados por diferentes personas, las que usaron diferentes convenciones, incluso para las mismas asociaciones arqueológicas reconocidas.

Definido el criterio de "contexto", se diseñó consecuentemente un formulario de registro lo suficientemente extendido para poder incluir tanto los datos relativos a su situación actual e inventario, así como aquellos derivados de su recuperación original; es decir de contexto arqueológico.

Esta ficha fue única y se convirtió en la principal herramienta de investigación, la cual se usó extensivamente en toda la colección, sufriendo sólo mínimas correcciones mientras se ajustaban los parámetros de registro y correlación de datos.

Elaborado el formulario se operó básicamente por observación directa del material y por una revisión acuciosa de las fichas de registro, especialmente las originales que aún permanecieron asociadas a los objetos. Esta labor se realizó ininterrumpidamente en toda la colección, excepto con los textiles que sólo fueron parcialmente registrados hacia el final de la misma. La documentación producida y almacenada en estas hojas de registro fue finalmente trasladada a una base de datos para su posterior manejo.

Aunque se contempló la cuantificación del material, la manipulación de este no incluyó en ningún caso el conteo de las muestras almacenadas debido a que estas no constituían un indicador relevante a la hora de reagrupar los contextos arqueológicos; de esta forma sólo se consideraron las bolsas de almacenaje como unidades singulares, y sobre esa misma condición fueron cuantificadas en los resultados.

Como es claro en la explicación, el método, tal como se describe, se diseñó exclusivamente para cubrir los aspectos relativos al reconocimiento y la reagrupación virtual de los objetos en series tabuladas de grupos -contextos- con posible significación cultural, los que se exponen más adelante. Su aplicación práctica no ha significado en ningún caso, y deseamos hacer énfasis en esto, la alteración de las condiciones en las cuales reconocimos el material de Huaca Concha almacenado en los gabinetes de la Escuela de arqueología.

\section{Correlaciones}

Como se explicó atrás, la definición de contexto fue clave para el reagrupamiento de los materiales en unidades con significación cultural. Para esto, se correlacionaron primariamente la procedencia y

25. De acuerdo al Dictionary of Terms and Techniques in Archaeology de Sara CHAMPION. Facts On File, Inc. NY, 1980. El Contexto es: "The spatial and chronological setting of an artefact or culture. The context of a find is its position on a site, its relationship through association with other artefacts, and its chronological position as revealed through stratigraphy". 
la asociación de los materiales con la fecha del levantamiento, las cuales se encontraron en las fichas de registros originales o nuevas. Aunque muchas de las referencias no fueron uniformes, esta combinación de indicadores fue eficaz para ordenar inicialmente la mayoría de la colección reconocida.

Aunque el procedimiento fue, como se puede deducir, bastante estandarizado, se trataron de utilizar algunos elementos auxiliares ${ }^{26}$ para poder relacionar los materiales arqueológicos inventariados con algunos de los contextos de los cuales se tenía referencia anterior, como el contexto funerario "FDA" del 26 de agosto de 1993. Lamentablemente, este intento fue poco eficaz, pues muchos de los materiales habían sido separados de sus contenedores originales por lo que la correlación se hizo principalmente en base a la información de las fichas de registro.

Las fichas de registro originales aportaron muchos elementos que fueron relevantes en la integración de los datos para agrupamientos, pero también permitieron interpolar información adicional que facilitó el ajuste de tales agrupaciones, especialmente porque en la mayoría de los casos los datos de contexto no fueron uniformes, como ya hemos dicho, incluso para las mismas asociaciones de artefactos. Así, a la fecha, la procedencia y la asociación, se sumaron los datos del excavador o firmante de la ficha y la presencia de códigos o claves anteriores de registro y catalogación.

El procedimiento general siguió básicamente un orden de agrupamiento encabezado por la fecha y luego la procedencia y la asociación. Así, materiales individuales con fechas únicas formaron grupos particulares pequeños, y muchos materiales con fechas coincidentes formaron grupos extensos, mismos que se fueron ajustando con los demás datos de contexto. Las subunidades formadas se ajustaron aún más con el uso de la referencias de los excavadores o registradores, e incluso con claves de catálogos anteriores.

Un elemento adicional en la correlación fueron los números o códigos de inventario, que se usaron en algunos casos para confirmar o ajustar algunos agrupamientos. Esto se pudo realizar debido a que muchos de los materiales catalogados por la Comisión se inventariaron en una secuencia lineal que en muchos casos siguió el orden original en que el material fue depositado. Es claro aquí, que la Comisión de Inventario no realizó una selección aleatoria en la mayoría de los materiales, por lo cual se hizo una catalogación progresiva, la cual nos ha servido en la correlación de datos.

En muy pocos casos los materiales quedaron sin ubicación, y esto se debió a la falta de información de registro asociada al material, principalmente la fecha de levantamiento. A pesar de esto, todo el material, incluso aquellos que carecen de fecha de recojo, ha formado unidades de contexto siguiendo el esquema del agrupamiento. Así, exceptuando algunos pocos textiles que quedaron sin registrar, la colección arqueológica de Huaca Concha debe considerarse positivamente reintegrada.

\section{Resultados}

Los resultados de la investigación han sido expresados en tablas, las cuales constituyen el final del proceso de correlación de datos previamente expuestos. En este sentido, las tablas son concluyentes respecto al ordenamiento llevado a cabo sobre la base de la información disponible. Para una mejor exposición, los resultados son organizados en la misma secuencia en que fueron obtenidos, desde los agrupamientos primarios hasta la definición de los contextos. Más adelante se hará una exposición de los problemas encontrados durante la labor de reagrupamiento, la cual sin duda ha afectado los resultados del trabajo.

26. Se usaron inicialmente durante el registro el Catálogo de materiales de la Huaca Concha de 1993. Manuscrito. Y el Inventario del material recuperado del Fardo disturbado A. Manuscrito. 


\section{Los grupos de recuperación}

Los grupos se consideraron como las asociaciones primarias de los materiales arqueológicos, los cuales se formaron por la vinculación de las fechas del levantamiento de los artefactos en el sitio. Estas asociaciones constituyeron series de recuperación coherentes que se fueron ajustando, como ya dijimos, mediante la incorporación de los datos de la autoría de las fichas, tanto de excavación ${ }^{27}$ como de registro. Basado en estas premisas (ver cuadro 1) se logró aislar 27 momentos de recuperación, los cuales se agruparon en 17 unidades relevantes; mismas que constituyen directamente las veces en que se intervino el sitio.

Aunque todos los grupos constituyen unidades con significación práctica, es decir, que deben expresar algún móvil en la intervención del sitio, hay una diferencia interesante entre la variación de las unidades que es posible notar a partir de las fechas asociadas. En este sentido, es posible inferir que los agrupamientos del $1 \mathrm{al}$ 7, a diferencia del resto de unidades, no parecen estar vinculados a un programa definido de intervención, sino a aproximaciones esporádicas y aleatorias en el monumento, y cuya razón específica nos es desconocida en la actualidad.

Este hecho contrasta notablemente con los grupos 8 al 16 que sí parecen corresponder a intervenciones más programadas y definidas, y de las cuales conocemos la motivación general, que fue la destrucción que el monumento venía sufriendo por la remodelación del estadio universitario. Aunque, como en las primeras unidades aisladas, existen grupos de fechas únicas, las secuencias de las mismas son tan coherentes que incluso parecen haber sido producto de una intervención diseñada sistemáticamente.

A partir de estas observaciones es fácil deducir que ambos macro grupos no se encuentran vinculados aunque haya existido una intención genérica de rescatar el monumento. Es más bien evidente, que las motivaciones específicas entre ambos parecen contraponerse. Un dato adicional en esta separación es que ambas intervenciones, asumiendo que fueran programadas, han durado con intervalos aproximadamente un $a \tilde{n} 0^{28}$, y aunque no creemos que los lapsos de tiempo estén de alguna manera relacionados, es obvio que el sitio, de alguna forma, ha recibido importante atención; aunque no lo suficientemente seria.

\section{Los contextos arqueológicos}

Una vez establecidos los grupos, los contextos se determinaron por medio de la contrastación y, especialmente, de la definición de las referencias sobre la procedencia y la asociación de los materiales en las fechas particulares en que se realizó su recuperación. Mediante esta labor los grupos adicionaron un nuevo nivel de análisis, el cual constituye en nuestro trabajo la unidad más reducida y significativa de la investigación; misma que en esencia, reorganiza los diferentes materiales arqueológicos en conjuntos con posibles significaciones culturales.

La definición de los contextos acarreó, no obstante, serias dificultades, especialmente por la gran variación en las referencias de las fichas de registro, motivo por el cual se tuvo que prestar especial atención a las descripciones de las asociaciones, mismas que han sido cruciales en esta labor. Aunque

27. La anotación del "excavador" en la notas de registro es meramente un eufemismo. Jamás se excavó el sitio durante las recuperaciones de materiales en todas las fechas registradas. En general, el procedimiento utilizado no pasó de un retiro de escombros y limpieza previo al levantamiento del material.

28. Sólo en 1993 se actuó, registradas, 16 veces sobre el monumento. Estamos seguros que ese mismo año, y durante 1994, el sitio fue intervenido discretamente por estudiantes otras veces más sin que se hicieran reportes sobre estos hechos. 
la separación implicó una correlación con la procedencia, muchos de los contextos, como se verá después en la discusión, van a ser objetados por la falta de una asociación relevante.

Aunque la validez de los contextos definidos es una cuestión discutible, el hecho es que se ha logrado identificar una cantidad impresionante de estos agrupamientos con un total de 84 unidades (ver cuadro 2), las cuales por sus propias referencias son altamente contrastables. En agrupamientos extensos como el número 9, que incluye 5 fechas de recuperación, se han aislado hasta 27 contextos independientes, lo que también constituye un resultado insospechado. Este alto número de contextos no es casual y sin duda representa una compleja realidad material evidenciada durante la intervención.

Hay que decir, sin embargo, que contextos pertenecientes a un grupo, pero correspondientes a diferentes subgrupos o fechas singulares de recuperación, han sido considerados como unidades individuales aunque podamos presumir que hayan intervenido una misma asociación de artefactos ${ }^{29}$. Esto se debe básicamente a que, por razones metodológicas, se ha considerado las fechas como sub grupos independientes, lo que ha evitado confusiones en la definición de los contextos. Un arreglo más detallado de estas unidades con fechas diferentes sólo es posible con nueva y mejor información.

En este sentido, es relevante destacar que el orden de la presentación de los contextos (ver cuadro 2) es bastante arbitrario, lo que se debe a que estos se han organizado progresivamente conforme se estuvo revisando el material arqueológico, algo que es particularmente notable en los grupos del 8 al 12. Dado que los contextos son unidades independientes, esta disposición (teóricamente) no debía afectar la naturaleza contrastable de las unidades, por lo cual no se ajustó la disposición de las mismas ${ }^{30}$. Así, a continuación, sólo se dotó de una clave a los contextos, y se definió su organización ${ }^{31 .}$

Por otra parte, los contextos definidos incluyeron en muchos casos una importantísima variación de artefactos (ver cuadro 3 y 4), los cuales jamás habían sido adecuadamente agrupados desde que se hizo el levantamiento. Estos materiales incluyeron, entre otros, muestras textiles, alfareras, botánicas, malacológicas, orgánicas, de tierra, de cestería, líticas y óseas, en combinaciones variadas de acuerdo al contexto específico aislado. En este sentido son relevantes los contextos funerarios ${ }^{32}$, que presentan una gama de materiales asociados y cuyas implicancias culturales aún deben ser evaluadas.

Como acabamos de mencionar, la mayoría de los contextos funerarios mostró combinaciones significativas de artefactos, incluyendo los que presentaron asociaciones disturbadas o desconocidas. Esta característica multicomponente de las unidades, es notablemente distintiva en las recuperaciones de 1993 y 1994 (grupos 8 al 16), a diferencia de las mucho más reducidas combinaciones de los contextos recuperados durante 1989 y $1990^{33}$.

29. Decimos presumir por que, basados en las referencias, es muy posible que contextos aislados en fechas diferentes correspondan a una misma asociación de artefactos. Dada la pobre información disponible sobre estos contextos no es factible asegurar que se traten de las mismas unidades o de simples coincidencias referenciales; lo que es especialmente probable dada las condiciones en que se operó la recuperación en 1993.30. Sin embargo, sería necesario hacer un nuevo ordenamiento a los contextos aislados en orden de determinar con más precisión las asociaciones materiales afectadas por la intervención.

31. Esta clave consiste de un número de grupo seguido de una letra mayúscula, tal como, p.e: 9G, que corresponde a una recuperación especifica llevada a cabo el 21 del julio de 1993. (Ver cuadro 2).

32. Especialmente los contextos 8B, 8G, 9E, 9N, 9X, 10C, 12A, 12C, 12G, 13A, y 14A.

33. A diferencia de la variación de grupos entre los años de la recuperación, es más claro ahora, en base a los contextos y sus materiales aislados, que las fechas del 1 al 7 no corresponden al mismo tipo de recuperación que las del 8 al 16 (Ver cuadro 3). 
Hay que destacar, sin embargo, que independientemente de las implicancias que se puedan deducir de los agrupamientos particulares, sea por conjunción de fechas o de variados contextos en las fechas mismas, todos los contextos específicos tienen una gran importancia intrínseca al exponer un material cultural que se estaba destruyendo y el cual no había sido nunca apropiadamente organizado y menos estudiado; sin contar además, que provienen de un sitio que casi no ha recibido atención científica contemporánea.

Ya que la colección del sitio presentó una organización particular derivada de su inventario, luego que se finalizó el reagrupamiento de los contextos de todas las cajas de almacenaje fueron etiquetadas con la intención de dotar a los materiales de una referencia inmediata a su contexto de pertenencia (ver cuadro 5). Esta etiqueta incluyó una numeración, el código de inventario y la clave del reagrupamiento con el grupo y el contexto por separado; siendo así la única guía de procedencia directamente asociada al material en toda la colección.

A pesar que esta etiqueta fue colocada, hasta que hicimos nuestra última intervención en el gabinete (julio del 2004), las cajas con el material del sitio no habían sido completamente numeradas o habían adquirido una clasificación definitiva ${ }^{34}$; lo que sin duda afectaba la organización de la colección en el registro. Este hecho sin embargo, no ha tenido mayores efectos en la distribución contextual del material, debido a que éste se basó fundamentalmente en el código de catálogo asignado por la Comisión de Inventario de la Escuela.

Esta guía de referencia, de acuerdo a lo antedicho, se complementa entonces con los cuadros adjuntos en el presente informe, ya sea para una determinación del tipo de contexto implicado, o para una visualización conjunta de los materiales asociados en sus propias unidades de procedencia. Podemos decir, hasta este punto, que los cuadros de asignación material a los contextos aislados, son el resultado más tangible de la investigación realizada.

\section{Otras disquisiciones}

Algunos problemas relativos a los resultados, y que afectan la naturaleza de los cuadros y del catálogo han sido reconocidos durante el trabajo de revisión de la colección material de Huaca Concha, siendo especialmente trascendentes cuando se reagruparon los contextos. Estos problemas están muy vinculados a la metodología en que la Comisión de Inventario efectuó su labor y la cual ha tenido un efecto decisivo en esta investigación. Debido a que el reagrupamiento de los contextos es un resultado basado en correlación y análisis, el objetivo de esta exposición es básicamente coadyuvar a entender mejor su naturaleza.

Parte de los hechos más interesantes con los que se tuvo que lidiar para poder reagrupar los contextos, fue el haber registrado material almacenado con contenido confuso o codificación repetida. Tres casos son altamente relevantes al respecto: primero, la detección de varias bolsas de material inventariado con códigos únicos y con fichas de registro ${ }^{35}$ asociadas a diferentes recuperaciones en el sitio; segundo, el hallazgo de bolsas con códigos repetidos pero con fichas y/o materiales diferenciados; y tercero, la presencia de numerosas bolsas de material con códigos repetidos.

34. Existía una doble numeración para las cajas con material botánico y orgánico; y la caja con textiles, que aún no terminaba de ser completamente ensamblada, no presentaba hasta ese momento número alguno de referencia. A parte de esto se debía reetiquetar, debido al movimiento del material hecho por la comisión de inventario, las cajas 7, 9, 10, 13, 15, 18, 22, 23, 26 (botánico), 26 (orgánico), 27, 30, 33, 80, y 81.

35. Fichas de registro originales. 
El primer problema se explica por una cuestión de procedimiento de la Comisión de inventario. En razón a que la colección fue catalogada de acuerdo a su orden de aparición, por espécimen y por registro, es que parte de las fichas originales, con sus materiales asociados, fueron unificadas cuando los registros en ellas coincidían; siendo insólito, aunque a la postre beneficioso, que esto sólo se haya hecho con parte de la colección. Para nosotros es evidente que, debido a la grandísima variedad de registros asociados a los materiales, la Comisión no pudo seguir realizando esta junta de artefactos.

Aunque la dimensión real de esta unificación no es conocida, puesto que sólo se identificaron las bolsas mezcladas que conservaron sus fichas originales de registro ${ }^{36}$, es preciso resaltar que la unión parcial de fichas y artefactos en el reordenamiento llevado a cabo durante el inventario generó una grave mezcla del material; especialmente si consideramos que la Comisión no tenía información precisa de los contextos de procedencia de estos materiales.

$\mathrm{Al}$ respecto, en nuestro catálogo nosotros tratamos a las fichas unificadas de manera independiente, es decir separándolas y dotándolas de un valor virtual en la reorganización y recuperación de los contextos, e introduciendo sus referencias como ítems existentes; lo cual, en extenso, nos permitió determinar mejor el contenido original de las asociaciones, aunque parte de las mismas, en forma física, hayan sido descontextuadas. El material, no obstante, debe considerarse existente y propenso a una restitución.

Para resolver esta inclusión en el catálogo, introdujimos un ardid y repetimos el número de inventario de la bolsa original en las fichas reasignadas virtualmente para cada contexto implicado, agregando sólo una letra minúscula de diferenciación; así las entradas del registro, en todos los cuadros además del catálogo, pueden ser diferenciadas claramente. La cantidad de bolsas registradas particularmente por este procedimiento debe, sin embargo, ser descontada de la cuenta total.

El segundo problema fue igualmente complejo, pero muy relacionado al anterior. Este consistió en el hallazgo de varias bolsas con códigos similares y fichas nuevas coincidentes, pero con fichas originales diferenciadas; lo que implicó, a diferencia del anterior caso, una inusual repetición de códigos en materiales claramente mezclados. El meollo del problema en esta ocasión, fue la separación de materiales asociados en variadas bolsas como un procedimiento estándar de catalogación, al que se sumó la distribución de las fichas originales entre las bolsas aisladas.

Lo que debe entenderse primariamente aquí, es que parte del material incluyendo sus fichas de registro asociadas, fue mezclado previamente a su separación, lo cual es consecuencia del método utilizado; que, como ya expusimos, consintió la idea temprana de unificar materiales que parecían coincidentes. Luego, se separó el material, probablemente debido al volumen adquirido por la unificación física de las bolsas originales ${ }^{37}$, separándose nuevamente también, sus fichas de registro.

Esta doble confusión del material es sin duda muy particular del trabajo de inventario y ha sido claramente inintencionada. En nuestra labor, al introducir las referencias procedimos tal como en el primer problema, considerando las fichas como valores virtuales en la configuración de los contextos.

36. Es posible que muchos otros materiales unificados no conservaran sus registros originales.

37. Posíblemente para manejar mejor la cantidad por bolsa. 
Nominalmente, sin embargo, no se alteró la codificación ni se crearon entradas vacías ${ }^{38}$, las bolsas existen como tales aunque el material contenido haya sido notablemente descompuesto ${ }^{39}$.

Por otra parte, se han detectado bolsas con iguales códigos pero cuyos materiales no se corresponden ${ }^{40}$, lo que nos parece, más que un error involuntario derivado del proceso de catalogación, una confusión post inventario. Es probable que varios materiales se hayan mezclado o sus fichas modernas hayan sido confundidas y/o separadas de los artefactos cuando se realizó la muestra Huaca Concha en diciembre del 2003. En todo caso, la principal afectación de este desarreglo sería la mezcla definitiva del material y la creación de una entrada falsa en el catálogo si no hay una corrección de la falla.

Finalmente, la tercera dificultad enfrentada, fue el reconocimiento de numerosas bolsas de material con fichas y códigos repetidos, pero que no parecían haber sido mezclados como producto de una manipulación errónea. Aunque también consecuencia del método, esto se hizo, muy posiblemente, cuando se catalogaron materiales del mismo ítem y con el mismo registro pero en una cantidad demasiada extensa; lo que dio como resultado un registro múltiple y confuso.

Aunque revisada la razón del tal ordenamiento es claro que los materiales no fueron afectados, al menos no tan drásticamente como en los dos primeros casos. La repetición de códigos sí introdujo numerosas entradas en nuestro catálogo, cosa que no podía obviarse puesto que cada ficha con código repetido representaba físicamente una bolsa de material en la colección. Estos ingresos, que corresponden idealmente a una única bolsa de material, ampliaron el conjunto de objetos asociados en contextos específicos de manera notable.

Debido a que mantuvimos los códigos sin modificación y ejecutamos las entradas en el catálogo, procedimos como en el caso anterior agregando un número correlativo a los códigos sucesivos que se presentaron en las listas del catálogo, y así en todos los cuadros relacionados; de esta forma es fácil notar la correlación. La diferencia, sin embargo, radica en que la sucesión se da únicamente en un contexto particular. Hay que agregar aquí, que en la cuenta total de bolsas, estas entradas no deben descontarse, a diferencia de los anteriores casos.

Otros hechos, tales como la repetición de códigos en las cajas de inventario, o el traslado de bolsas con material entre cajas ${ }^{41}$, no constituyeron en sí elementos críticos relevantes en el reagrupamiento y recatalogación de los contextos. Nosotros comprendemos a cabalidad que el inventario estaba aún en proceso cuando terminamos nuestra intervención, por lo cual no era posible tener toda la colección absolutamente estática para nuestros intereses; en ese sentido es necesario reconocer que algunas referencias de los cuadros deben ser actualizadas para su mejor utilidad.

38. Al código original solo se le agregó un número consecutivo para seguir la correlación. En un caso, sin embargo, la mezcla de fichas en bolsas de códigos repetidos generó la introducción de una entrada ficticia, aquí al número se le agregó una letra (ver entrada 168/18).

39. Ver en el catálogo las entradas $229 / 18$ y la 168/18.

40. Confrontar contenido de la caja 16.

41. Incluso hallamos, en nuestra labor de verificación, bolsas de Huaca Concha en cajas con rótulos que correspondían a otros sitios. 


\section{Los responsables del levantamiento}

Otro de los resultados más importantes de la investigación fue el reconocimiento de la autoría sobre las recuperaciones materiales efectuadas en el sitio. Aunque la autoría en el registro se presenta siempre individual, ésta es interpretada aquí como un crédito grupal ya que, como se verá después, la mayoría de las recuperaciones fueron efectuadas fundamentalmente por conjuntos de estudiantes integrados por bases o promociones únicas, y con el apoyo eventual de estudiantes de otros años.

Aunque es evidente que la responsabilidad es consustancial a los participantes que representan a sus bases, hay que aclarar que, en ningún caso, bases totales o completas participaron de estos actos; y en algunos momentos incluso, grupos muy reducidos de estudiantes de una base organizaron y ejecutaron recojo de material del sitio. Sobre la evidencia por tanto, la participación exacta de promociones de estudiantes y el grado de responsabilidad en los hechos, ya sea directa o indirecta, es una cuestión difícil de cuantificar en la actualidad.

Sin embargo, tal como se observa en el catálogo y especialmente en el cuadro 3, los créditos primarios han sido incluidos de acuerdo a la referencia exacta de las fichas originales, las cuales en muchos casos han presentado la doble nómina: excavador-registrador. Los nombres implicados en las fichas están tan claramente asociados en casi todos los conjuntos contextuales, siendo evidente que los levantamientos de material se correlacionan con las bases o promociones a los cuales esas referencias indican, por lo que la generalización es posible.

Mediante un trabajo de correlación, hemos podido elaborar un cuadro primario de asignación para el levantamiento de material en casi todos los contextos aislados en este trabajo. Esta asignación está determinada por la nominación de los responsables en el registro y la excavación de estos materiales, siendo especialmente importante la frecuencia dominante de la base a la cual las referencias indican. La referencia a una base es notablemente consistente en la mayoría de contextos que sólo unos pocos han sido asignados como levantamientos sin referencia o de referencia desconocida (ver cuadro 6).

En la nomina existen asociaciones ambiguas, como la del contexto $12 \mathrm{~F}$, que también puede corresponder a otra promoción; y es posible que algunas asociaciones sean dudosas por el registro único o mayoritario de una sola persona, mientras la recuperación real se asocie a otra base. Asignaciones sin referencia o de referencia desconocida están también presentes, especialmente en contextos donde las iniciales han dominado en las fichas y registros. Sobre las primeras asociaciones de responsabilidad, sin embargo, es claro que se registran los nombres de participantes de otras bases en las fichas, lo cual significa una participación conjunta de bases en los levantamientos.

Consideramos no obstante, que las correlaciones son muy coherentes, especialmente si las evaluamos en conjunto. Basado en las fechas de los levantamientos y la frecuencia de contextos asociados, a continuación se elaboró un cuadro de responsabilidad de las recuperaciones por grupos (ver cuadro 7) el cual expone de manera más extensa la relación de los levantamientos de material y la base a la que estos se encontraron vinculados. El resultado de la asociación lograda es tan significativo que hemos podido asociar grandes conjuntos de grupos y fechas a bases únicas.

17 grupos y 26 fechas de recuperación en 4 años, vinculados a solo 5 bases estudiantiles las cuales son las principales responsables de la presencia del material, es un resultado que podemos considerar muy interesante dada la historia trágica del sitio en los últimos años. Aunque las recuperaciones deben también considerarse un logro conjunto de muchas bases de menor participación, está claro que fueron solo estudiantes los principales responsables del rescate. Este es el saldo hasta el momento, quizá en el futuro sea posible ajustar estos cuadros y poder reconocer mejor a todos los que se involucraron en la defensa y conservación del sitio. 


\section{Discusión}

Vamos a enfocar la discusión en dos aspectos que pensamos son los más relevantes y centrales en la investigación efectuada, estos son: la metodología y los resultados obtenidos. Como se ha explicado previamente, dichos aspectos han sido afectados por los sucesos relacionados al levantamiento de los materiales y a su disposición tardía, por lo que una revisión de la operación efectuada y sus consecuencias es necesaria. Aunque este es un intento por verificar la naturaleza de nuestro trabajo, una evaluación más precisa deberá venir cuando se incrementen los registros y se sumen a ellos datos de los propios involucrados en el levantamiento y almacenaje de estos materiales.

\section{Acerca del método}

Tal como se expuso, nuestro trabajo fue muy diferente al de la Comisión de Inventario lo que se puede constatar claramente en el grado de manipulación de la colección, sin embargo esta es especialmente clara en lo que concerniente a la definición del contexto como el punto crucial, y objetivo, en la organización de los datos recuperados de las fichas de registro. Sólo así pudimos reorganizar el material que la misma Comisión dispersó y descontextualizó en forma tan general.

Aunque el método está basado en una premisa teórica, este puede resumirse como un proceso de revisión y correlación crítica. Todo nuestro objeto de trabajo, las bolsas de material y sus registros, fueron acuciosamente revisados durante la adquisición de datos sin alterar en absoluto su disposición y almacenaje, por lo que se puede considerar al estudio como una intervención superficial en sentido estricto. Cualquier uso adicional de la información, incluyendo su traslado a una base de datos, no altera esta condición general del trabajo.

La correlación que siguió a la revisión del material, y que se hizo independientemente de esta, tuvo como único condicionamiento la comparación indiscriminada de la información obtenida, incluso usando inferencias deductivas a la hora de establecer las agrupaciones relevantes. En este sentido, la selección de grupos y subgrupos podría tomarse como excesiva si consideramos que algunos de ellos están compuestos por unidades singulares, de fechas, contextos e incluso de materiales. Considerando este hecho, debe estimarse que la determinación final, nominal, de cada contexto específico, fue producto de un serio y exigente ejercicio analítico.

Si nos basamos en la disposición y condición del material recuperado, es posible afirmar que, metodológicamente, el trabajo ha tenido una fundamentación adecuada. Es probable, sin embargo, que esta pueda ser replanteada agregando nueva información sobre los contextos y la forma de levantamiento, tomando en cuenta, además, que los artefactos, en su mayoría, no fueron adecuadamente contextualizados cuando se hizo la recuperación de los mismos. Si los resultados son consecuencia del procedimiento, podemos esperar que estos también estén sujetos a modificación y mejoramiento futuro.

\section{Acerca de los resultados}

Desde una perspectiva puramente teórica, podríamos considerar los resultados como una hipótesis a contratar. En este sentido, la definición y validez teórica del reagrupamiento debe pasar por considerar que los resultados se lograron siguiendo un proceso definido, el cual puede ser epistemológicamente contrastado; es decir, se basó en una observación, se planteó un problema y se formuló una hipótesis: el agrupamiento. El valor último de este resultado debe, por tanto, ser sujeto de contrastación. 
Metodológicamente, por otra parte, los resultados se lograron siguiendo una escala en forma deductiva, la cual se realizó mediante múltiples ajustes hasta alcanzar su unidad mínima, el contexto; mismo que en esencia debe considerarse como una unidad discreta en el sentido lógico del término. Aunque los resultados en forma genérica incluyen tres niveles: grupo, fecha y contexto, solo se consideraron dos de ellos en la explicación (el grupo y el contexto) por tratarse de formulaciones abstractas, diseñadas para establecer un orden formal taxativo.

Para el establecimiento de los contextos y la definición de un orden formal entre ellos, está claro que se uniformaron las descripciones adrede, fundamentalmente dada la variación particular en la observación de procedencia y las asociaciones incluidas; lo que se hizo con intenciones normativas. Esta definición formal permite tener una perspectiva de asociación entre los contextos dispersos, los que podrían unificarse con más y mejor información. En nuestra presentación (ver cuadro 2 y posteriores) es evidente que el orden de la lista fue aleatorio, tal como se ejerció el orden de la correlación.

Aunque la presentación de los contextos puede ser ultimadamente criticada, hay que decir que los cuadros de asignación, en todos los niveles, han sido deliberadamente manejados, aún para la inclusión de los artefactos en sus respectivos contextos; lo que se hizo por efecto del método tal como se está explicando. Aunque la tabulación es ilustrativa y la formalización puede ser inferida, este trabajo ha tratado de hacer extremadamente explícita la presentación del método y su puesta en práctica con los resultados previstos.

A diferencia de la validez teórica de los resultados, arqueológicamente es posible considerar crítica la relevancia de los contextos definidos, lo que puede concluirse de la variación porcentual entre aquellos contextos bien establecidos, y aquellos que presentan procedencia y asociaciones desconocidas o disturbadas (ver cuadro 8). La desproporción presente es tan grande que el valor referencial de la intervención general es mínimo, $22.6 \%$ de todos los contextos, y con una producción de información contextual pésimamente documentada, 11 fechas de 27 (40.7\%).

Hay que aclarar, sin embargo, que dada la definición de contexto que estamos usando, la falta de una referencia en la nominación de estas unidades ha anulado el valor arqueológico de muchos de ellos, lo que es una consecuencia natural de la mediocridad del registro. Nueva información podría sustancialmente incrementar el valor relativo de la documentación, pero hasta que eso suceda debemos establecer sin atenuantes que la intervención estudiantil fue mala y deficiente. Hasta el día de hoy, hay que admitir, ningún contexto arqueológico de la Huaca Concha ha sido adecuadamente documentado, incluyendo el fardo A (Clave: 12A), el cual fue registrado por estudiantes de $1 \mathrm{er}$ año ${ }^{42}$ (Figs. 1, 2, 3, 4 y 5)

Vista la intención del "rescate" no es una sorpresa que el 94.7\% de todos los contextos "completos", es decir adecuadamente definidos, sean de naturaleza funeraria. Sólo un único contexto, correspondió a un relleno arqueológico (ver cuadro 9). Aunque el porcentaje es abrumador en las referencias funerarias, estas se podrían reducir con nueva información. Es probable sin embargo, que muchas referencias a entierros no se puedan asociar directamente entre ellas, aunque correspondan a un solo contexto en una fecha específica, debido a la carencia de un registro adecuado.

Aunque en general la estimación de la intervención pueda ser muy limitada, particularmente la perspectiva es diferente, más si examinamos el contenido de algunas asociaciones de artefactos, tales

42. Los datos relativos al levantamiento, características del contexto y ofrendas, además de algunos gráficos, fueron publicados en 1995. Ver nota número 1. 
como la de los contextos 8B, 8G, 9N, y 12A. La riqueza en la variación material puede ser representativa para fines de estudios culturales, sin desmedro de su soporte físico, es decir el sitio arqueológico. Es evidente, claro esta, que primero deben confirmarse los agrupamientos, y después deben de realizarse estos de manera tangible, rescatando los fardos funerarios de los gabinetes de la casona por ejemplo.

Aclarando que esta no es una recomendación, es preciso realizar una selección de contextos para su estudio específico, especialmente ahora que los materiales pueden ser reconstituidos en grupos con implicancias culturales. Esto debe hacerse para evitar el uso del material en forma desagregada de su contexto natural, cosa que ha pasado repetidamente y con consecuencias negativas para la colección ${ }^{43}$. Entre todo el grueso de colecciones arqueológicas que posee la Escuela es muy probable que los materiales recuperados de la Huaca Concha constituyan las únicas muestras de contextos asociados, listos para ser estudiadas en forma integral, cuestión que no debe desestimarse.

Respecto a otro aspecto de la colección, durante nuestra intervención hicimos un conteo de las bolsas y envolturas de material arqueológico que manipulamos durante el trabajo, mismos que literalmente significan una entrada efectiva en nuestro catálogo. Aunque nunca realizamos una cuenta concreta de cada artefacto singular, jamás supimos tampoco cuales fueron los estándares, o si los hubo, para el manejo de la cantidad a almacenar en cada unidad de contenedor, y en ninguna de sus escalas, bolsas y cajas ${ }^{44}$, por lo que los contenedores se consideraron iguales en todos los casos, incluso para bolsas repetidas.

La cuenta que realizamos para cada contexto (cuadro 10), y en general para todos los grupos (cuadro 11), se hicieron con la intención de tener un parámetro de comparación entre la cantidad de materiales en contextos similares. Debido, sin embargo, a la falta de referencias, nunca pudimos tener una apreciación coherente de cuanto se trastocó el número de contenedores durante el traslado, y cuantas veces se incrementaron estos con la junta de materiales que se consideraron similares, por lo que una discusión extensa no es pertinente ahora.

En nuestro trabajo no obstante, hemos dejado los cuadros presentes para poder apreciar la variación en el número de contenedores por contexto y grupos, los cuales son por si mismo interesantes. En este sentido son especialmente notables las fechas $22 / 7 / 93$ con 45 unidades, y la fecha 26/8/93 con 56 ; ambas fechas se corresponden con los importantes contextos funerarios $9 \mathrm{~N}$ y $12 \mathrm{~A}$, levantados por estudiantes de 3 er y 1 er año respectivamente, lo que puede significar que hay cierta correspondencia cuantitativa, aunque aun falta verificar esto.

\section{Conclusiones}

Nuestro proyecto ha tratado de ser lo más acucioso posible, y en este intento hemos posiblemente reforzado nuestra visión crítica sobre los procedimientos seguidos durante la recuperación y almacenaje de los materiales arqueológicos del sitio. Sin embargo, nuestra primera conclusión debe ser la de reconocer el extraordinario valor de todos los intentos por recuperar el material, guardarlo y almacenarlo, sin importar el tiempo que este haya tomado; especialmente considerando que todas estas actividades fueron emprendidas, diseñadas y realizadas, en todos los casos, por estudiantes universitarios.

43. Por ejemplo, tejidos asociados en una misma bolsa, y pertenecientes a un contexto singular, fueron divididos en conjuntos separados para su análisis por estudiantes de la Escuela. Si estos conjuntos separados perdieron sus fechas y datos de procedencia, entonces la descontextualización de estos artefactos ha sido grave. Sólo la bolsa 184-H12 fue dividida al menos en tres conjuntos diferentes.

44- Por ejemplo, el material textil que pudimos reconocer se encontró en envolturas de papel especial, no embolsados, mas sí colocados juntos en una caja de cartón. 
Huaca Concha ha significado un importante hito en nuestra carrera universitaria, y nosotros, los que participamos de esas recuperaciones, nos hemos visto envueltos en la responsabilidad moral de resarcir de alguna forma el abandono que hicimos de las reliquias de nuestro viejo monumento; en ese sentido, este trabajo debe considerarse un intento particular e incompleto de pagar esa deuda. Hay aún muchas historias particulares que deben ser escritas sobre el sitio, una huaca cubierta en la desgracia por la tribuna de un estadio inservible y una cochera vacía; el sitio está aun allí, a pesar de todo, esperando ser salvado otra vez.

En una perspectiva académica, esperamos que la reagrupación de los contextos recuperados haya significado una modesta contribución a la arqueología de Lima; y más al registro de los sitios del campus de la Universidad de San Marcos. Es una ironía pensar que si la universidad no hubiese abandonado sus extraordinarios monumentos, en la actualidad podría haber tenido uno de los parques arqueológicos más notables de la capital. A diferencia de los materiales arqueológicos muebles, los que ahora estudiamos de la Huaca Concha, es el gran edificio monumental el que hubiese brillado y dado muchos mas testimonios del pasado nacional.

El estudio, tal como se ha discutido más arriba, ha sido fundamentalmente de naturaleza organizativa, y esa es intrínsicamente su principal característica. Recordatorio de la desgracia de un monumento, y el soporte a nuevas investigaciones serán, probablemente, sus mayores alcances futuros. Para nosotros, es posible más y mejor investigación en los materiales de Huaca Concha, de eso no hay ninguna duda, sólo esperamos que nueva y mayor información aparezca para enriquecer nuestro conocimiento de este sitio arqueológico y fomentar su rescate, lo cual sería poco en honor de nuestros antepasados limeños.

Al final, debemos asegurar con decisión que la Huaca Concha no es un monumento inexistente, desaparecido o totalmente destruido; Huaca Concha es sólo uno de los muchos sitios arqueológicos que se siguen devastando en el Perú, el cual ha recibido casi ninguna atención científica. Es una desgracia moral para la arqueología del país que sitios de la capital tengan que ser explícitamente rescatados, intervenidos o estudiados para ser considerados existentes. Ahora podemos preguntarnos ¿Cómo y cuantas veces debemos revivir una huaca en el Perú?, ¿Cuándo se acabará la desidia contra los monumentos arqueológicos de Lima?, ¿Cuántas veces más tendremos que rescatar la Huaca Concha?

\section{Agradecimientos}

Los autores desean agradecer encarecidamente el apoyo y soporte recibido del, en el año 2005, Director de la Escuela de Arqueología de la Universidad Nacional Mayor de San Marcos, Licenciado Daniel Morales Chocano, sin cuya motivación este trabajo hubiese sido imposible de realizar. Asimismo a la licenciada María Ysela Leyva en la introducción a la restaurada colección Huaca Cocha; y al egresado Carlos Vega por su colaboración en el registro de los materiales. También deseamos agradecer por su desinteresada e importantísima contribución a este trabajo, a los licenciados Consuelo Gonzales, Pedro Espinoza, Flavio Estrada, Gerald Zubiaga y Pedro Novoa. Y a la señorita Miriam Infante. 


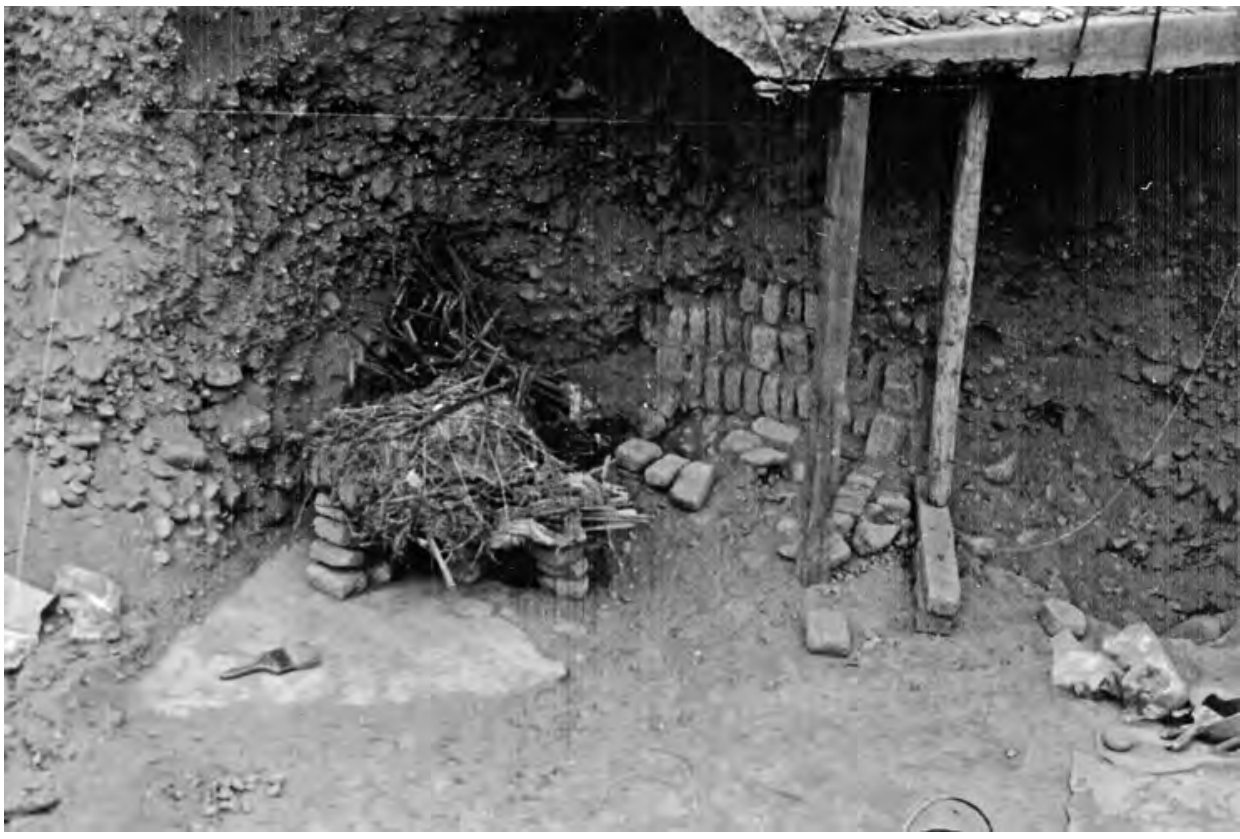

1. Fardo A (12A) luego de su limpieza y retiro de ofrendas. Foto por Gori Tumi.

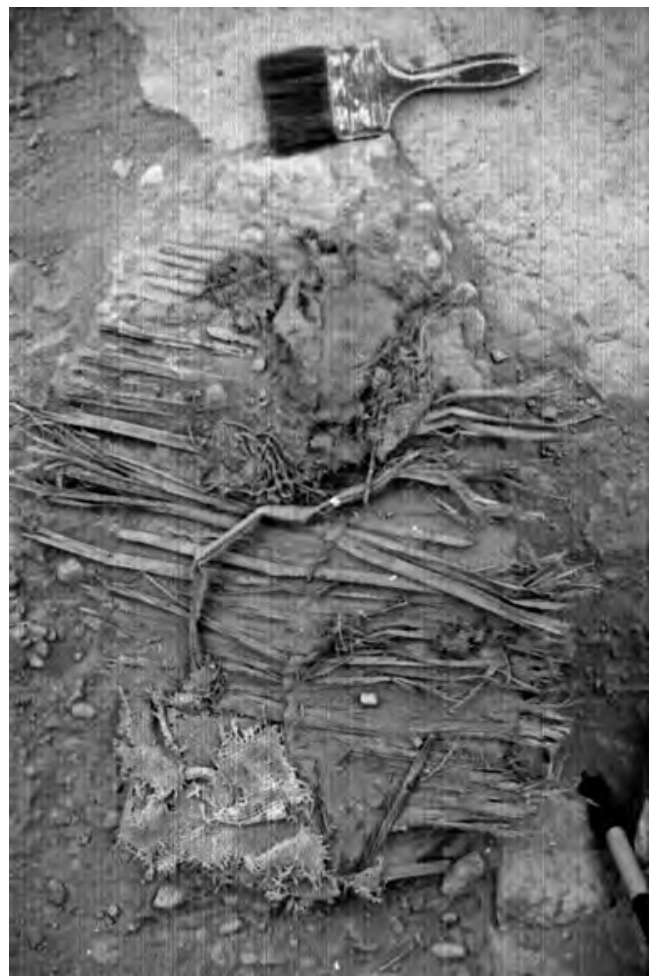

2. impronta del Fardo A luego de su retiro. Se puede observar que la estructura de cañas fue depositada sobre una torta de barro húmedo. Foto por Gori Tumi. 


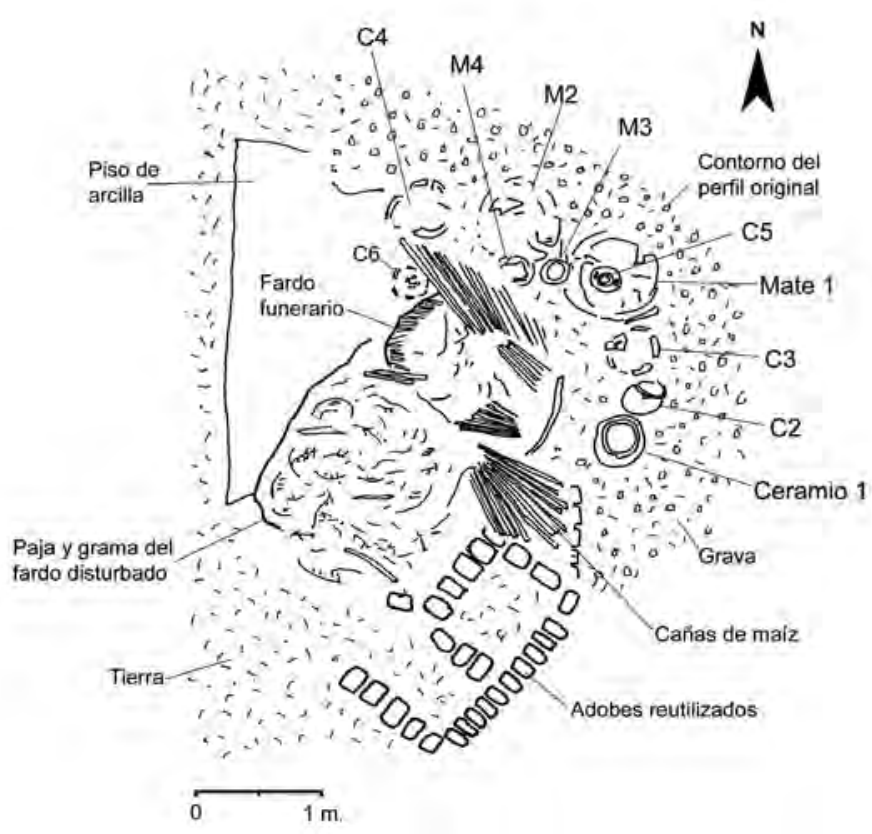

3. Dibujo de planta del Fardo A. 26 de agosto de 1993. Dibujo por Gori Tumi. vasijas enteras. Dibujo por Gori Tumi.
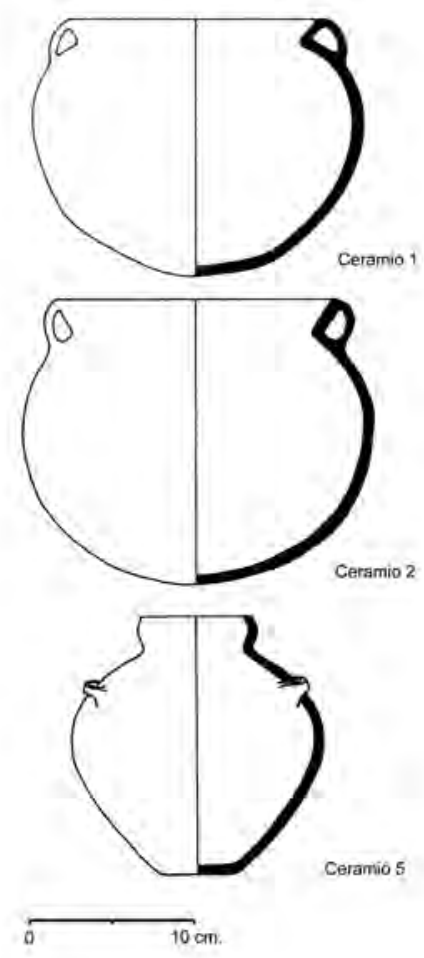
CUADRO 1

AGRUPAMIENTO DEL MATERIAL POR FECHAS Y ASOCIACIÓN DE ELLAS

\begin{tabular}{|c|c|c|}
\hline Número de grupo & Fecha & Número de fechas \\
\hline 1 & $1 / 2 / 89$ & 1 \\
\hline 2 & $22 / 11 / 89$ & 2 \\
\hline 3 & $12 / 12 / 89$ & 3 \\
\hline 4 & $24 / 1 / 90$ & 4 \\
\hline 5 & $3 / 2 / 90$ & 5 \\
\hline 6 & $7 / 2 / 90$ & 6 \\
\hline 7 & $13 / 2 / 90$ & 7 \\
\hline \multirow{2}{*}{8} & $16 / 6 / 93$ & 8 \\
\hline & $17 / 6 / 93$ & 9 \\
\hline \multirow{5}{*}{9} & $20 / 7 / 93$ & 10 \\
\hline & $21 / 7 / 93$ & 11 \\
\hline & $22 / 7 / 93$ & 12 \\
\hline & $23 / 7 / 93$ & 13 \\
\hline & $24 / 7 / 93$ & 14 \\
\hline \multirow{2}{*}{10} & $22 / 8 / 93$ & 15 \\
\hline & $23 / 8 / 93$ & 16 \\
\hline 11 & $25 / 8 / 93$ & 17 \\
\hline \multirow{2}{*}{12} & $26 / 8 / 93$ & 18 \\
\hline & $27 / 8 / 93$ & 19 \\
\hline 13 & $2 / 9 / 93$ & 20 \\
\hline \multirow{3}{*}{14} & $6 / 9 / 93$ & 21 \\
\hline & $7 / 9 / 93$ & 22 \\
\hline & $8 / 9 / 93$ & 23 \\
\hline \multirow{2}{*}{15} & $21 / 7 / 94$ & 24 \\
\hline & $23 / 7 / 94$ & 25 \\
\hline 16 & $1 / 8 / 94$ & 26 \\
\hline 17 & SR & 27 \\
\hline
\end{tabular}



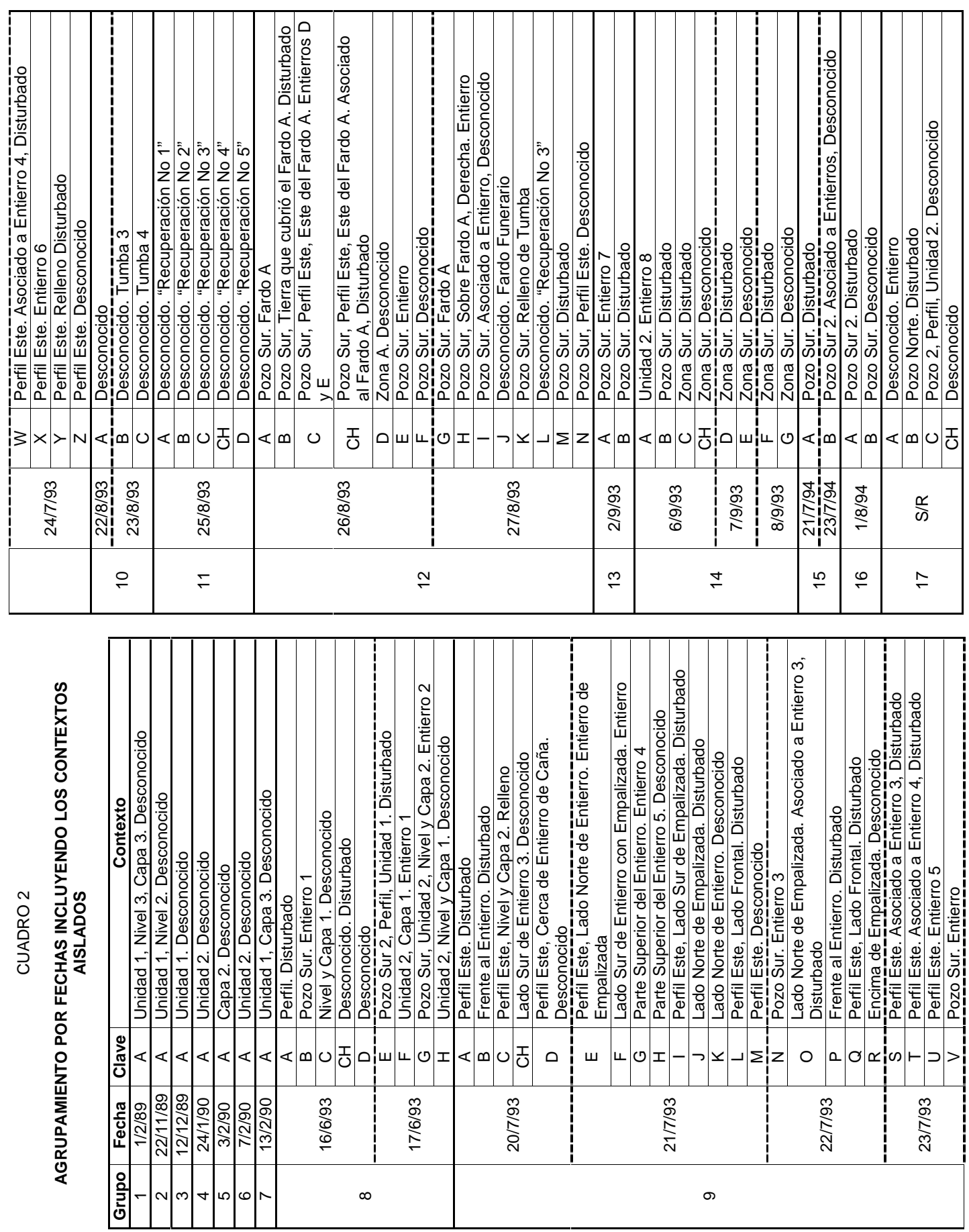


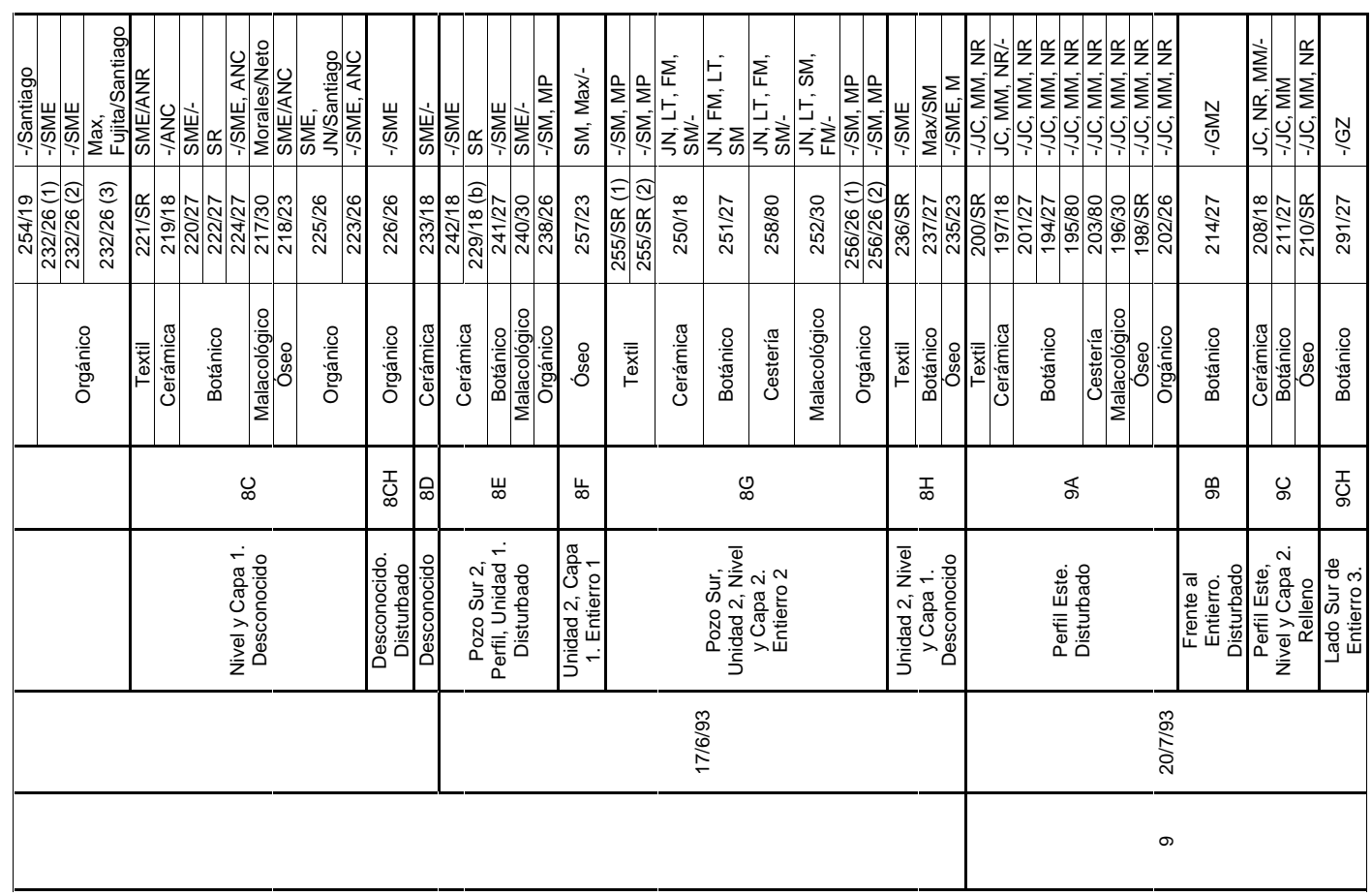

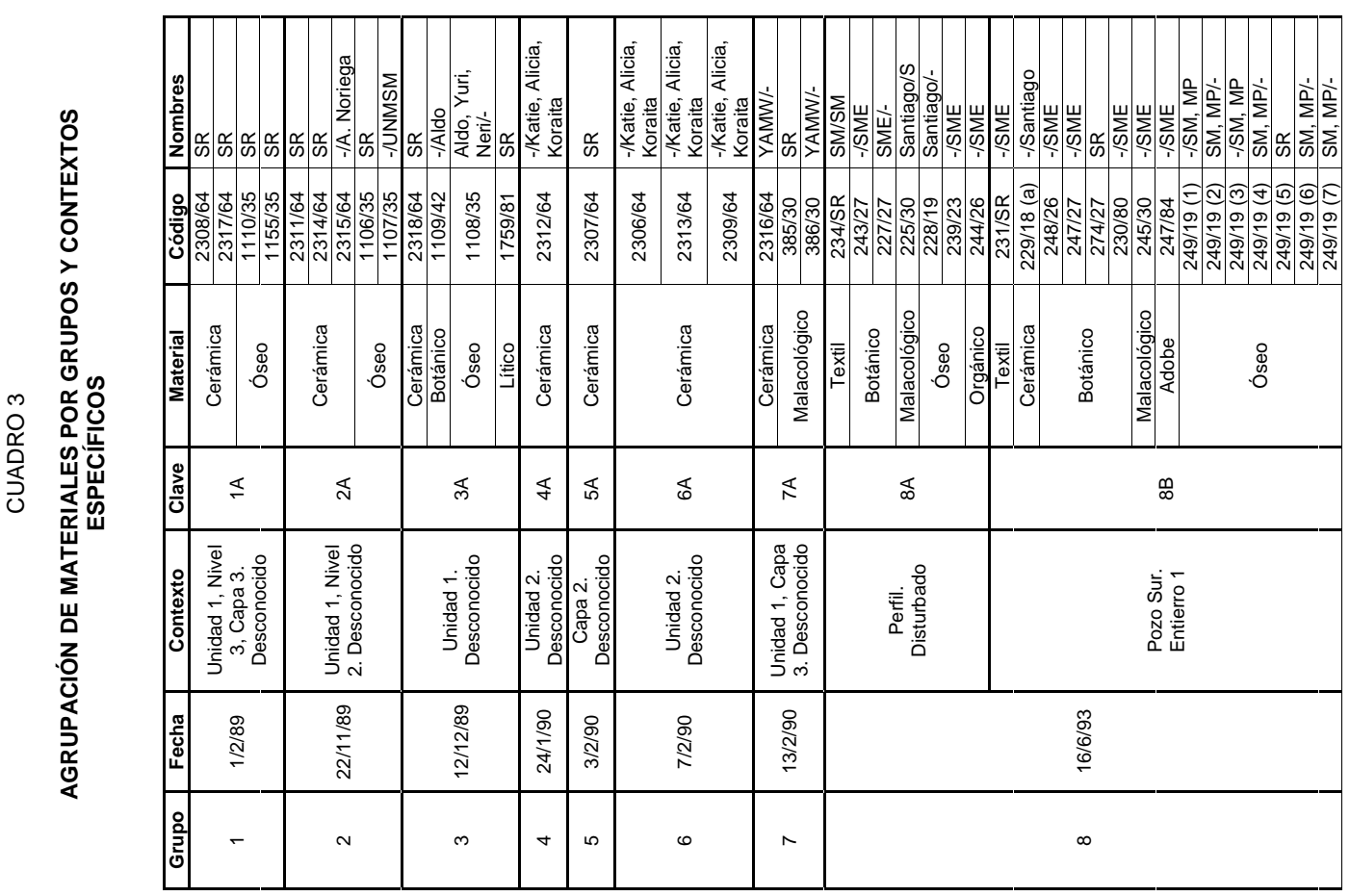




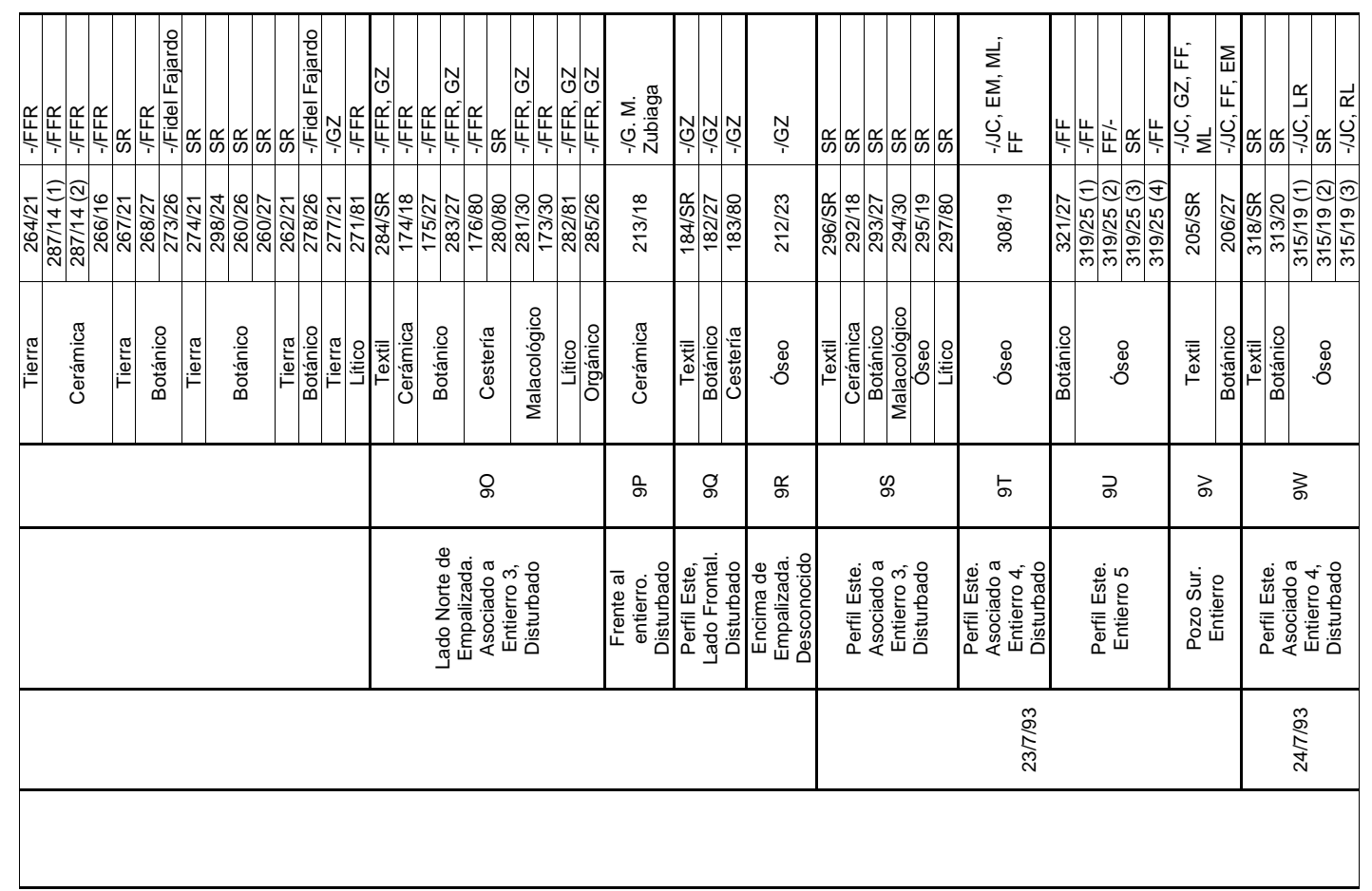

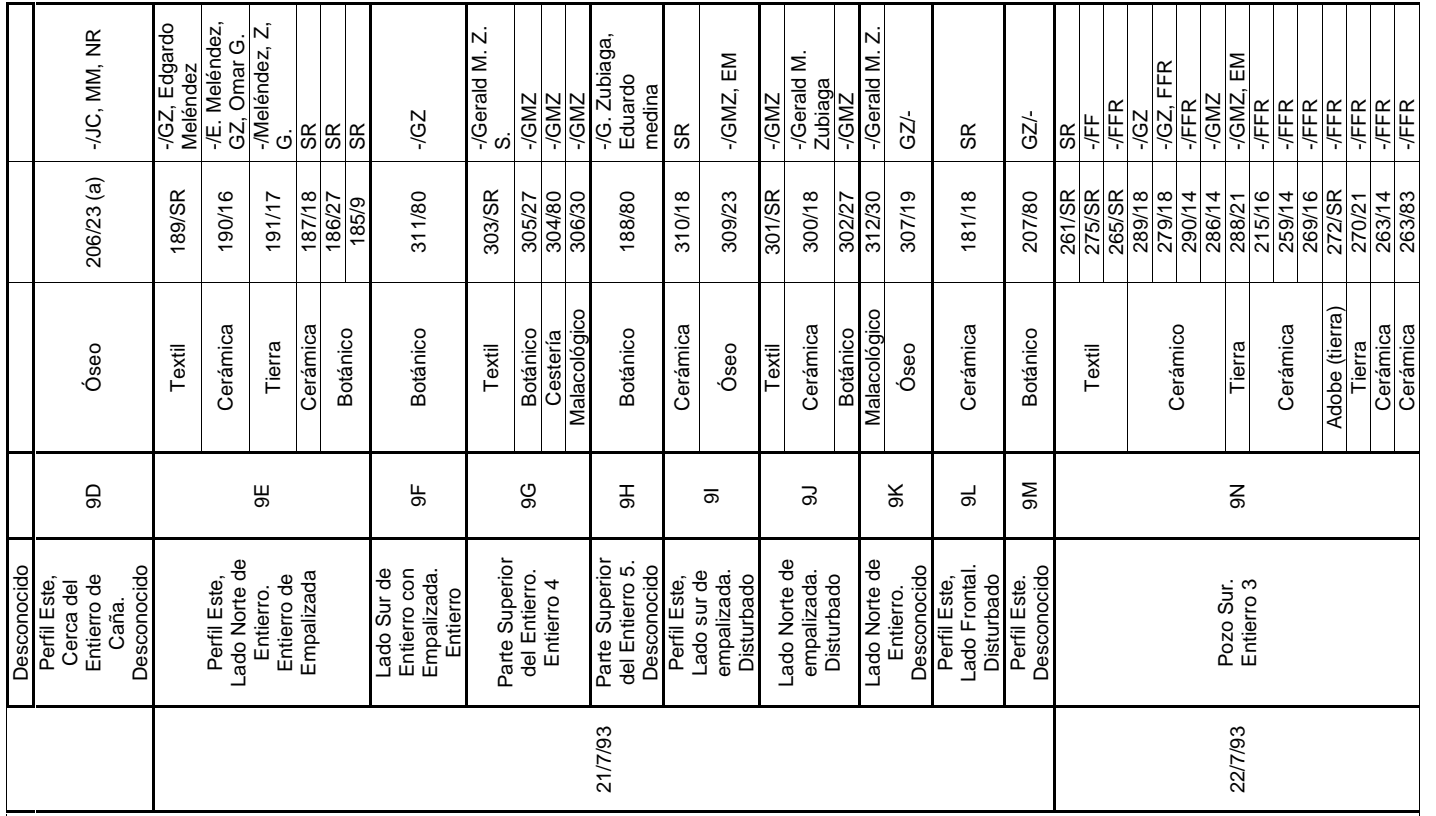




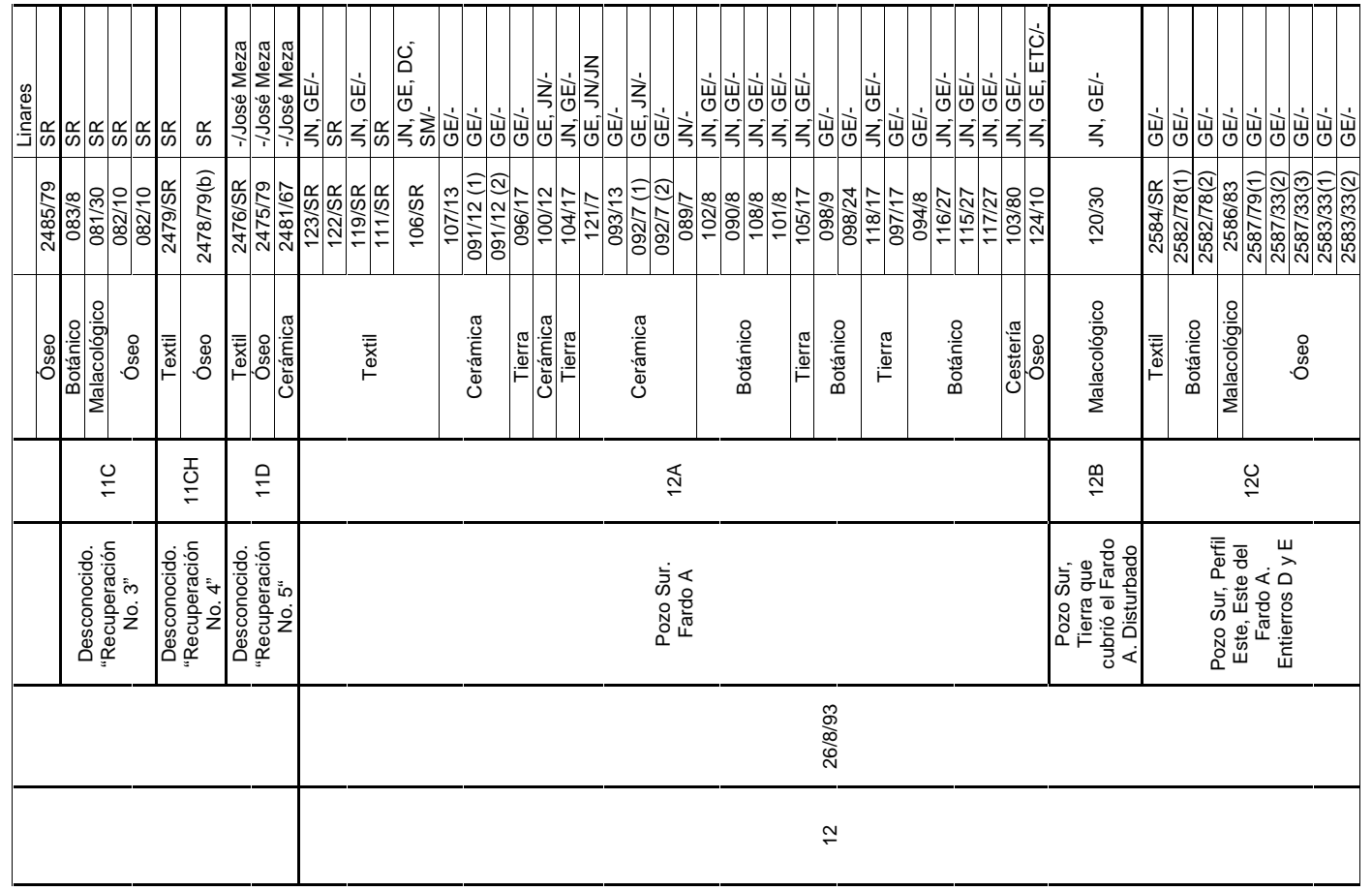

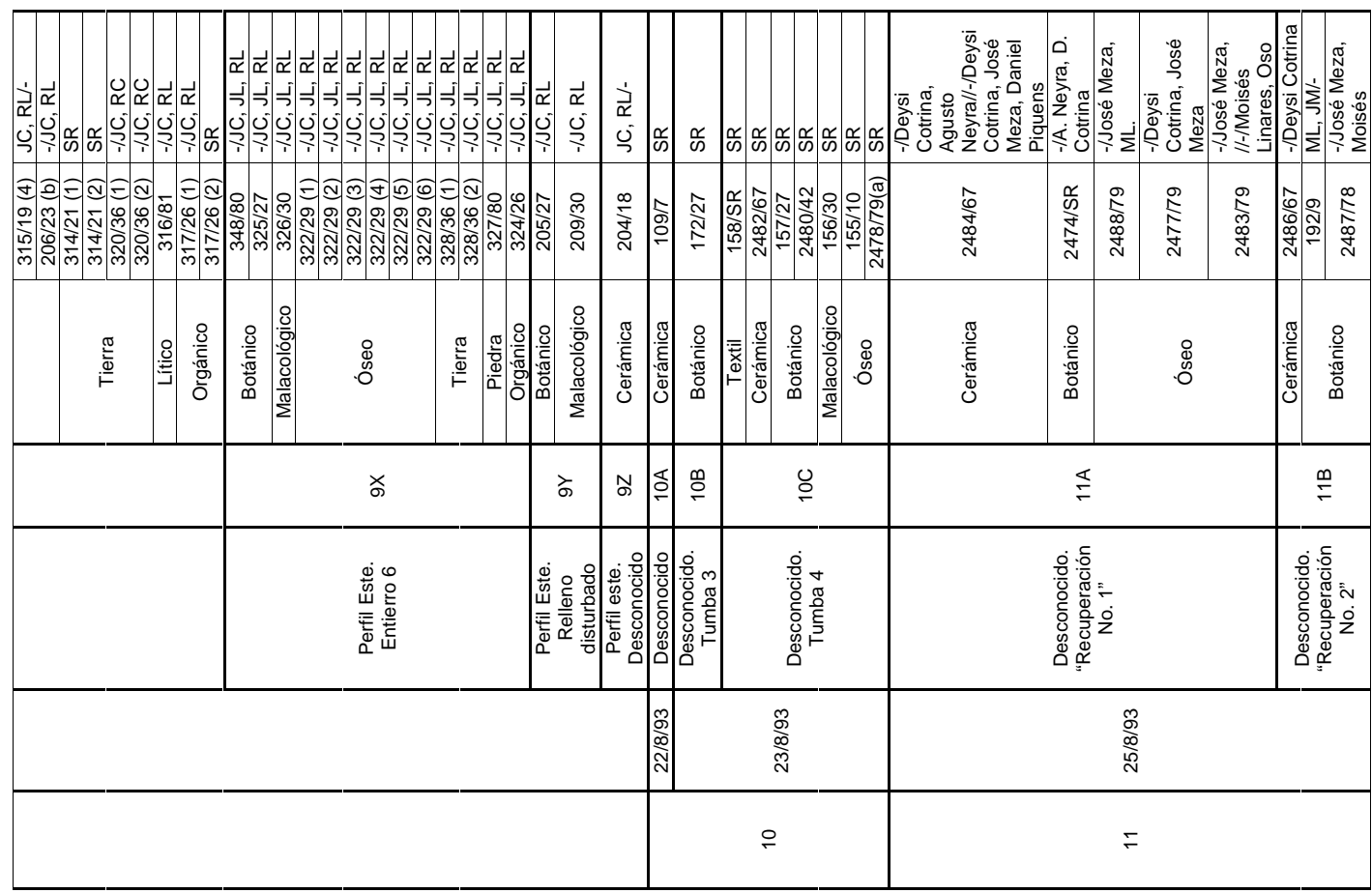




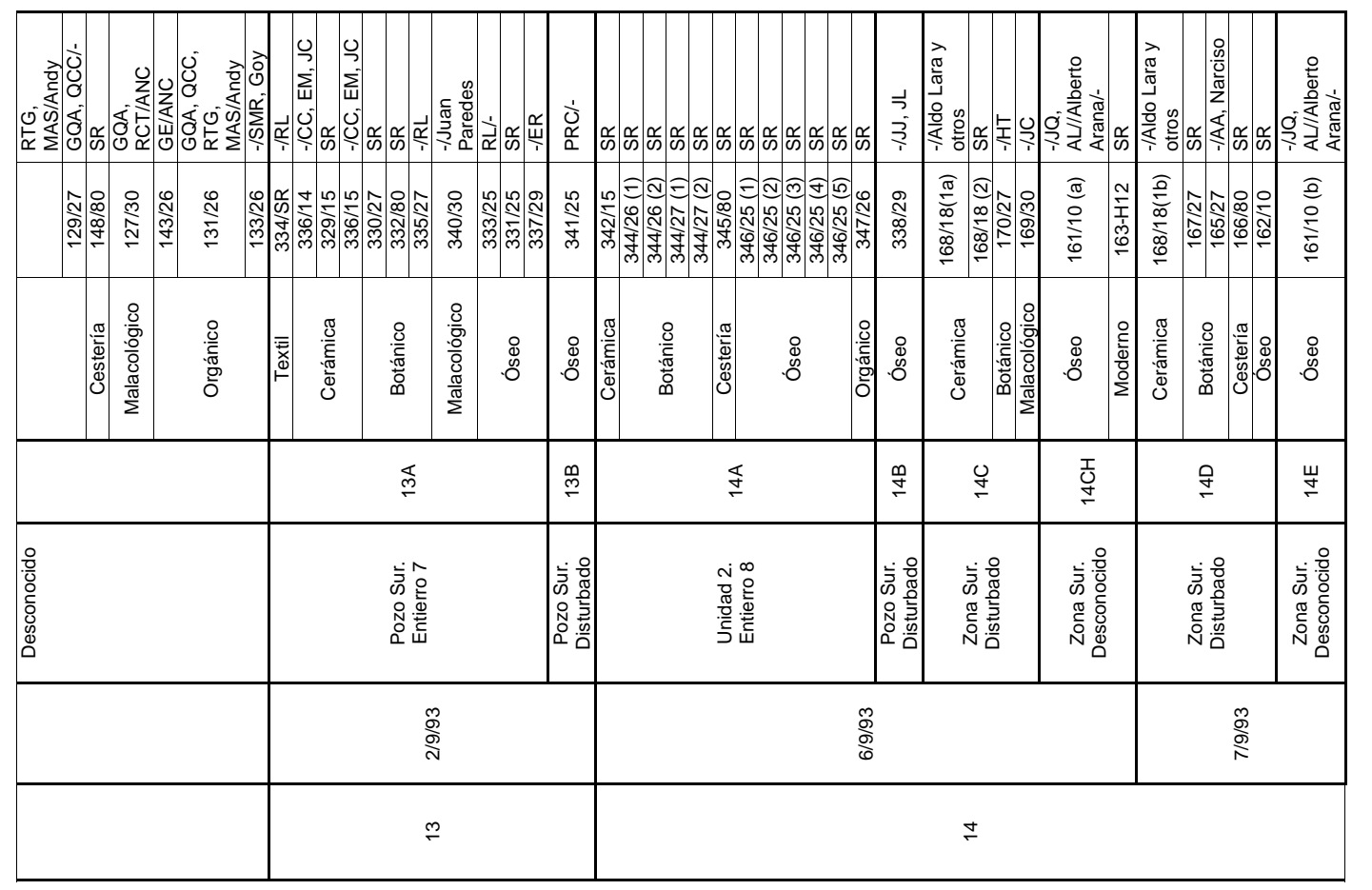

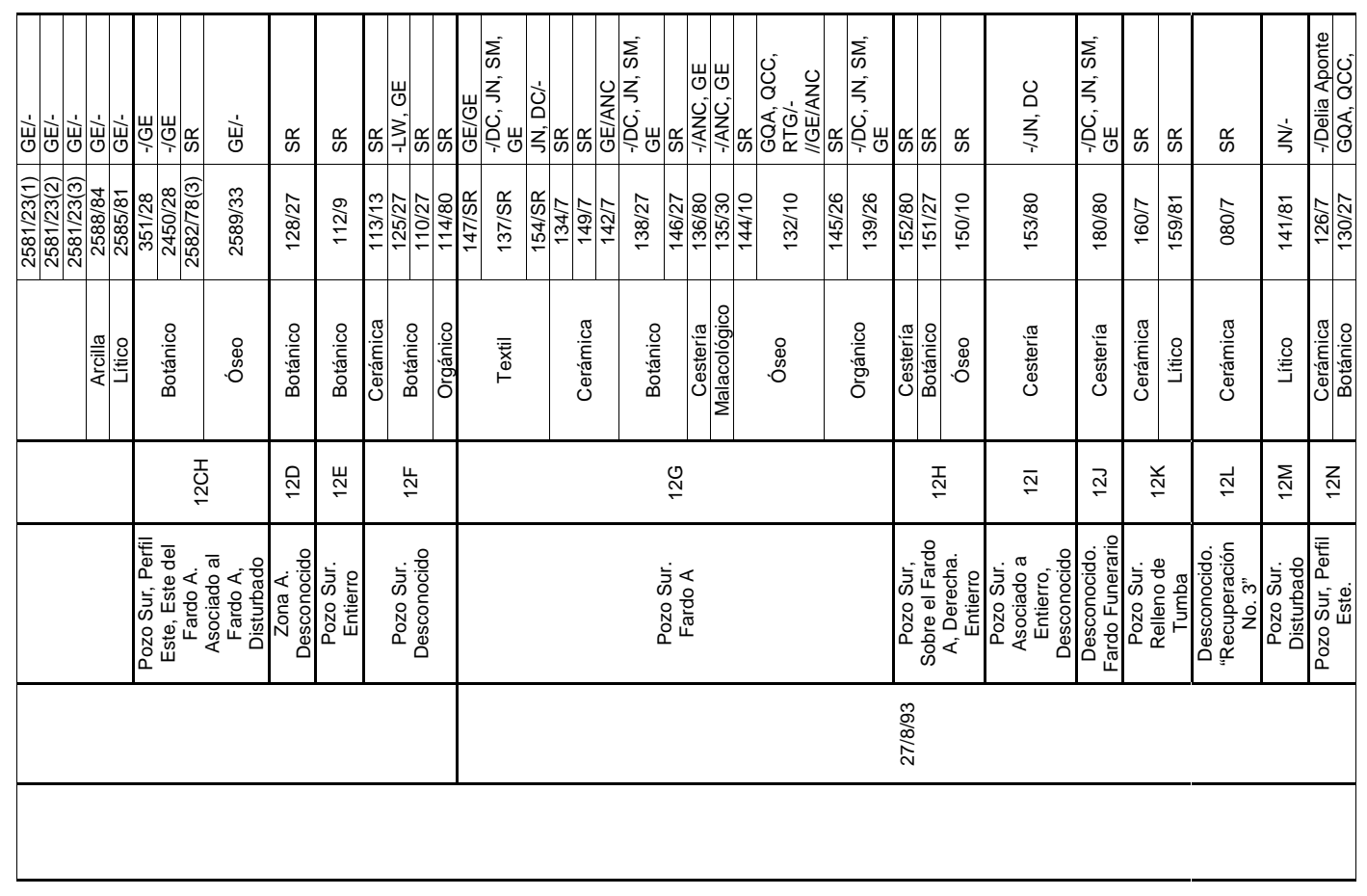




\begin{tabular}{|c|c|c|c|c|c|c|c|c|c|c|c|}
\hline 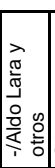 & & & & & 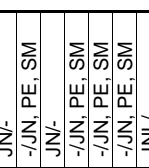 & 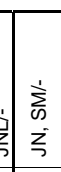 & $\frac{r}{\omega}$ & $\frac{\mathscr{c}}{\infty}$ & 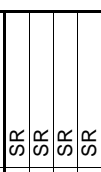 & $\frac{\infty}{\infty}$ & 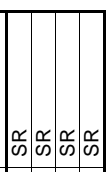 \\
\hline 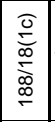 & 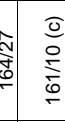 & 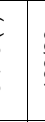 & 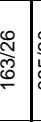 & 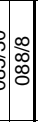 & 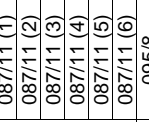 & 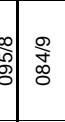 & $\begin{array}{l}\stackrel{1}{0} \\
\text { \& }\end{array}$ & 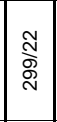 & 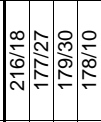 & 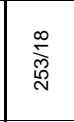 & 象 \\
\hline 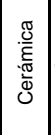 & 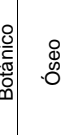 & & : & : & 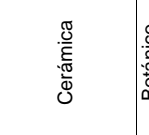 & 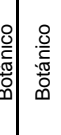 & $\begin{array}{l}\text { ̊. } \\
\text { On }\end{array}$ & 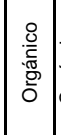 & : & 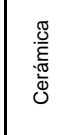 & 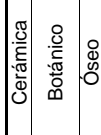 \\
\hline 岁 & & J & & 点 & 茴 & 佩 & $\stackrel{\infty}{\circ}$ & 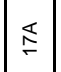 & $\stackrel{n}{\sim}$ & $\underset{\nearrow}{0}$ & 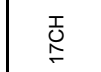 \\
\hline 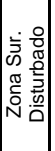 & 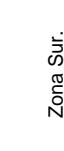 & 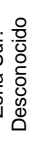 & & 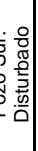 & 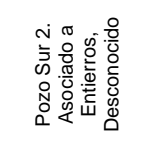 & 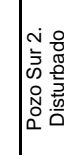 & 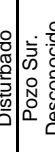 & 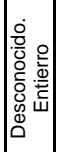 & 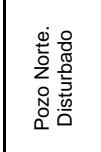 & 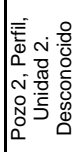 & 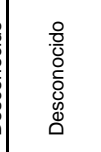 \\
\hline & 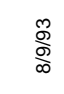 & & & 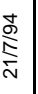 & 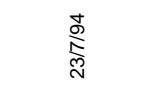 & & 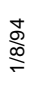 & \multicolumn{4}{|c|}{ 品 } \\
\hline & & & & & $\stackrel{2}{\sim}$ & & $\stackrel{1}{\circ}$ & \multicolumn{4}{|c|}{ ㄱ } \\
\hline
\end{tabular}



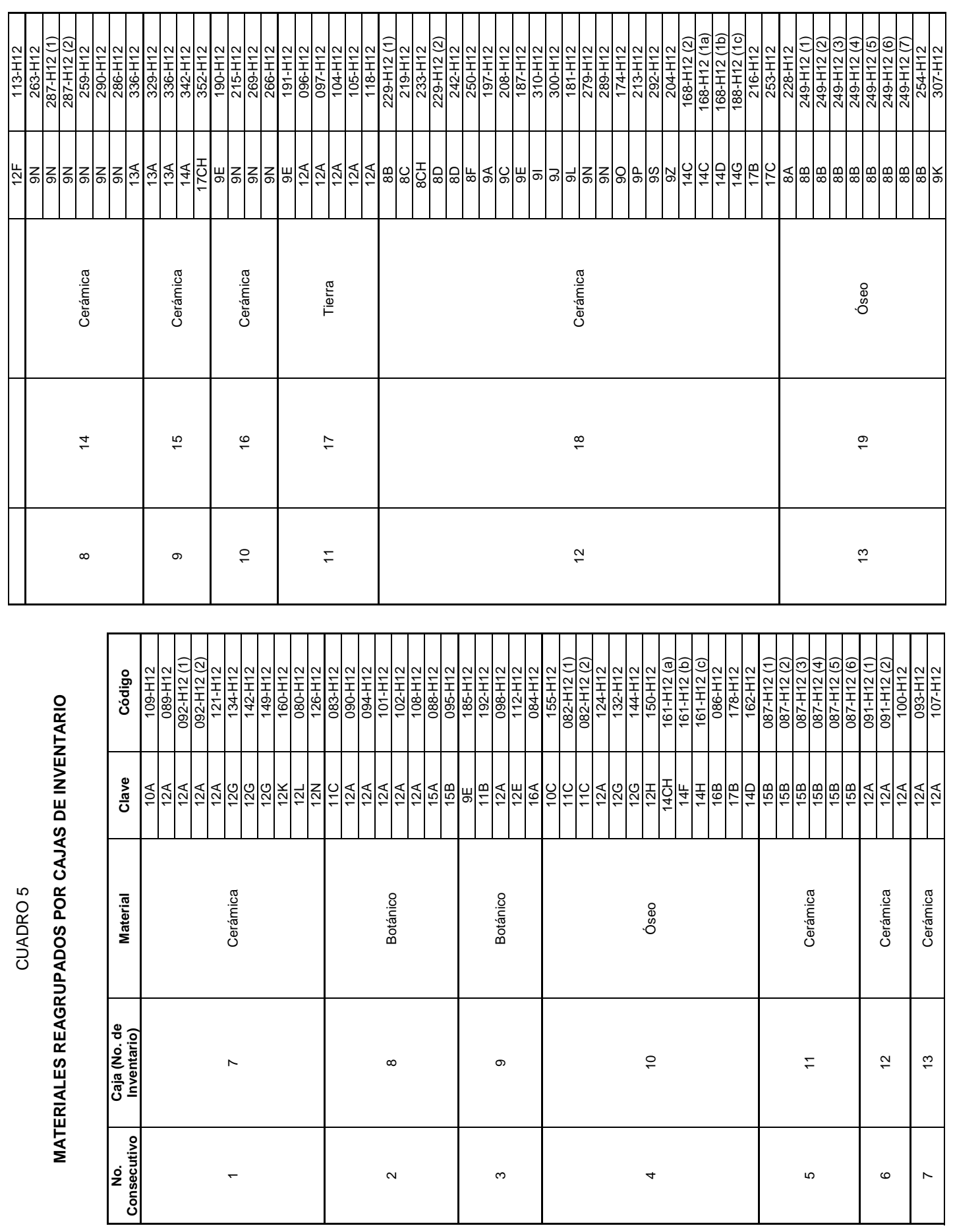


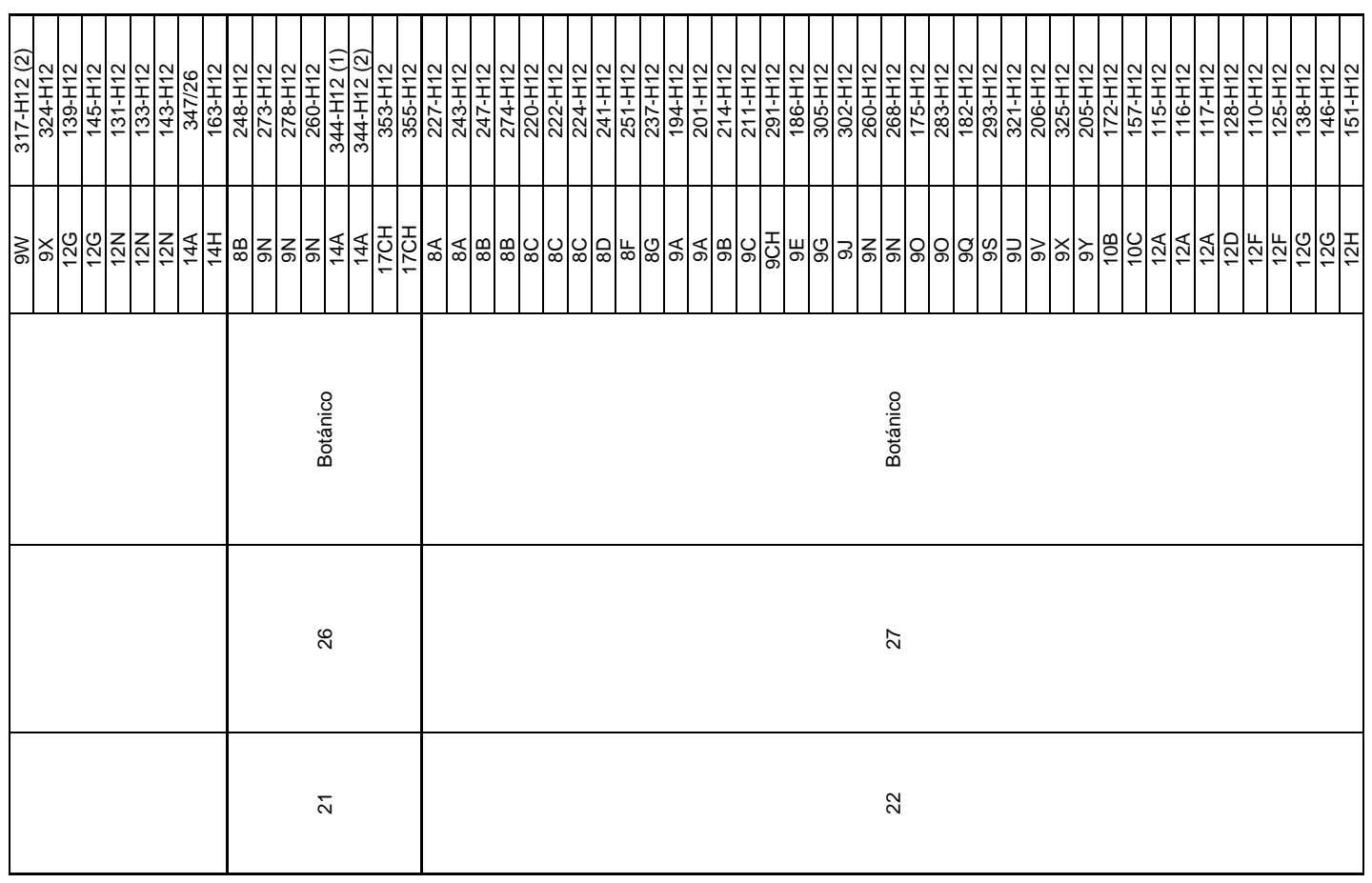

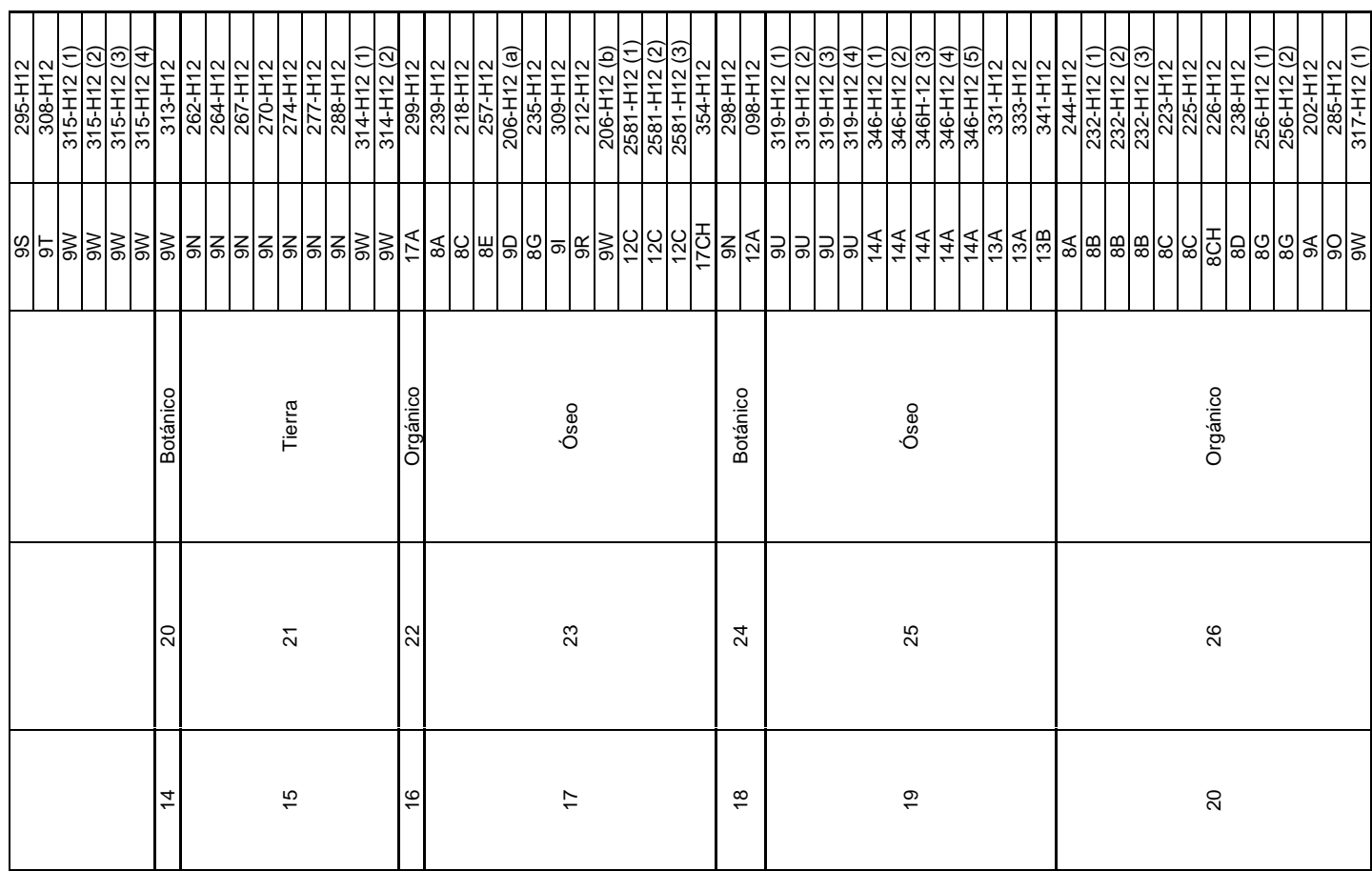



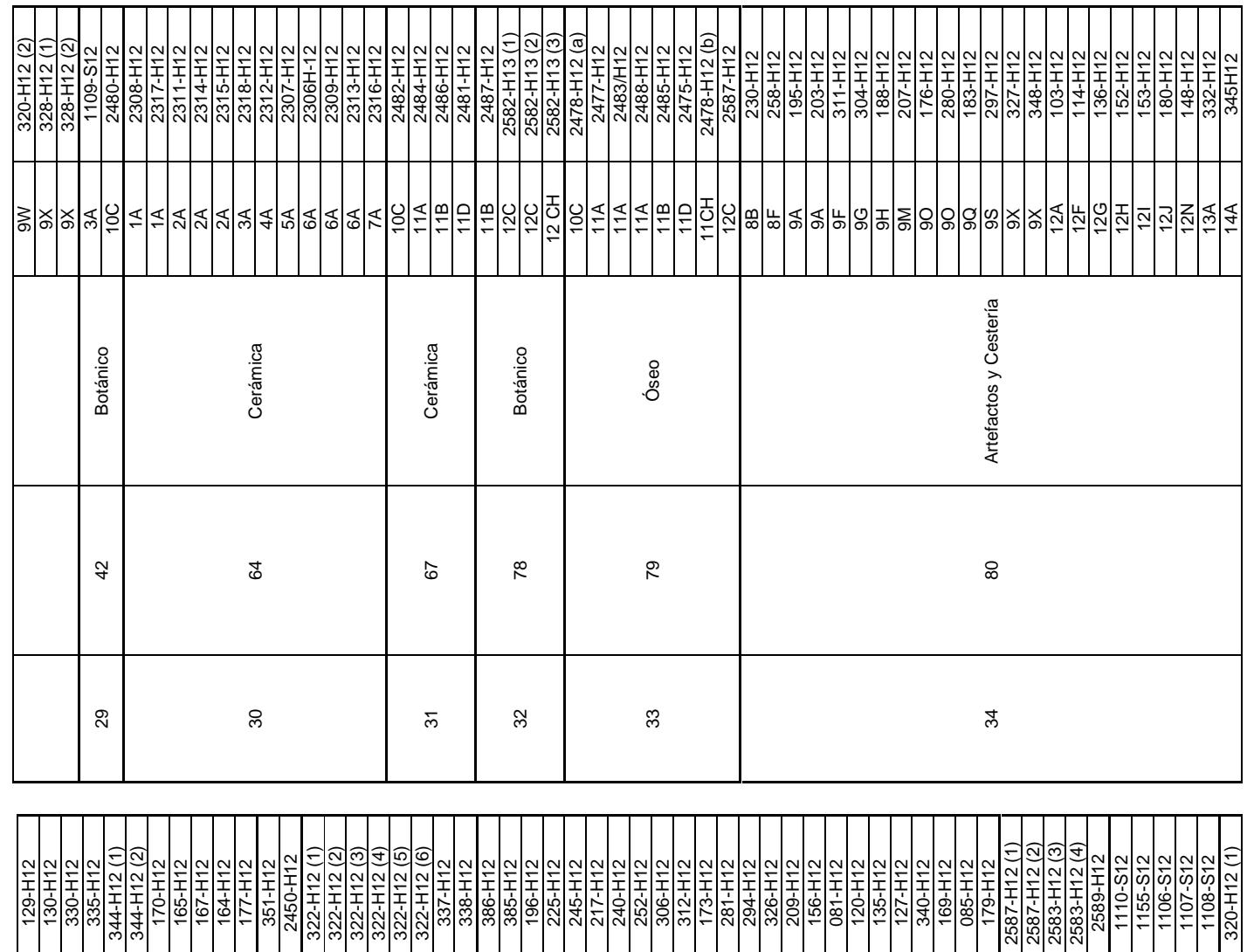

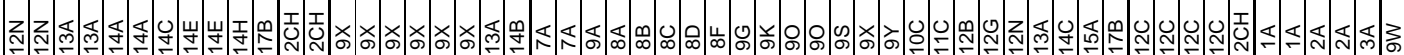

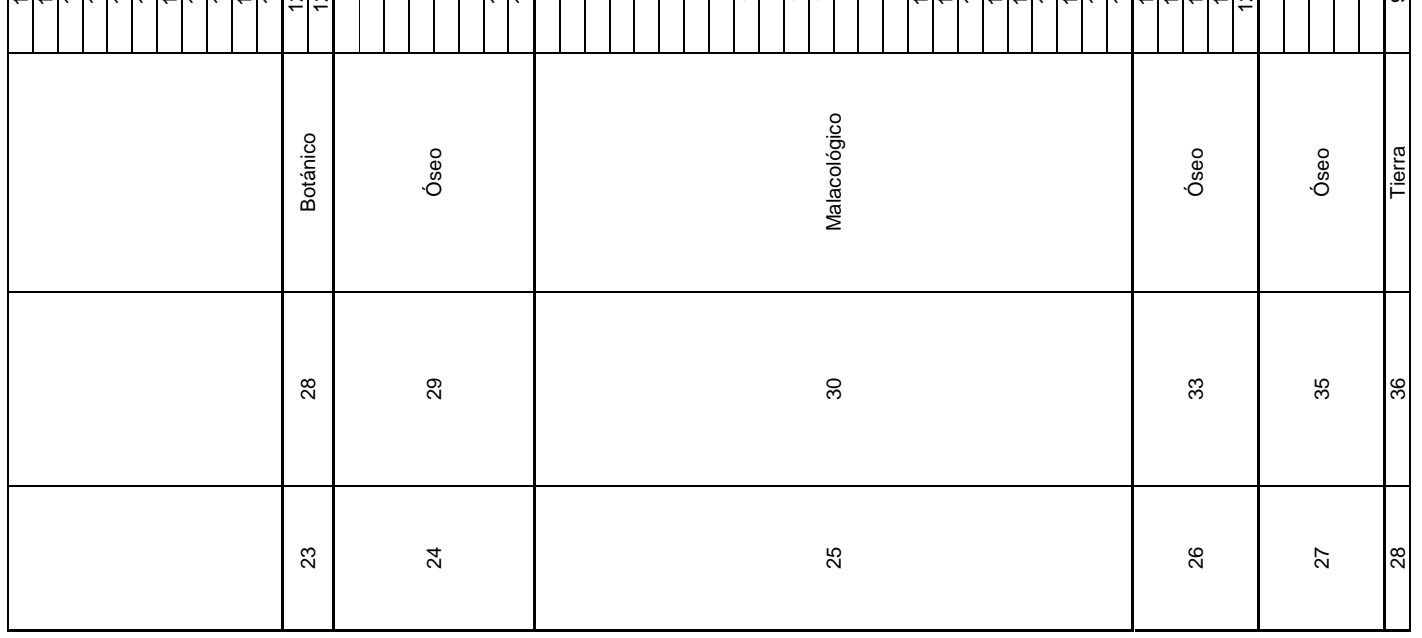




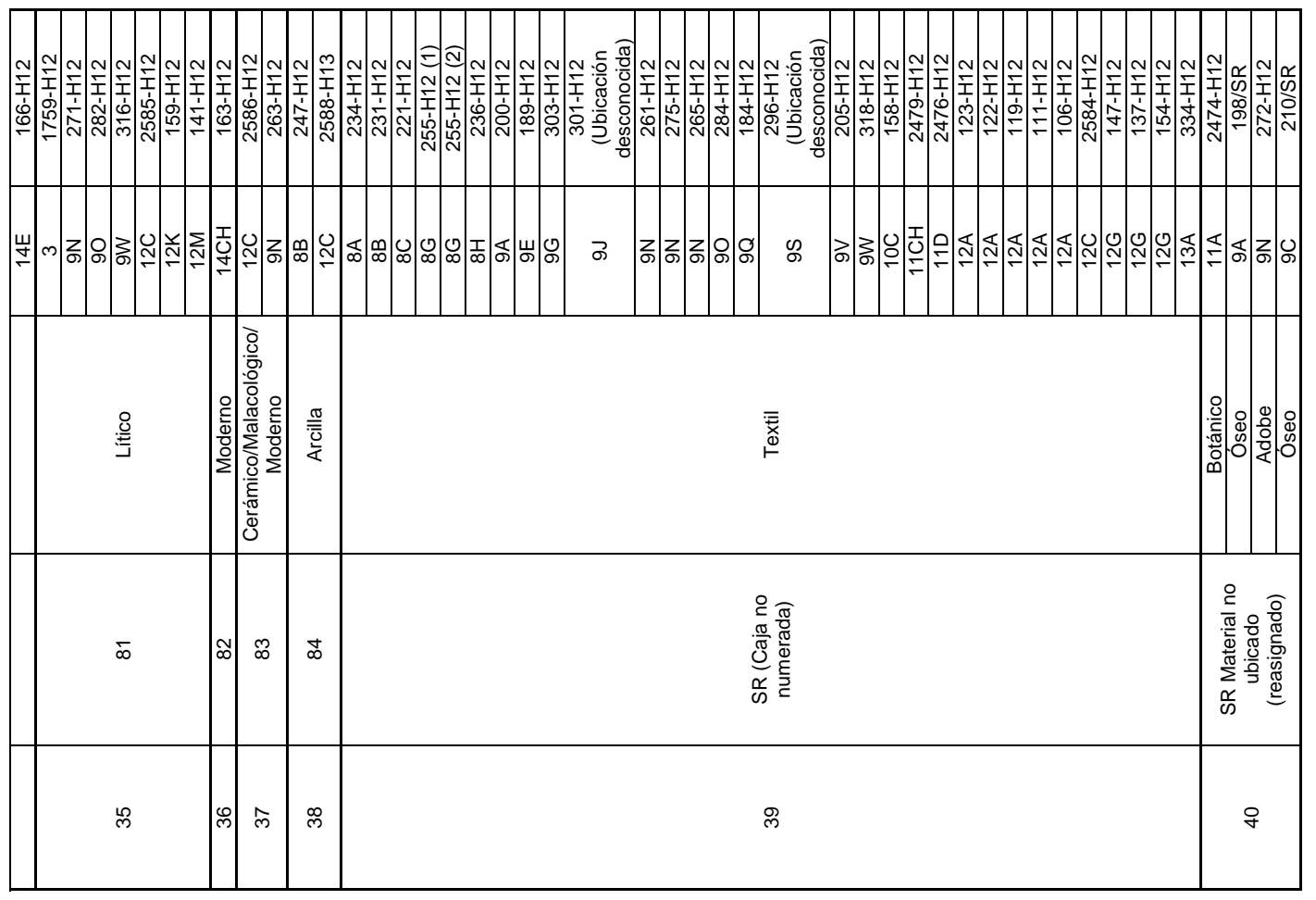




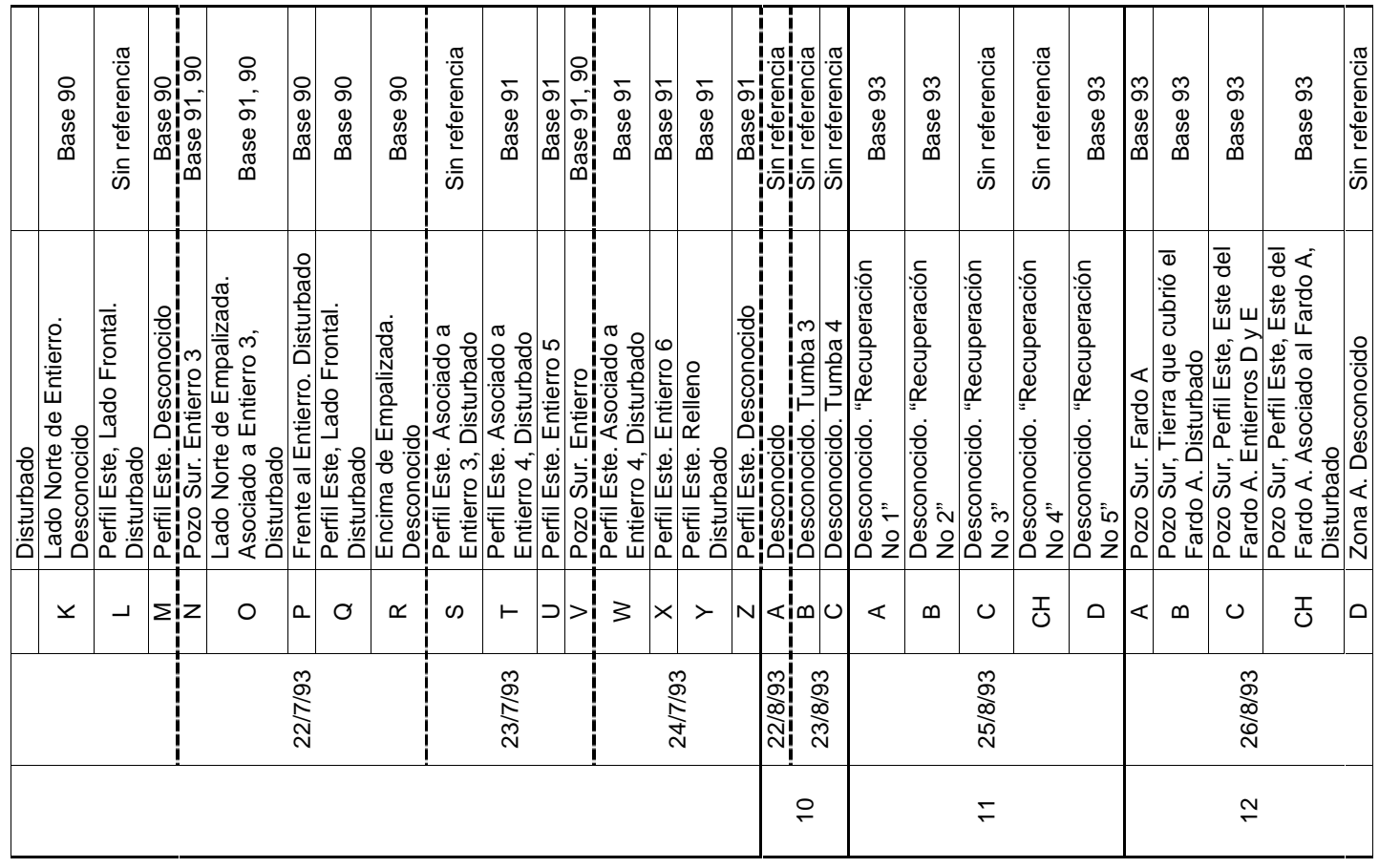

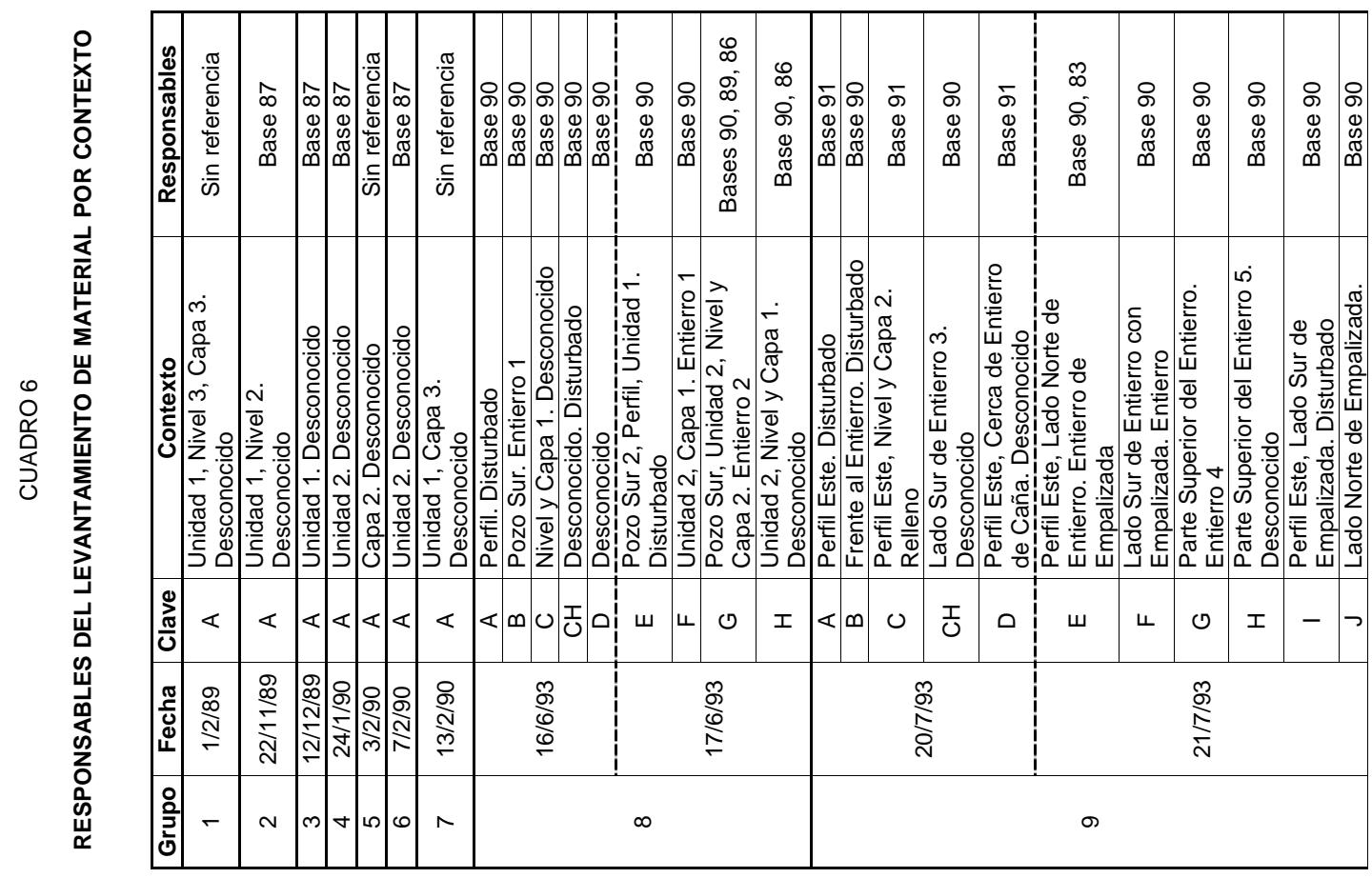




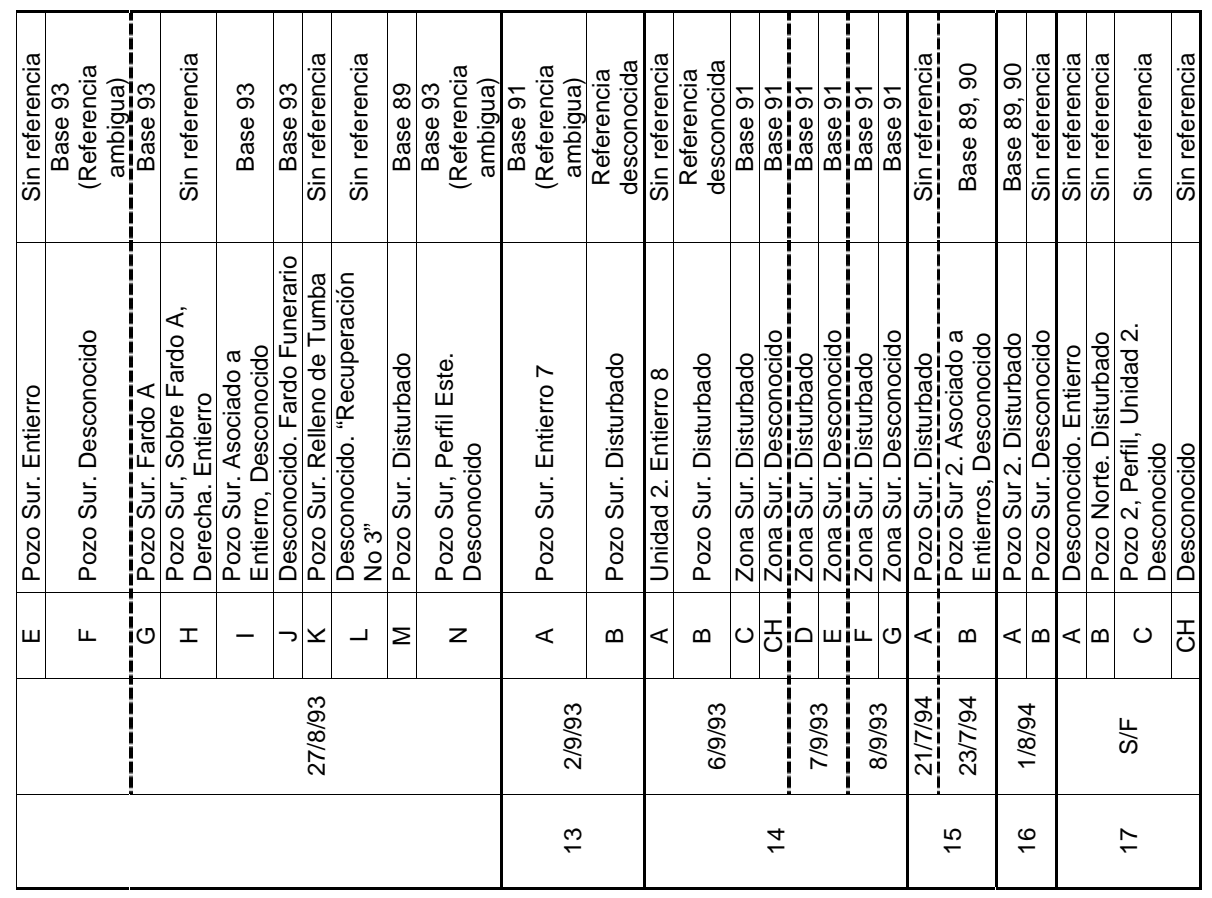



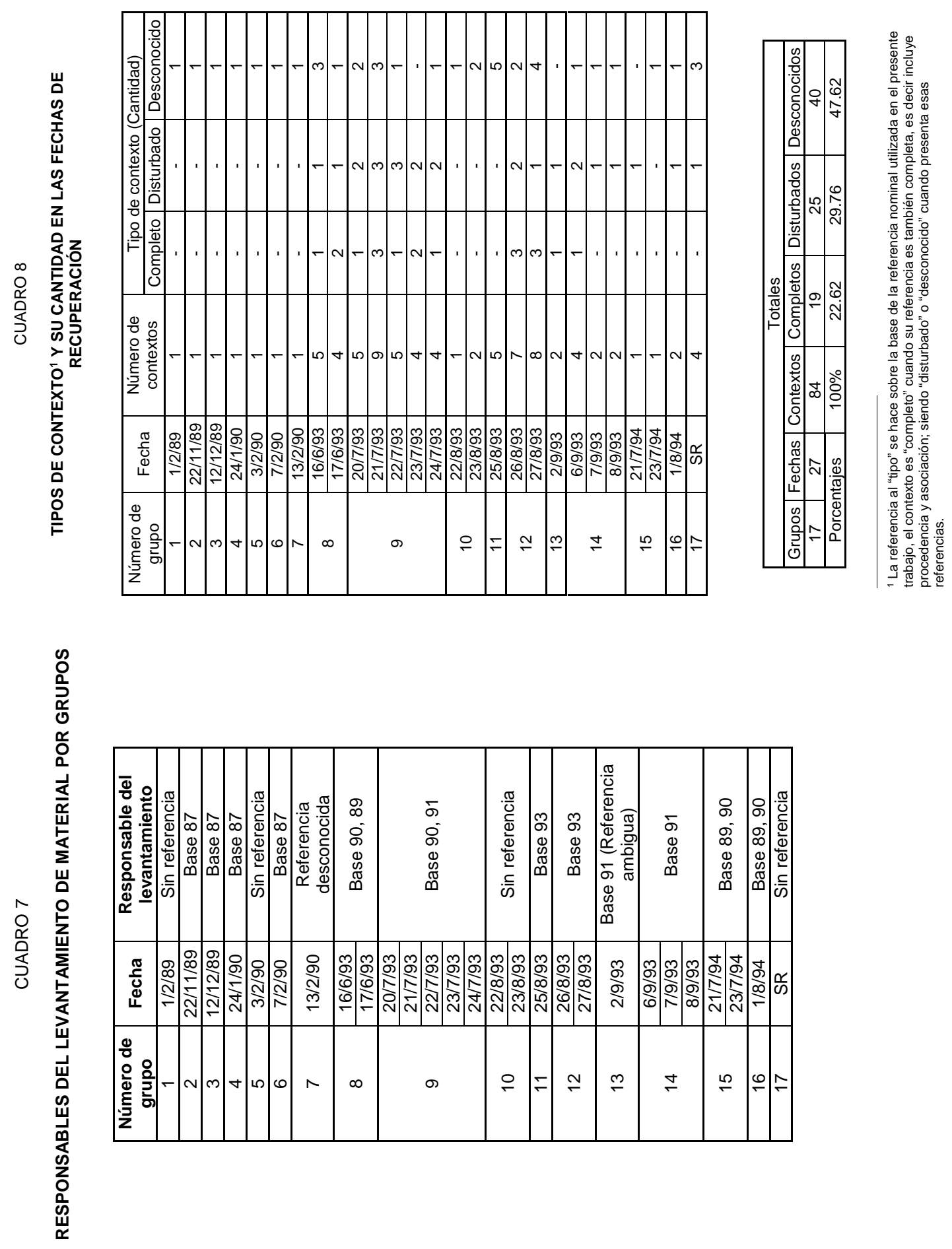

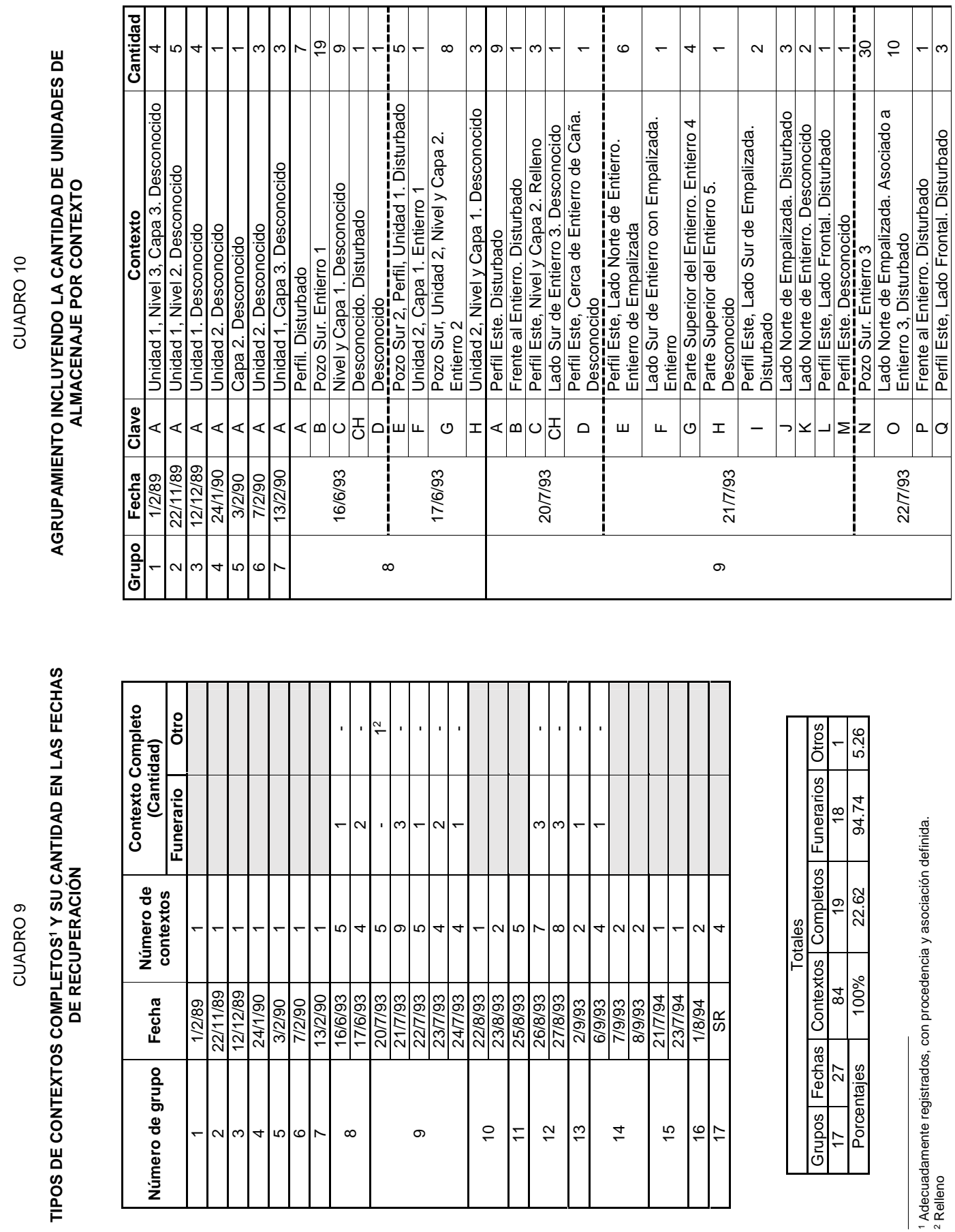
CUADRO 11

TOTAL DE UNIDADES RECUPERADAS POR FECHAS Y GRUPOS

\begin{tabular}{|c|c|c|c|}
\hline Número de grupo & Fecha & \multicolumn{2}{|c|}{ Totales } \\
\hline 1 & $1 / 2 / 89$ & \multicolumn{2}{|c|}{4} \\
\hline 2 & $22 / 11 / 89$ & \multicolumn{2}{|c|}{5} \\
\hline 3 & $12 / 12 / 89$ & \multicolumn{2}{|c|}{4} \\
\hline 4 & $24 / 1 / 90$ & \multicolumn{2}{|c|}{1} \\
\hline 5 & $3 / 2 / 90$ & \multicolumn{2}{|c|}{1} \\
\hline 6 & $7 / 2 / 90$ & \multicolumn{2}{|c|}{3} \\
\hline 7 & $13 / 2 / 90$ & \multicolumn{2}{|c|}{3} \\
\hline \multirow{2}{*}{8} & $16 / 6 / 93$ & 37 & \multirow{2}{*}{54} \\
\hline & $17 / 6 / 93$ & 17 & \\
\hline \multirow{5}{*}{9} & $20 / 7 / 93$ & 15 & \multirow{5}{*}{125} \\
\hline & $21 / 7 / 93$ & 21 & \\
\hline & $22 / 7 / 93$ & 45 & \\
\hline & 23/7/93 & 14 & \\
\hline & $24 / 7 / 93$ & 30 & \\
\hline \multirow{2}{*}{10} & $22 / 8 / 93$ & 1 & \multirow{2}{*}{9} \\
\hline & $23 / 8 / 93$ & 8 & \\
\hline 11 & $25 / 8 / 93$ & \multicolumn{2}{|c|}{18} \\
\hline \multirow{2}{*}{12} & $26 / 8 / 93$ & 56 & \multirow{2}{*}{87} \\
\hline & $27 / 8 / 93$ & 31 & \\
\hline 13 & 2/9/93 & \multicolumn{2}{|c|}{12} \\
\hline \multirow{3}{*}{14} & $6 / 9 / 93$ & 19 & \multirow{3}{*}{29} \\
\hline & $7 / 9 / 93$ & 6 & \\
\hline & $8 / 9 / 93$ & 4 & \\
\hline \multirow{2}{*}{15} & $21 / 7 / 94$ & 2 & \multirow{2}{*}{9} \\
\hline & $23 / 7 / 94$ & 7 & \\
\hline 16 & $1 / 8 / 94$ & \multicolumn{2}{|c|}{2} \\
\hline 17 & SR & \multicolumn{2}{|c|}{10} \\
\hline \multicolumn{2}{|l|}{ Total Ge } & \multicolumn{2}{|c|}{376} \\
\hline
\end{tabular}


Gori Echevarría y Alex Zúñiga / Los contextos funerarios y los materiales arqueológicos de la Huaca Concha

Anexo

CATALOGO DE MATERIALES ARQUEOLÓGICOS REAGRUPADOS. COLECCIÓN HUACA CONCHA Deposito de la Escuela de Arqueología, UNMSM.

\begin{tabular}{|c|c|c|c|c|c|c|}
\hline Fecha y Contexto & Procedencia & Asociación/Referencia & Material & Código/Caja (2003) & Excavó/Registró & $\begin{array}{c}\text { Códigos } \\
\text { anteriores/Notas }\end{array}$ \\
\hline $1 / 2 / 89$ C. $1 A$ & Sector 12 & $\mathrm{SR}$ & Cerámica & $2308 / 64$ & $\mathrm{SR}$ & $\begin{array}{l}\text { Fecha de selección } \\
13 / 7 / 01 \text { en ficha que } \\
\text { lee: "Sitio } \\
\text { arqueológico } \\
\text { Maranga". }\end{array}$ \\
\hline SR & $\begin{array}{l}\text { Sector } 12 \text {, Unidad } \\
1 \text {, Nivel y capa } 3\end{array}$ & SR & Cerámica & $2317 / 64$ & SR & $\begin{array}{l}\text { Fecha de selección } \\
13 / 7 / 01\end{array}$ \\
\hline $1 / 2 / 89$ & Sector 12 , Nivel 3 & SR & Óseo & $1110 / 35$ & SR & $\begin{array}{l}\text { Óseo de camélido. } \\
\text { Fecha de selección } \\
\text { 13/7/01 }\end{array}$ \\
\hline $1 / 2 / 89$ & $\begin{array}{l}\text { Sector 12, Unidad } \\
\text { 1, Capa } 3\end{array}$ & $\mathrm{SR}$ & Óseo & $1155 / 35$ & SR & $\begin{array}{l}\text { Fecha de selección } \\
13 / 7 / 01\end{array}$ \\
\hline $22 / 11 / 89$ C. $2 A$ & $\begin{array}{l}\text { Unidad 1, Segundo } \\
\text { nivel }\end{array}$ & SR & Cerámica & $2311 / 64$ & SR & $\begin{array}{l}\text { Fecha de selección } \\
13 / 7 / 01\end{array}$ \\
\hline SR & $\begin{array}{l}\text { Sector 12, Unidad } \\
\text { 1, Nivel } 2\end{array}$ & SR & Cerámica & $2314 / 64$ & SR & $\begin{array}{l}\text { Fecha de selección } \\
13 / 7 / 01\end{array}$ \\
\hline SR & $\begin{array}{l}\text { Sector 12, Unidad } \\
\text { 1, Capa } 2\end{array}$ & SR & Cerámica & $2315 / 64$ & -/A. Noriega & $\begin{array}{l}\text { Fecha de Selección } \\
13 / 7 / 01\end{array}$ \\
\hline SR & $\begin{array}{l}\text { Sector } 12 \text {, Unidad } \\
1 \text {, Capa } 2\end{array}$ & SR & Óseo & $1106 / 35$ & SR & $\begin{array}{l}\text { Fecha de selección } \\
\text { 13/7/01 }\end{array}$ \\
\hline $22 / 11 / 89$ & $\begin{array}{l}\text { Sector 12, Unidad } \\
1 \text {, Nivel } 2\end{array}$ & SR & Óseo & $1107 / 35$ & -/UNMSM & $\begin{array}{l}\text { Fecha de selección } \\
13 / 7 / 01\end{array}$ \\
\hline $12 / 12 / 89$ C. $3 A$ & Sector 12 , Unidad 1 & SR & Cerámica & $2318 / 64$ & $\mathrm{SR}$ & $\begin{array}{l}\text { Fecha de selección } \\
13 / 7 / 01 . \text { La bolsa } \\
\text { original contenía } \\
\text { moluscos y óseos } \\
\text { asociados. }\end{array}$ \\
\hline $12 / 12 / 89$ & Sector 12, Unidad 1 & SR & \begin{tabular}{|l|} 
Botánico \\
\end{tabular} & $1109 / 42$ & -IAldo & SR \\
\hline $12 / 12 / 89$ & Sitio-CU-S12-U1 & SR & Óseo & $1108 / 35$ & Aldo, Yuri, Neri/- & No 4. Material \\
\hline
\end{tabular}

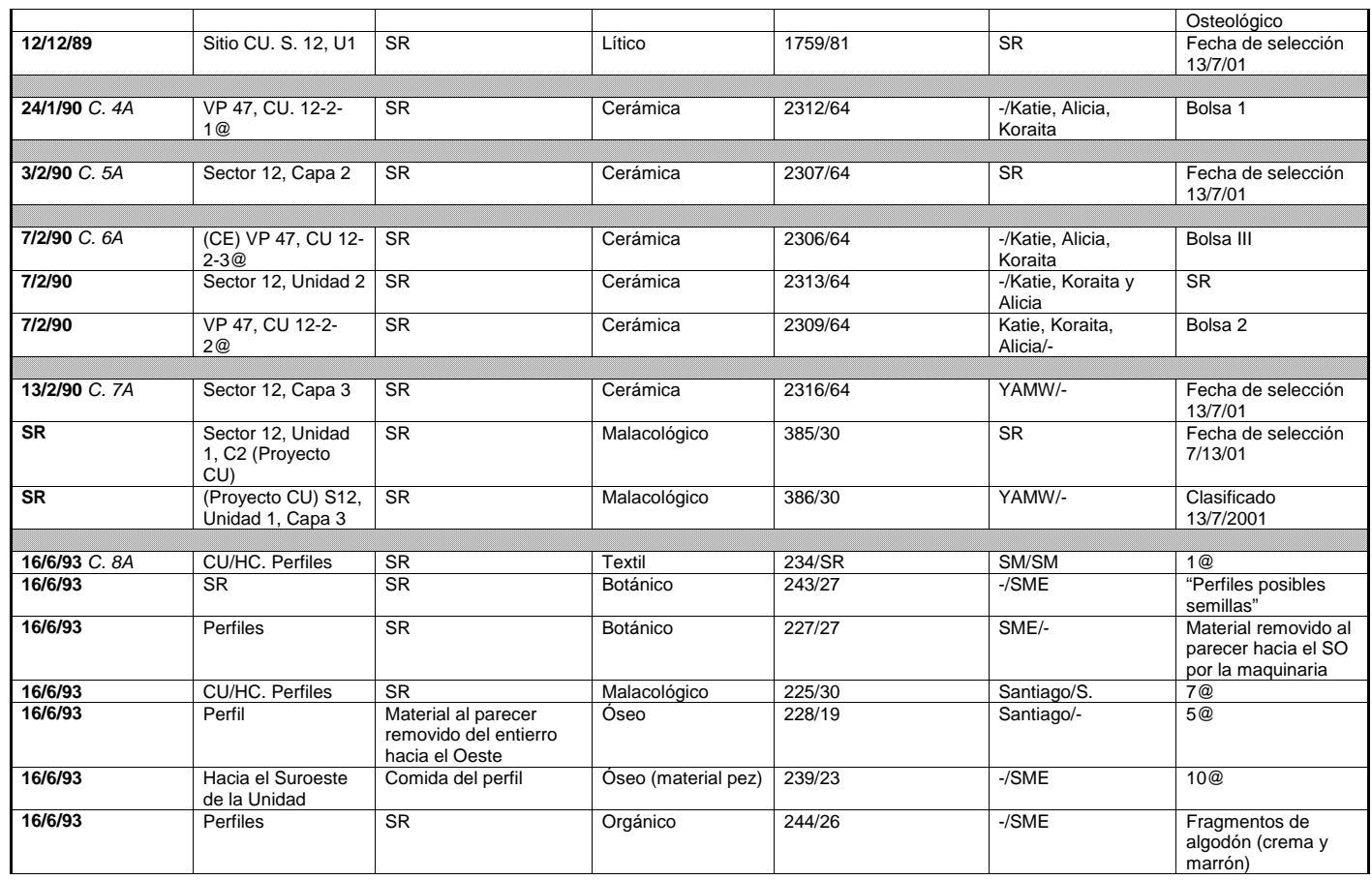


Arqueología y Sociedad 29, 2015: 183 - 231

\begin{tabular}{|c|c|c|c|c|c|c|}
\hline $16 / 6 / 93$ C. $8 B$ & Oeste del estadio & \begin{tabular}{|l|} 
Material del mismo \\
entierro
\end{tabular} & Textil & $231 / \mathrm{SR}$ & -/SME & SR \\
\hline $16 / 6 / 93$ & Oeste del estadio & $\begin{array}{l}\text { Entierro, material del } \\
\text { mismo entierro }\end{array}$ & Cerámica & $229 / 18(1)$ & -/Santiago & 16@ \\
\hline $16 / 6 / 93$ & Oeste del Estadio & $\begin{array}{l}\text { Material del mismo } \\
\text { entierro } 1\end{array}$ & Botánico & $248 / 26$ & -/SME & SR \\
\hline $16 / 6 / 93$ & Oeste del estadio & $\begin{array}{l}\text { Material del mismo } \\
\text { entierro }\end{array}$ & Botánico & $247 / 27$ & -SME & $\begin{array}{l}\text { Código de material } \\
\text { repetido en caja } 84\end{array}$ \\
\hline $16 / 6 / 93$ & Oeste del estadio & $\begin{array}{l}\text { Material del mismo } \\
\text { entierro }\end{array}$ & Botánico & $274 / 27$ & SR & SR \\
\hline $16 / 6 / 93$ & SR & $\begin{array}{l}\text { Material del mismo } \\
\text { entierro }\end{array}$ & Cestería & $230 / 80$ & $-/ \mathrm{SME}$ & SR \\
\hline $16 / 6 / 93$ & Oeste del estadio & $\begin{array}{l}\text { Material del mismo } \\
\text { entierro }\end{array}$ & Malacológico & $245 / 30$ & $-/ S M E$ & SR \\
\hline 16/6/93 & Oeste del Estadio & $\begin{array}{l}\text { Material del mismo } \\
\text { entierro }\end{array}$ & Adobe & $247 / 84$ & -/SME & $\begin{array}{l}\text { Código de material } \\
\text { repetido en caja } 27\end{array}$ \\
\hline $16 / 6 / 93$ & $\begin{array}{l}\text { Oeste del estadio, } \\
\text { Pozo Sur, Unidad } 1\end{array}$ & Entierro 1 & Óseo & $249 / 19(1)$ & -/SM, MP & SR \\
\hline $16 / 6 / 93$ & $\begin{array}{l}\text { Pozo Sur, Unidad } \\
1 \text {, Oeste del } \\
\text { estadio }\end{array}$ & Entierro 1 & Óseo & $249 / 19(2)$ & $\mathrm{SM}, \mathrm{MP} /-$ & SR \\
\hline $16 / 6 / 93$ & $\begin{array}{l}\text { Oeste del estadio, } \\
\text { Pozo Sur, Unidad } 1\end{array}$ & Entierro 1 & Óseo & $249 / 19(3)$ & -/SM, MP & SR \\
\hline $16 / 6 / 93$ & Pozo Sur, Unidad 1 & \begin{tabular}{|l|} 
Entierro 1 \\
\end{tabular} & Óseo & $249 / 19$ (4) & SM, MP/- & SR \\
\hline $16 / 6 / 93$ & $\begin{array}{l}\text { Oeste del estadio, } \\
\text { Pozo Sur, Unidad } 1\end{array}$ & Entierro 1 & Óseo & 249/19 (5) & SR & SR \\
\hline 16/6/93 & Pozo Sur, Unidad 1 & \begin{tabular}{|l|} 
Entierro 1 \\
\end{tabular} & Óseo & $249 / 19(6)$ & SM, MP/- & SR \\
\hline 16/6/93 & Pozo Sur, Unidad 1 & \begin{tabular}{|l|} 
Entierro 1 \\
\end{tabular} & Óseo & $249 / 19(7)$ & SM, MPI- & SR \\
\hline SR & Capa 2 & $\begin{array}{l}\text { Entierro. Del mismo } \\
\text { entierro }\end{array}$ & Óseo & $254 / 19$ & -/Santiago & $\begin{array}{l}\text { Número del entierro } \\
\text { "2", en el contexto, } \\
\text { no en ficha original }\end{array}$ \\
\hline $16 / 6 / 93$ & Oeste del Estadio & $\begin{array}{l}\text { Material del mismo } \\
\text { entierro }\end{array}$ & Orgánico & $232 / 26(1)$ & -/SME & SR \\
\hline $16 / 6 / 93$ & Oeste del Estadio & $\begin{array}{l}\text { Material del mismo } \\
\text { entierro }\end{array}$ & Orgánico & $232 / 26(2)$ & -/SME & SR \\
\hline $16 / 6 / 93$ & SR & Asociado al Entierro & Orgánico & $232 / 26(3)$ & Max, Fujita/Santiago & $\begin{array}{l}\text { Material plumario. } \\
\text { Asociado al entierro }\end{array}$ \\
\hline $16 / 6 / 93$ C. $8 C$ & $\begin{array}{l}\text { Nivel y Capa } 1 . \\
\text { Oeste del Estadio }\end{array}$ & SR & \begin{tabular}{|l|} 
Textil \\
\end{tabular} & $221 / S R$ & SME/ANR & $\begin{array}{l}\text { 3@ En la ficha } \\
\text { nueva se lee: } \\
\text { "Entierro 3" }\end{array}$ \\
\hline
\end{tabular}

3

\begin{tabular}{|c|c|c|c|c|c|c|}
\hline $16 / 6 / 93$ & $\begin{array}{l}\text { Oeste del Estadio, } \\
\text { tnbuma principal } \\
\text { Capa } 1\end{array}$ & SR & Cetámica & $219 / 18$ & IANC & 20 (9) \\
\hline $16 / 6 / 93$ & $\begin{array}{l}\text { Oeste del estadio, } \\
\text { patio principal Capa } \\
\text { i }\end{array}$ & SR & Botánico & $220 / 27$ & SME/- & SR \\
\hline $16 / 6 / 93$ & $\begin{array}{l}\text { Oeste del estadio, } \\
\text { parte principal, } \\
\text { Nivel } 1\end{array}$ & SR & Botánico & $222 / 27$ & SR & SR \\
\hline $16 / 6 / 93$ & Nivel y capa 1 & Asociado a textil & Botảnico & $224 / 27$ & ISME, ANC & SR \\
\hline $16 / 6 / 93$ & $\begin{array}{l}\text { Oeste del estedío, } \\
\text { Capa } 1\end{array}$ & SR & Ósed & $218 / 23$ & SME/ANC & 6@ \\
\hline $16 / 6 / 93$ & Capa 1 & SR & Orgánico & $225 / 26$ & SME, JN/Santiago & $9 @$ \\
\hline $16 / 6 / 93$ & $\begin{array}{l}\text { Oestie del estadio, } \\
\text { parte principal. } \\
\text { Nivel y Capa } 1\end{array}$ & & Orgânicọo & $223 / 26$ & -ISME, ANC & SR \\
\hline $16 / 6 / 93 \mathrm{C} .8 \mathrm{CH}$ & $S R$ & Material femovido & Orgánico & $226 / 26$ & $-1 S M E$ & $\begin{array}{l}\text { Carbón. Material } \\
\text { removido al parecer } \\
\text { hacia el Suroeste } \\
\text { por la maquina } \\
\end{array}$ \\
\hline $17 / 6 / 93$ C. $8 E$ & Unidad 1 & $\begin{array}{l}\text { Ceramica del material } \\
\text { que cayo al talud del } \\
\text { perfil de la unicad } \\
\end{array}$ & Cerámica & $242 / 18$ & -ISME & 19@8 \\
\hline $17 / 6 / 93$ & $\begin{array}{l}\text { Pozo Sur 2, Perfil } \\
\text { Unidad } 1\end{array}$ & SR & Cntamica & $229 / 18(2)$ & SR & $\begin{array}{l}17 \text { (9) Fecha no en } \\
\text { ficha ariginal }\end{array}$ \\
\hline $17 / 6 / 93$ & Unidad 1 & $\begin{array}{l}\text { Cemido del material } \\
\text { que cayó al talud del } \\
\text { perfil de la unidad }\end{array}$ & Botánticos & $241 / 27$ & -ISME & SR \\
\hline $17 / 6 / 93$ & Unidad 1 & $\begin{array}{l}\text { Cemido del material } \\
\text { que cayó al talud del } \\
\text { perfil de la unidad }\end{array}$ & Malaoológico & $240 / 30$ & SMEI- & SR \\
\hline $17 / 6 / 93$ & Unidad 1 & $\begin{array}{l}\text { Cemido del mate que } \\
\text { cayo al talud. del perfil } \\
\text { de la unidad }\end{array}$ & Orgánico & $238 / 26$ & ASM. MP & SR \\
\hline
\end{tabular}


Gori Echevarría y Alex Zúñiga / Los contextos funerarios y los materiales arqueológicos de la Huaca Concha

\begin{tabular}{|c|c|c|c|c|c|c|}
\hline & Entierro 1 & vértebra en la unidad & & & & \\
\hline $17 / 6 / 93$ C. $8 G$ & $\begin{array}{l}\text { Pozo Sur, Unidad } \\
2 \text {, Nivel y Capa } 2\end{array}$ & Asociado a Entierro 2 & Textil & 255/SR (1) & -/SM, MP & $\begin{array}{l}\text { Hay dos bolsas con } \\
\text { el mismo número }\end{array}$ \\
\hline $17 / 6 / 93$ & $\begin{array}{l}\text { Pozo Sur, Unidad } \\
2, \text { Nivel y Capa } 2\end{array}$ & Asociado a Entierro 2 & Textil & 255/SR (2) & -/SM, MP & SR \\
\hline SR & Pozo sur, Unidad 2 & Entierro 2 & Cerámica & $250 / 18$ & $\mathrm{JN}, \mathrm{CT}, \mathrm{FM}, \mathrm{SM} /-$ & SR \\
\hline SR & Pozo Sur, Unidad 2 & Asociado a Entierro 2 & Botánico & $251 / 27$ & 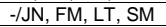 & SR \\
\hline $17 / 6 / 93$ & $\begin{array}{l}\text { Pozo Sur, Unidad } \\
\text { 2, Nivel } 2\end{array}$ & Asociado a Entierro 2 & Cestería & $258 / 80$ & JN, CT, FM, SM/- & SR \\
\hline SR & Pozo Sur, Unidad 2 & Entierro 2 & Malacológico & $252 / 30$ & $\mathrm{JN}, \mathrm{CT}, \mathrm{SM}, \mathrm{FM} /-$ & SR \\
\hline $17 / 6 / 93$ & $\begin{array}{l}\text { Pozo Sur, Unidad } \\
2, \text { Nivel y Capa } 2\end{array}$ & Asociado a Entierro 2 & Orgánico & $256 / 26(1)$ & -/SM, MP & SR \\
\hline SR & $\begin{array}{l}\text { Pozo Sur, Unidad } \\
\text { 2, Nivel y Capa } 2\end{array}$ & Asociado a Entierro 2 & Orgánico & $256 / 26(2)$ & $-/ \mathrm{SM}, \mathrm{MP}$ & SR \\
\hline $17 / 6 / 93 \mathrm{C} .8 \mathrm{H}$ & $\begin{array}{l}\text { Unidad 2, Nivel y } \\
\text { Capa 1 }\end{array}$ & SR & Textil & $236 / S R$ & $-/ \mathrm{SME}$ & SR \\
\hline $17 / 6 / 93$ & Unidad 2, Capa 1 & SR & Botánico & $237 / 27$ & Max/SM & $\begin{array}{l}\text { Material óseo, textil } \\
\text { y orgánico asociado }\end{array}$ \\
\hline $17 / 6 / 93$ & Unidad 2, Capa 1 & $\mathrm{SR}$ & Óseo & $235 / 23$ & -/SME, M. & SR \\
\hline 20/7/93 C. $9 A$ & Perfil Este & Material de desmonte & Textil & $200 / S R$ & -/JC. MM, NR & \begin{tabular}{|l|} 
Material de \\
desmonte, textil, \\
molusco, madera.
\end{tabular} \\
\hline $20 / 7 / 93$ & $\begin{array}{l}\text { Perfil Este. Lado } \\
\text { Oeste del entierro }\end{array}$ & Desmonte. $30 \mathrm{~cm}$. & Cerámica & $197 / 18$ & JC, MM, NR/- & $\begin{array}{l}\text { Fecha no en ficha } \\
\text { original. }\end{array}$ \\
\hline 20/7/93 & Perfil Este & Material de desmonte & Botánico & $201 / 27$ & -/JC. MM, NR & SR \\
\hline 20/7/93 & Perfil Este & Material del desmonte & Botánico & $194 / 27$ & $-/ \mathrm{JC}, \mathrm{MM}, \mathrm{NR}$ & SR \\
\hline $20 / 7 / 93$ & Perfil Este & Material de desmonte & Botánico & $195 / 80$ & $-/ \mathrm{JC}, \mathrm{MM}, \mathrm{NR}$ & $\begin{array}{l}\text { "Artefacto con color", } \\
\text { madera }\end{array}$ \\
\hline 20/7/93 & Perfil Este & Material del desmonte & Cestería & $203 / 80$ & $-\mathrm{IJC}, \mathrm{MM}, \mathrm{NR}$ & Restos de soguillas \\
\hline $20 / 7 / 93$ & Perfil Este & Material de desmonte & Malacológico & $196 / 30$ & $-/ \mathrm{JC}, \mathrm{MM}, \mathrm{NR}$ & Bolsa 25@ \\
\hline 20/7/93 & Perfil Este & Material del desmonte & Óseo & 198/SR & -/JC, MM, NR & SR \\
\hline 20/7/93 & Perfil Este & Material de desmonte & Orgánico & $202 / 26$ & -/JC. MM. NR & Cabello \\
\hline $20 / 7 / 93$ C. $9 B$ & Frente al Entierro & Disturbado & Botánico & $214 / 27$ & $-/ G M Z$ & SR \\
\hline $20 / 7 / 93$ C. $9 C$ & Perfil Este, Capa 2 & $\mathrm{SR}$ & Cerámica & $208 / 18$ & $\mathrm{JC}, \mathrm{NR}, \mathrm{MM} /-$ & SR \\
\hline $20 / 7 / 93$ & Capa 2 del relleno & SR & Botánico & $211 / 27$ & $-/ \mathrm{JC}, \mathrm{MM}$ & $\begin{array}{l}\text { "Ubicado en el } \\
\text { dibujo" }\end{array}$ \\
\hline $20 / 7 / 93$ & $\begin{array}{l}\text { Nivel y Capa 2, } \\
\text { Perfil Este }\end{array}$ & SR & Óseo & $210 / \mathrm{SR}$ & $-/ J C, M M, N R$ & SR \\
\hline
\end{tabular}

5

\begin{tabular}{|c|c|c|c|c|c|c|}
\hline $20 / 7 / 93 \mathrm{C} .9 \mathrm{CH}$ & $\begin{array}{l}\text { En lado sur a } \\
1.50 \mathrm{~m} \text { aprox. de } \\
\text { Entierro } 3\end{array}$ & $\mathrm{SR}$ & Botánico & $291 / 27$ & $-/ G Z$ & $\begin{array}{l}\text { Bolsa 18@ (Mate) } \\
\text { Asociado } \\
\text { posiblemente con } \\
\text { ceramio partido. }\end{array}$ \\
\hline $20 / 7 / 93$ C. $9 D$ & $\begin{array}{l}\text { Pozo Sur, Perfil } \\
\text { Este, cerca al } \\
\text { entierro de caña }\end{array}$ & $\mathrm{SR}$ & Óseo & $206 / 23$ (a) & $-/ \mathrm{JC}, \mathrm{MM}, \mathrm{NR}$ & $\begin{array}{l}\text { La misma bolsa } \\
\text { Incluye material del } \\
24 / 7 / 93\end{array}$ \\
\hline 1993 C. $9 E$ & $\begin{array}{l}\text { Perfil Este, lado } \\
\text { Norte, entierro de } \\
\text { empalizada }\end{array}$ & $\mathrm{SR}$ & Textil & $189 / \mathrm{SR}$ & $\begin{array}{l}\text {-/GZ, Edgardo } \\
\text { Meléndez }\end{array}$ & $\begin{array}{l}\text { Parte del textil } \\
\text { adherido a la } \\
\text { empalizada }\end{array}$ \\
\hline $21 / 7 / 93$ & $\begin{array}{l}\text { Perfil Este, lado } \\
\text { Norte, entierro de } \\
\text { empalizada }\end{array}$ & SR & Cerámica & $190 / 16$ & $\begin{array}{l}\text {-/E Meléndez, GZ, } \\
\text { Omar G. }\end{array}$ & SR \\
\hline $21 / 7 / 93$ & $\begin{array}{l}\text { Lado Norte de } \\
\text { Entierro de } \\
\text { empalizada, Perfil } \\
\text { Este }\end{array}$ & SR & Tierra & $191 / 17$ & -/Meléndez, Z, G & $\begin{array}{l}\text { Dentro del Ceramio } \\
190\end{array}$ \\
\hline $21 / 7 / 93$ & $\begin{array}{l}\text { Lado norte del } \\
\text { entierro }\end{array}$ & Entierro en empalizada & Cerámica & $187 / 18$ & SR & $\begin{array}{l}\text { Se encontró en la } \\
\text { bolsa junto a mate y } \\
\text { tusas }\end{array}$ \\
\hline $21 / 7 / 93$ & $\begin{array}{l}\text { Lado Norte del } \\
\text { entierro }\end{array}$ & Entierro de empalizada & Botánico & $186 / 27$ & SR & $\begin{array}{l}\text { Se encontró en la } \\
\text { misma bolsa junto a } \\
\text { mate y cerámica }\end{array}$ \\
\hline $21 / 7 / 93$ & $\begin{array}{l}\text { Perfil Este, ubicado } \\
\text { al lado Norte del } \\
\text { entierro }\end{array}$ & Entierro en empalizada & Botánico & $185 / 9$ & $\mathrm{SR}$ & Mate \\
\hline 21/7/93 C. $9 F$ & $\begin{array}{l}\text { Lado Sur de } \\
\text { entierro con } \\
\text { empalizada }\end{array}$ & Ubicado en entierro & Botánico & $311 / 80$ & $-/ G Z$ & $\begin{array}{l}\text { Artefacto, aguja. } \\
\text { Madera. Filmada }\end{array}$ \\
\hline $21 / 7 / 93$ C. $9 G$ & $\begin{array}{l}\text { Encima de la parte } \\
\text { superior del } \\
\text { entierro }\end{array}$ & Asociado a Entierro 4 & Textil & $303 / \mathrm{SR}$ & -/Gerald MZS & $\begin{array}{l}\text { "Encontrado encima } \\
\text { de la parte superior } \\
\text { del entierro" }\end{array}$ \\
\hline $21 / 7 / 93$ & $\begin{array}{l}\text { Encima de la parte } \\
\text { superior del } \\
\text { entierro }\end{array}$ & Asociado a Entierro 4 & Botánico & $305 / 27$ & $-/ G M Z$ & SR \\
\hline $21 / 7 / 93$ & $\begin{array}{l}\text { Encontrado encima } \\
\text { de la parte superior } \\
\text { del entierro }\end{array}$ & Asociado a entierro 4 & Cestería & $304 / 80$ & $-/ G M Z$ & SR \\
\hline 21/7/93 & Lado Norte de & Asociado a Entierro 4 & Malacológico & $306 / 30$ & $-/ G M Z$ & SR \\
\hline
\end{tabular}


Arqueología y Sociedad 29, 2015: 183 - 231

\begin{tabular}{|c|c|c|c|c|c|c|}
\hline & empalizada & & & & & \\
\hline $21 / 7 / 93$ C. $9 H$ & $\begin{array}{l}\text { Encontrado en } \\
\text { parte superior de } \\
\text { Entierro No } 5\end{array}$ & $\overline{S R}$ & Botánico & $188 / 80$ & $\begin{array}{l}\text {-/G. Zubiaga, } \\
\text { Edgardo Meléndez }\end{array}$ & $\begin{array}{l}\text { Artefacto, "Posible } \\
\text { nariz". Madera }\end{array}$ \\
\hline 21/7/93 C. 91 & $\begin{array}{l}\text { Lado Sur de } \\
\text { empalizada, Perfil } \\
\text { Este }\end{array}$ & Disturbado & Cerámica & $310 / 18$ & $-/ G M Z, E M$ & SR \\
\hline $21 / 7 / 93$ & $\begin{array}{l}\text { Lado Sur de } \\
\text { empalizada, Perfil } \\
\text { Este }\end{array}$ & Disturbado & Óseo & $309 / 23$ & -/GMZ, EM & SR \\
\hline $21 / 7 / 93$ C. $9 \mathrm{~J}$ & $\begin{array}{l}\text { Lado Norte de } \\
\text { empalizada }\end{array}$ & Disturbado & Textil & $301 / \mathrm{SR}$ & $-/ G M Z$ & SR \\
\hline $21 / 7 / 93$ & $\begin{array}{l}\text { Lado Norte de } \\
\text { empalizada } \\
\text { disturbada }\end{array}$ & Disturbado & Cerámica & $300 / 18$ & -/Gerald M. Zubiaga & SR \\
\hline $21 / 7 / 93$ & $\begin{array}{l}\text { Lado Norte de } \\
\text { empalizada }\end{array}$ & Material disturbado & Botánico & $302 / 27$ & $-/ G M Z$ & SR \\
\hline 21/7/93 C. $9 K$ & $\begin{array}{l}\text { Sector HC. Ubicado } \\
\text { al lado Norte del } \\
\text { entierro }\end{array}$ & SR & Malacológico & $312 / 30$ & -/Gerald M. Z. & SR \\
\hline $21 / 7 / 93$ & $\begin{array}{l}\text { Lado Norte } \\
\text { Empalizada }\end{array}$ & SR & Óseo & $307 / 19$ & GZ/- & SR \\
\hline 21/7/93 C. $9 L$ & $\begin{array}{l}\text { Lado Frontal, Perfil } \\
\text { Este }\end{array}$ & Disturbado & Cerámica & $181 / 18$ & SR & SR \\
\hline 21/7/93 C. $9 M$ & Perfil Este & SR & Botánico & $207 / 80$ & GZ/- & $\begin{array}{l}\text { Artefacto escultórico } \\
\text { antropomorfo. } \\
\text { Madera. Calero }\end{array}$ \\
\hline $22 / 7 / 93$ C. $9 N$ & SR & Asociado a Entierro 3 & Textil & $261 / \mathrm{SR}$ & SR & $\begin{array}{l}\text { Material encontrado } \\
\text { dentro del Mate } \\
\text { entero } 260-\mathrm{H} 12\end{array}$ \\
\hline $22 / 7 / 93$ & SR & Asociado a Entierro 3 & Textil & $275 / \mathrm{SR}$ & $-/ F F$ & $\begin{array}{l}\text { Material encontrado } \\
\text { dentro del Mate 273- } \\
\mathrm{H} 12\end{array}$ \\
\hline $22 / 7 / 93$ & SR & Asociado a Entierro 3 & Textil & $265 / S R$ & -/FFR & $\begin{array}{l}\text { Material encontrado } \\
\text { dentro de la } \\
\text { Cerámica 263-H12 }\end{array}$ \\
\hline $22 / 7 / 93$ & SR & Asociado a Entierro 3 & Cerámica & $289 / 18$ & $-/ G Z$ & $\begin{array}{l}\text { Bolsa 14. Dato de } \\
\text { contexto no en ficha } \\
\text { original }\end{array}$ \\
\hline
\end{tabular}

\begin{tabular}{|c|c|c|c|c|c|c|}
\hline $22 / 7 / 93$ & $\begin{array}{l}\text { Lado Norte de la } \\
\text { empalizada }\end{array}$ & Entierro No. 3 & Cerámica & $279 / 18$ & $-/ G Z, F F R$ & Bolsa 11 \\
\hline $22 / 7 / 93$ & SR & $\begin{array}{l}\text { Asociado a Entierro No } \\
3\end{array}$ & Cerámica & $290 / 14$ & -/FFR & $\begin{array}{l}\text { Bolsa } 16 @ \text { Parte de } \\
\text { una vasija } \\
\text { anteriormente } \\
\text { registrada. }\end{array}$ \\
\hline $22 / 7 / 93$ & Lado Norte & $\begin{array}{l}\text { Asociado a Entierro No } \\
3\end{array}$ & Cerámica & $286 / 14$ & $-/ G M Z$ & $\begin{array}{l}\text { Ceramio No } 3 \text {, vasija } \\
\text { fragmentada }\end{array}$ \\
\hline $22 / 7 / 93$ & SR & Asociado a Entierro 3. & Tierra & $288 / 21$ & -/GMZ, EM & $\begin{array}{l}\text { Contenido del } \\
\text { ceramio } 3(286-\mathrm{H} 12)\end{array}$ \\
\hline $22 / 7 / 93$ & $\mathrm{SR}$ & Ajuar & Cerámica & $215 / 16$ & -/FFR & Ceramio No. 6 \\
\hline $22 / 7 / 93$ & SR & SR & Cerámica & $259 / 14$ & -/FFR & $\begin{array}{l}\text { Bolsa 1@ } \\
\text { Fracturada. } \\
\text { Cerámica } 7\end{array}$ \\
\hline $22 / 7 / 93$ & SR & SR & Cerámica & $269 / 16$ & -/FFR & $\begin{array}{l}\text { Bolsa 5@ Vasija } \\
\text { entera. Ceramio } 8\end{array}$ \\
\hline $22 / 7 / 93$ & SR & Asociado a entierro 3 & Adobe & $272 / S R$ & -/FFC & $\begin{array}{l}\text { Material encontrado } \\
\text { dentro de la vasija } \\
269 \text {. }\end{array}$ \\
\hline $22 / 7 / 93$ & SR & Asociado a entierro 3. & Tierra & $270 / 21$ & -/FFC & $\begin{array}{l}\text { Dentro de la vasija } \\
269\end{array}$ \\
\hline $22 / 7 / 93$ & SR & Asociado a Entierro 3 & Cerámica & $263 / 14$ & -/FFR & $\begin{array}{l}\text { "Elemento 9" Vasija } \\
\text { fracturada que } \\
\text { contenía tierra y } \\
\text { textil }\end{array}$ \\
\hline $22 / 7 / 93$ & SR & Asociado a Entierro 3 & Cerámica & $263 / 83$ & -/FFR & $\begin{array}{l}\text { Bolsa 3@ "Elemento } \\
\text { 9". La referencia a la } \\
\text { asociación no esta } \\
\text { en la ficha original }\end{array}$ \\
\hline $22 / 7 / 93$ & SR & Asociado a Entierro 3. & Tierra & $264 / 21$ & -/FFR & $\begin{array}{l}\text { Dentro de la } \\
\text { cerámica } 263\end{array}$ \\
\hline $22 / 7 / 93$ & SR & Asociado a entierro 3 & Cerámica & $287 / 14(1)$ & -/FFR & $\begin{array}{l}\text { Cerámica 10. Vasija } \\
\text { fragmentada }\end{array}$ \\
\hline $22 / 7 / 93$ & SR & $\begin{array}{l}\text { Asociado a Entierro No } \\
3\end{array}$ & Cerámica & $287 / 14(2)$ & -/FFR & $\begin{array}{l}\text { Cerámica } 10, \text { vasija } \\
\text { fragmentada }\end{array}$ \\
\hline $22 / 7 / 93$ & SR & Entierro 3 & Cerámica entera & $266 / 16$ & -/FFR & $\begin{array}{l}\text { Bolsa 4@. Cerámica } \\
\text { 11. Cadera ajuar }\end{array}$ \\
\hline $22 / 7 / 93$ & SR & Asociado a entierro 3. & Tierra & $267 / 21$ & SR & $\begin{array}{l}\text { Dentro de la Vasija } \\
\text { cerámica } 266\end{array}$ \\
\hline $22 / 7 / 93$ & $\mathrm{SR}$ & Asociado a entierro 3 & Botánico & $268 / 27$ & -/FFR & Material encontrado \\
\hline
\end{tabular}


Gori Echevarría y Alex Zúñiga / Los contextos funerarios y los materiales arqueológicos de la Huaca Concha

\begin{tabular}{|c|c|c|c|c|c|c|}
\hline & & & & & & $\begin{array}{l}\text { dentro de la vasija } \\
266-\mathrm{H} 12\end{array}$ \\
\hline $22 / 7 / 93$ & $\begin{array}{l}\text { Sitio Ciudad } \\
\text { Universitaria, sector } \\
\text { Huaca Concha }\end{array}$ & Asociado a entierro 3 & Botánico & $273 / 26$ & -/Fidel Fajardo & $\begin{array}{l}\text { Bolsa 8@. Mate 4b. } \\
\text { Dato de contexto no } \\
\text { en ficha original }\end{array}$ \\
\hline $22 / 7 / 93$ & SR & Asociado a entierro 3 & Tierra & $274 / 21$ & SR & Dentro del Mate 273 \\
\hline $22 / 7 / 93$ & Pozo Sur, & $\begin{array}{l}\text { Tumba } 3 \text { Asociado a } \\
\text { entierro } 3\end{array}$ & Botánico & $298 / 24$ & SR & $\begin{array}{l}\text { 6@. Mate entero } 5 . \\
\text { Mate con contenido } \\
\text { tierra y textil }\end{array}$ \\
\hline $22 / 7 / 93$ & SR & Entierro 3 & Botánico & $260 / 26$ & SR & $\begin{array}{l}\text { Mate } 5 b \text {. Mate } \\
\text { entero, contenía } \\
\text { material botánico y } \\
\text { textil }\end{array}$ \\
\hline $22 / 7 / 93$ & SR & Asociado a entierro 3 & Botánico & $260 / 27$ & SR & $\begin{array}{l}\text { Material encontrado } \\
\text { dentro del mate } \\
\text { entero }(260-\mathrm{H} 12)\end{array}$ \\
\hline $22 / 7 / 93$ & SR & Asociado a entierro 3. & Tierra & $262 / 21$ & SR & $\begin{array}{l}\text { Procede del Mate } \\
\text { entero (260-H12) }\end{array}$ \\
\hline $22 / 7 / 93$ & $\begin{array}{l}\text { Sitio: Cuidad } \\
\text { Universitaria, } \\
\text { Sector Huaca } \\
\text { Concha }\end{array}$ & Asociado a entierro 3 & Botánico & $278 / 26$ & -/Fidel Fajardo & $\begin{array}{l}\text { Bolsa 10@. Mate } \\
\text { fragmentado, } \\
\text { contenía fragmentos } \\
\text { de algodón. (este y } \\
\text { el dato de contexto } \\
\text { no en ficha original) }\end{array}$ \\
\hline $22 / 7 / 93$ & SR & Asociado a Entierro 3. & Tierra & $277 / 21$ & $-/ G Z$ & $\begin{array}{l}\text { Material dentro del } \\
\text { mate } 276\end{array}$ \\
\hline $22 / 7 / 93$ & SR & Asociado a entierro 3 & Lítico & $271 / 81$ & -/FFC & $\begin{array}{l}\text { Material encontrado } \\
\text { dentro de la vasija } \\
269 \text { (Dato no en } \\
\text { ficha original) }\end{array}$ \\
\hline $22 / 7 / 93$ C. $9 O$ & $\begin{array}{l}\text { Lado Norte de } \\
\text { empalizada }\end{array}$ & \begin{tabular}{|l|} 
Disturbado. Asociado a \\
Entierro 3
\end{tabular} & Textil & $284 / S R$ & -/FFR, GZ & SR \\
\hline $22 / 7 / 93$ & $\begin{array}{l}\text { Lado Norte de } \\
\text { entierro } 3\end{array}$ & Disturbado & Cerámica & $174 / 18$ & -/FFR & Ítem 38 \\
\hline $22 / 7 / 93$ & $\begin{array}{l}\text { Lado Norte del } \\
\text { entierro No } 3\end{array}$ & Disturbado & Botánico & $175 / 27$ & -/FFR & $\begin{array}{l}\text { Ítem 38. } 9 \\
\text { fragmentos de } \\
\text { coronta, un } \\
\text { fragmento de mate }\end{array}$ \\
\hline $22 / 7 / 93$ & $\begin{array}{l}\text { Lado Norte de } \\
\text { empalizada }\end{array}$ & $\begin{array}{l}\text { Disturbado, asociado a } \\
\text { Entierro 3 }\end{array}$ & Botánico & $283 / 27$ & -/FF, GZ & SR \\
\hline
\end{tabular}

9

\begin{tabular}{|c|c|c|c|c|c|c|}
\hline $22 / 7 / 93$ & $\begin{array}{l}\text { Lado Norte del } \\
\text { Entierro } 3\end{array}$ & Disturbado & Cestería & $176 / 80$ & -/FFR & SR \\
\hline $22 / 7 / 93$ & $\begin{array}{l}\text { Lado Norte de } \\
\text { empalizada }\end{array}$ & $\begin{array}{l}\text { Disturbado, asociado a } \\
\text { entierro } 3\end{array}$ & Cestería & $280 / 80$ & SR & SR \\
\hline $22 / 7 / 93$ & $\begin{array}{l}\text { Lado Norte de } \\
\text { empalizada }\end{array}$ & $\begin{array}{l}\text { Disturbado, asociado a } \\
\text { Entierro } 3\end{array}$ & Malacológico & $281 / 30$ & -/FER, GZ & SR \\
\hline $22 / 7 / 93$ & Lado Norte & $\begin{array}{l}\text { Disturbado Entierro No } \\
3 .\end{array}$ & Malacológico & $173 / 30$ & -/FFR & Ítem 38 \\
\hline $22 / 7 / 93$ & $\begin{array}{l}\text { Lado Norte de } \\
\text { empalizada }\end{array}$ & $\begin{array}{l}\text { Disturbado, asociado a } \\
\text { Entierro } 3\end{array}$ & Lítico & $282 / 81$ & -/FFR, GZ & SR \\
\hline $22 / 7 / 93$ & $\begin{array}{l}\text { Lado Norte de } \\
\text { Empalizada }\end{array}$ & $\begin{array}{l}\text { Disturbado, Asociado a } \\
\text { Entierro } 3\end{array}$ & Orgánico & $285 / 26$ & -/FFR, GZ & SR \\
\hline $22 / 7 / 93$ C. $9 P$ & Frente al entierro & Disturbado & Cerámica & $213 / 18$ & -/G. M. Zubiaga & SR \\
\hline $22 / 7 / 93$ C. $9 Q$ & $\begin{array}{l}\text { Lado Frontal, perfil } \\
\text { Este }\end{array}$ & Disturbado & Textil & $184 / \mathrm{SR}$ & $-/ G Z$ & $\begin{array}{l}\text { Encontrado con } \\
\text { adobitos sueltos }\end{array}$ \\
\hline $22 / 7 / 93$ & $\begin{array}{l}\text { Lado Frontal, perfil } \\
\text { Este }\end{array}$ & SR & Botánico & $182 / 27$ & $-/ G Z$ & $\begin{array}{l}\text { Encontrado con } \\
\text { adobitos. Se } \\
\text { encontró dentro de } \\
\text { los textiles }\end{array}$ \\
\hline $22 / 7 / 93$ & $\begin{array}{l}\text { Lado Frontal, Perfil } \\
\text { Este }\end{array}$ & SR & Cestería & $183 / 80$ & $-/ G Z$ & $\begin{array}{l}\text { Se encontró con los } \\
\text { adobitos sueltos, se } \\
\text { encontró con los } \\
\text { textiles }\end{array}$ \\
\hline $22 / 7 / 93$ C. $9 R$ & $\begin{array}{l}\text { Encima de la } \\
\text { empalizada }\end{array}$ & $\mathrm{SR}$ & Óseo & $212 / 23$ & $-/ G Z$ & $\mathrm{SR}$ \\
\hline $23 / 7 / 93$ C. $9 S$ & $\begin{array}{l}\text { Pozo Sur, Perfil } \\
\text { Este }\end{array}$ & $\begin{array}{l}\text { Disturbado, asociado a } \\
\text { Entierro } 3\end{array}$ & Textil & $296 / S R$ & $\mathrm{SR}$ & SR \\
\hline $23 / 7 / 93$ & $\begin{array}{l}\text { Pozo Sur, Perfil } \\
\text { Este }\end{array}$ & Entierro 3 & Cerámica & $292 / 18$ & SR & $\begin{array}{l}\text { Bolsa 23. Objetos } \\
\text { disturbados bajo las } \\
\text { vasijas }\end{array}$ \\
\hline $23 / 7 / 93$ & $\begin{array}{l}\text { Pozo Sur, Perfil } \\
\text { Este }\end{array}$ & Entierro 3, disturbado & Botánico & $293 / 27$ & $\mathrm{SR}$ & Bolsa 24 \\
\hline $23 / 7 / 93$ & $\begin{array}{l}\text { Pozo Sur, Perfil } \\
\text { Este }\end{array}$ & $\begin{array}{l}\text { Disturbado, asociado a } \\
\text { Entierro } 3\end{array}$ & Malacológico & $294 / 30$ & SR & SR \\
\hline $23 / 7 / 93$ & $\begin{array}{l}\text { Pozo Sur, Perfil } \\
\text { Este }\end{array}$ & $\begin{array}{l}\text { Disturbado, asociado a } \\
\text { Entierro } 3\end{array}$ & Óseo & $295 / 19$ & SR & SR \\
\hline $23 / 7 / 93$ & SR & $\begin{array}{l}\text { Asociado a Entierro } 3 . \\
\text { Disturbado }\end{array}$ & Lítico & $297 / 80$ & SR & Artefacto \\
\hline $23 / 7 / 93$ C. $9 T$ & Pozo Sur, Perfil & Entierro 4, disturbado & Óseo & $308 / 19$ & $-/ \mathrm{JC}, \mathrm{EM}, \mathrm{ML}, \mathrm{FF}$ & $21 @$ \\
\hline
\end{tabular}




\begin{tabular}{|c|c|c|c|c|c|c|}
\hline & Este & & & & & \\
\hline $23 / 7 / 93$ C. $9 U$ & $\begin{array}{l}\text { Pozo Sur, Perfil } \\
\text { Este }\end{array}$ & Entierro 5 & Botánico & $321 / 27$ & $-/ F F$ & SR \\
\hline $23 / 7 / 93$ & $\begin{array}{l}\text { Pozo Sur, Perfil } \\
\text { Este }\end{array}$ & Entierro 5 & Óseo & $319 / 25(1)$ & $-/ F F$ & SR \\
\hline $23 / 7 / 93$ & Pozo Sur & Entierro 5 & Óseo & $319 / 25$ (2) & FF/- & SR \\
\hline 23/7/93 & $\begin{array}{l}\text { Pozo Sur, Perfil } \\
\text { Este }\end{array}$ & Entierro 5 & Óseo & $319 / 25$ (3) & SR & SR \\
\hline $23 / 7 / 93$ & $\begin{array}{l}\text { Pozo Sur, Perfil } \\
\text { Este }\end{array}$ & SR & Óseo & $319 / 25(4)$ & $-/ F F$ & SR \\
\hline $23 / 7 / 93$ C. $9 \mathrm{~V}$ & Pozo Sur & Material de entierro & Textil & $205 / S R$ & $-/ J C, G Z, F F, M L$ & $\begin{array}{l}\text { Material textil y maíz } \\
\text { del entierro, que lo } \\
\text { rodeaba. "Lo } \\
\text { rodeaba posible } \\
\text { petate en buen } \\
\text { estado (incompleto, } \\
\text { restos de textil } \\
\text { delgado)" Nota ( ) no } \\
\text { en ficha original }\end{array}$ \\
\hline $23 / 7 / 93$ & Pozo Sur & Material de entierro & Botánico & $206 / 27$ & $-/ J C, F F, E M$ & $\begin{array}{l}\text { Lo rodeaba textil y } \\
\text { maíz del entierro. } \\
\text { Código duplicado en } \\
\text { la caja } 23\end{array}$ \\
\hline $24 / 7 / 93$ C. $9 W$ & $\begin{array}{l}\text { Pozo Sur, Perfil } \\
\text { Este }\end{array}$ & Material del Entierro 4 & Textil & $318 / \mathrm{SR}$ & $-/ J C, R L$ & $\begin{array}{l}\text { Material óseo, } \\
\text { vegetal. La fecha y } \\
\text { los nombres no } \\
\text { están en la ficha } \\
\text { original }\end{array}$ \\
\hline $24 / 7 / 93$ & $\begin{array}{l}\text { Pozo Sur, Perfil } \\
\text { Este }\end{array}$ & Entierro disturbado 4 & Botánico & $313 / 20$ & SR & $\begin{array}{l}\text { Material en bloque, } \\
\text { mate, huesos, } \\
\text { vegetales y telar }\end{array}$ \\
\hline $24 / 7 / 93$ & $\begin{array}{l}\text { Pozo sur, Perfil } \\
\text { este }\end{array}$ & Entierro 4, disturbado & Óseo & $315 / 19(1)$ & $-/ J C, L R$. & SR \\
\hline $24 / 7 / 93$ & SR & Entierro 4, disturbado & Óseo & $315 / 19$ (2) & SR & SR \\
\hline $24 / 7 / 93$ & $\begin{array}{l}\text { Pozo Sur, Perfil } \\
\text { Este }\end{array}$ & Entierro 4, disturbado & Óseo & $315 / 19(3)$ & $-/ \mathrm{JC}, \mathrm{RL}$ & SR \\
\hline 24/7/93 & Pozo Sur & Entierro 4, disturbado & Óseo & $315 / 19$ (4) & $\mathrm{JC}, \mathrm{RL} /-$ & $\mathrm{SR}$ \\
\hline $24 / 7 / 93$ & $\begin{array}{l}\text { Pozo Sur, Perfil } \\
\text { Este }\end{array}$ & SR & Óseo & $206 / 23$ (b) & -/JC. RL & $\begin{array}{l}\text { Parte del Entierro } \\
\text { disturbado ya }\end{array}$ \\
\hline
\end{tabular}

11

\begin{tabular}{|c|c|c|c|c|c|c|}
\hline & & & & & & $\begin{array}{l}\text { registrado. Esta } \\
\text { bolsa incluye } \\
\text { materiales del } \\
20 / 7 / 93 \\
\end{array}$ \\
\hline 24/7/93 & $\begin{array}{l}\text { Pozo Sur, Perfil } \\
\text { Este }\end{array}$ & Asociado a Entierro 4 & Tierra & $314 / 21(1)$ & SR & Dentro del mate \\
\hline $24 / 7 / 93$ & $\begin{array}{l}\text { Pozo sur, Perfil } \\
\text { Este }\end{array}$ & Asociado a Entierro 4 & Tierra & $314 / 21(2)$ & SR & $\begin{array}{l}\text { Tierra cernida dentro } \\
\text { del mate }\end{array}$ \\
\hline $24 / 7 / 93$ & $\begin{array}{l}\text { Pozo Sur, Perfil } \\
\text { Este }\end{array}$ & Entierro No. 4 & Tierra & $320 / 36(1)$ & $-/ J C, R C$ & $\begin{array}{l}\text { Muestra de tierra } \\
\text { para flotación }\end{array}$ \\
\hline $24 / 7 / 93$ & $\begin{array}{l}\text { Pozo Sur, Perfil } \\
\text { Este }\end{array}$ & Entierro No. 4 & Tierra & $320 / 36(2)$ & $-/ J C, R C$ & $\begin{array}{l}\text { Muestra de tierra } \\
\text { para flotación }\end{array}$ \\
\hline $24 / 7 / 93$ & $\begin{array}{l}\text { Pozo sur, Perfil } \\
\text { Este }\end{array}$ & Asociado a entierro 4 & Lítico & $316 / 81$ & $-/ J C, R L$ & SR \\
\hline $24 / 7 / 93$ & $\begin{array}{l}\text { Pozo Sur, Perfil } \\
\text { Este }\end{array}$ & $\begin{array}{l}\text { Parte superior del } \\
\text { Entierro } 4\end{array}$ & Orgánico & $317 / 26$ (1) & $-/ J C, R L$ & $\begin{array}{l}\text { Algodón quemado, } \\
\text { vegetal, óseo }\end{array}$ \\
\hline 24/7/93 & $\begin{array}{l}\text { Pozo Sur, Perfil } \\
\text { Este }\end{array}$ & Material del Entierro 4 & Orgánico & $317 / 26(2)$ & SR & $\begin{array}{l}\text { Óseo, telas que lo } \\
\text { cubría. Vegetal, } \\
\text { (semillas y algodón) }\end{array}$ \\
\hline $24 / 7 / 93$ C. $9 X$ & $\begin{array}{l}\text { Pozo Sur, Perfil } \\
\text { Este }\end{array}$ & Asociado a Entierro 6 & Botánico & $348 / 80$ & $-/ J C, J L, R L$ & SR \\
\hline $24 / 7 / 93$ & $\begin{array}{l}\text { Pozo sur, Perfil } \\
\text { Este }\end{array}$ & Asociado a Entierro 6 & Botánico & $325 / 27$ & $-/ J C, J L, R L$ & SR \\
\hline $24 / 7 / 93$ & $\begin{array}{l}\text { Pozo Sur, Perfil } \\
\text { Este }\end{array}$ & Asociado a Entierro 6 & Malacológico & $326 / 30$ & $-/ J C, J L, R L$ & SR \\
\hline $24 / 7 / 93$ & $\begin{array}{l}\text { Pozo Sur, Perfil } \\
\text { Este }\end{array}$ & Entierro 6 & Óseo & $322 / 29(1)$ & $-/ J C, J L, R L$ & SR \\
\hline $24 / 7 / 93$ & $\begin{array}{l}\text { Pozo Sur, Perfil } \\
\text { Este }\end{array}$ & Entierro No 6 & Óseo & $322 / 29(2)$ & $-/ J C, J \mathrm{~L}, \mathrm{RL}$ & SR \\
\hline $24 / 7 / 93$ & $\begin{array}{l}\text { Pozo Sur, Perfil } \\
\text { Este }\end{array}$ & Entierro 6 & Óseo & $322 / 29(3)$ & $-/ J C, J L, R L$ & SR \\
\hline $24 / 7 / 93$ & $\begin{array}{l}\text { Pozo Sur, Perfil } \\
\text { Este }\end{array}$ & Entierro No 6 & Óseo & $322 / 29(4)$ & $-/ J C, J L, R L$ & SR \\
\hline $24 / 7 / 93$ & $\begin{array}{l}\text { Pozo Sur, Perfil } \\
\text { Este }\end{array}$ & Entierro No 6 & Óseo & $322 / 29(5)$ & $-/ J C, J L, R L$ & SR \\
\hline $24 / 7 / 93$ & $\begin{array}{l}\text { Pozo Sur, Perfil } \\
\text { Este }\end{array}$ & Entierro No 6 & Óseo & $322 / 29(6)$ & $-/ J C, J L, R L$ & SR \\
\hline $24 / 7 / 93$ & $\begin{array}{l}\text { Pozo Sur, Perfil } \\
\text { Este }\end{array}$ & Entierro No. 6 & Tierra & $328 / 36(1)$ & $-/ J C, J \mathrm{~L}, \mathrm{RL}$ & Muestra de tierra \\
\hline $24 / 7 / 93$ & Pozo Sur, Perfil & Entierro No. 6 & Tierra & $328 / 36(2)$ & $-/ J C, J L, R L$ & Muestra de tierra \\
\hline
\end{tabular}


Gori Echevarría y Alex Zúñiga / Los contextos funerarios y los materiales arqueológicos de la Huaca Concha

\begin{tabular}{|c|c|c|c|c|c|c|}
\hline & Este & & & & & \\
\hline $24 / 7 / 93$ & $\begin{array}{l}\text { Pozo Sur, Perfil } \\
\text { Este }\end{array}$ & Asociado a Entierro 6 & Piedra & $327 / 80$ & $-/ J C, J L, R L$ & Piruro \\
\hline $24 / 7 / 93$ & $\begin{array}{l}\text { Pozo Sur, Perfil } \\
\text { Este }\end{array}$ & $\begin{array}{l}\text { Asociado a Entierro No. } \\
6\end{array}$ & Orgánico & $324 / 26$ & $-/ J C, J L, R L$ & Pupas y carbón \\
\hline $24 / 7 / 93$ C. $9 Y$ & $\begin{array}{l}\text { Pozo Sur, Perfil } \\
\text { Este }\end{array}$ & $\begin{array}{l}\text { Material disturbado de } \\
\text { relleno }\end{array}$ & Botánico & $205 / 27$ & $-/ J C, R L$ & $\begin{array}{l}\text { Restos de vegetales } \\
\text { y madera }\end{array}$ \\
\hline $24 / 7 / 93$ & $\begin{array}{l}\text { Perfil Este, Pozo } \\
\text { Sur. Capa } 2\end{array}$ & Material relleno & Malacológico & $209 / 30$ & $-/ J C, R L$ & $\begin{array}{l}\text { Molusco, cerámico y } \\
\text { óseo (estuvo } \\
\text { agrupado con...) }\end{array}$ \\
\hline $24 / 7 / 93$ C. $9 Z$ & $\begin{array}{l}\text { Pozo Sur, Perfil } \\
\text { Este }\end{array}$ & SR & Cerámica & $204 / 18$ & $\mathrm{JC}, \mathrm{RL} /-$ & SR \\
\hline $22 / 8 / 93$ C. $10 A$ & SR & SR & Cerámica & $109 / 7$ & $\mathrm{SR}$ & (ítem 40) \\
\hline $23 / 8 / 93$ C. $10 B$ & SR & Tumba 3 & Botánico & $172 / 27$ & SR & $\begin{array}{l}\text { (ítem } 31 \text { ) "va a caja } \\
5 / 7 \text { bolsa C" } 5 \text { C@ }\end{array}$ \\
\hline $23 / 8 / 93$ C. $10 \mathrm{C}$ & $\mathrm{SR}$ & Tumba 4 & Textil & 158/SR & $\overline{S R}$ & SR \\
\hline $23 / 8 / 93$ & SR & Tumba 4 & Cerámica & $2482 / 67$ & SR & SR \\
\hline $23 / 8 / 93$ & SR & Tumba No 4 & Botánico & $157 / 27$ & SR & $\begin{array}{l}\text { "Tumba } 4 \text {, caja } 5 \text {, } \\
\text { bolsa d. Un } \\
\text { fragmento de posible } \\
\text { mate" }\end{array}$ \\
\hline $23 / 8 / 93$ & SR & Tumba No 4 & Botánico, mate & $2480 / 42$ & SR & SR \\
\hline $23 / 8 / 93$ & SR & Tumba No 4 & Malacológico & $156 / 30$ & SR & Caja 5, bolsa 13 \\
\hline $23 / 8 / 93$ & SR & Tumba No 4 & Óseo & $155 / 10$ & SR & $\begin{array}{l}\text { *d. Caja 5, bolsa d. } \\
\text { ítem } 32\end{array}$ \\
\hline $23 / 8 / 93$ & SR & $\begin{array}{l}\text { Tumba 4, Recuperación } \\
4\end{array}$ & Óseo & $2478 / 79$ (a) & SR & $\begin{array}{l}\text { Dos fichas juntas. } \\
\text { Misma bolsa con } \\
2478 \text { (b) }\end{array}$ \\
\hline $25 / 8 / 93$ C. $11 A$ & SR & Recuperación No1 & Cerámica & $2484 / 67$ & $\begin{array}{l}\text {-/Deysi Cotrina, } \\
\text { Agusto Neyra//- } \\
\text { /José Meza, Deysi } \\
\text { Cotrina, Daniel } \\
\text { Pickens }\end{array}$ & Dos fichas juntas \\
\hline $25 / 8 / 93$ & SR & Recuperación No 1 & Botánico & 2474/SR & $\begin{array}{l}\text {-/A. Neyra, D. } \\
\text { Cotrina }\end{array}$ & SR \\
\hline $25 / 8 / 93$ & SR & Recuperación No 1 & Óseo & $2488 / 79$ & -/José Meza, ML. & SR \\
\hline $25 / 8 / 93$ & SR & Recuperación No 1 & Óseo & $2477 / 79$ & -/Deysi Cotrina, & SR \\
\hline
\end{tabular}

13

\begin{tabular}{|c|c|c|c|c|c|c|}
\hline & & & & & José Meza & \\
\hline $25 / 8 / 93$ & $\mathrm{SR}$ & $\begin{array}{l}\text { Recuperación No } 1 . \\
\text { /Matriz }\end{array}$ & Óseo y tierra & $2483 / 79$ & $\begin{array}{l}\text {-/José Meza, } \\
\text { Moisés Linares, } \\
\text { Oso. }\end{array}$ & SR \\
\hline $25 / 8 / 93$ C. $11 B$ & $\mathrm{SR}$ & Recuperación № 2 & Cerámica & $2486 / 67$ & -/Deysi Cotrina & $\mathrm{SR}$ \\
\hline $25 / 8 / 93$ & SR & Recuperación No 2 & Botánico & $192 / 9$ & $\mathrm{ML}, \mathrm{JM} /-$ & $\begin{array}{l}\text { *a. Recuperación No } \\
\text { 2. Mate entero } \\
\text { deteriorado. Ítem } 29 \text {. }\end{array}$ \\
\hline $25 / 8 / 93$ & SR & Recuperación No 2 & Botánico & $2487 / 78$ & $\begin{array}{l}\text {-/José Meza, } \\
\text { Moisés Linares }\end{array}$ & $\begin{array}{l}\text { Contenido del Mate. } \\
\text { Material encontrado } \\
\text { en el mate }\end{array}$ \\
\hline $25 / 8 / 93$ & $\mathrm{SR}$ & Recuperación No 2 & Óseo & $2485 / 79$ & $\mathrm{SR}$ & Óseo y tierra \\
\hline $25 / 8 / 93$ C. $11 C$ & $\mathrm{SR}$ & Recuperación No 3 & Botánico & $083 / 8$ & $\mathrm{SR}$ & $\begin{array}{l}\text { Bolsa 6. Mate. } \\
\text { incluye óseos y } \\
\text { fragmentos } \\
\text { cerámicos }\end{array}$ \\
\hline $25 / 8 / 93$ & $\mathrm{SR}$ & Recuperación № 3 & Malacológico & $081 / 30$ & $\mathrm{SR}$ & Bolsa 6 \\
\hline $25 / 8 / 93$ & $\mathrm{SR}$ & Recuperación № 3 & Óseo & $082 / 10(1)$ & $\mathrm{SR}$ & Bolsa 6. Ítem 58 \\
\hline $25 / 8 / 93$ & $\mathrm{SR}$ & $\mathrm{SR}$ & Óseo & $082 / 10(2)$ & $\mathrm{SR}$ & Bolsa 6. Ítem 58 \\
\hline $25 / 8 / 93 \mathrm{C} .11 \mathrm{CH}$ & $\mathrm{SR}$ & $\begin{array}{l}\text { Recuperación No } 4, \\
\text { Tumba } 4\end{array}$ & Textil & $2479 / \mathrm{SR}$ & $\mathrm{SR}$ & SR \\
\hline $25 / 8 / 93$ & SR & $\begin{array}{l}\text { Tumba 4, Recuperación } \\
\text { No } 4\end{array}$ & Óseo & $2478 / 79$ (b) & SR & SR \\
\hline $25 / 8 / 93$ C. $11 D$ & $\mathrm{SR}$ & Recuperación No 5 & Textil & $2476 / S R$ & -/José Meza & SR \\
\hline $25 / 8 / 93$ & $\mathrm{SR}$ & Recuperación No 5 & Cerámica & $2481 / 67$ & -/José Meza & SR \\
\hline $25 / 8 / 93$ & $\mathrm{SR}$ & Recuperación No 5 & Óseo & $2475 / 79$ & -/José Meza & $\mathrm{SR}$ \\
\hline $26 / 8 / 93$ C. $12 A$ & Pozo Sur & $\begin{array}{l}\text { FDA. // FDA Fardo } \\
\text { funerario }\end{array}$ & Textil & $123 / \mathrm{SR}$ & $\begin{array}{l}\text { JN, GE/- // DC, JN, } \\
\text { SM, GE/- }\end{array}$ & $\begin{array}{l}\text { Material } 22 \text {. } \\
\text { Fragmento textil // } \\
2 \mathrm{~A} @ \text {. Esta bolsa } \\
\text { presenta dos fichas } \\
\text { originales: } 26 / 8 / / 27 / 8\end{array}$ \\
\hline $26 / 8 / 93$ & Pozo Sur & FDA & Textil & $122 / \mathrm{SR}$ & $\mathrm{JN}, \mathrm{GE} /-$ & $\begin{array}{l}\text { Material } 22, \\
\text { fragmento textil. Los } \\
\text { datos, que fueron } \\
\text { tomados antes del } \\
\text { último } \\
\text { almacenamiento del } \\
\text { textil, no se } \\
\text { verificaron en la }\end{array}$ \\
\hline
\end{tabular}


Arqueología y Sociedad 29, 2015: 183 - 231

\begin{tabular}{|c|c|c|c|c|c|c|}
\hline & & & & & & \begin{tabular}{|l|} 
tarjeta de registro \\
del inventario final.
\end{tabular} \\
\hline $26 / 8 / 93$ & Pozo Sur & FDA. Entierro & Textil & $119 / \mathrm{SR}$ & JN, GE/- & \begin{tabular}{|l|} 
Elementos textiles. \\
Material 6
\end{tabular} \\
\hline $26 / 8 / 93$ & Pozo Sur & SR & Textil & $111 / \mathrm{SR}$ & SR & SR \\
\hline $26 / 8 / 93$ & Pozo Sur & SR & Textil & $106 / \mathrm{SR}$ & $-/ \mathrm{JN}, \mathrm{GE}, \mathrm{DC}, \mathrm{SM}$ & SR \\
\hline $26 / 8 / 93$ & Pozo Sur & FDA, ofrenda & Cerámica & $107 / 13$ & GE/- & $\begin{array}{l}\text { Ceramio No. 1. Ítem } \\
28\end{array}$ \\
\hline $26 / 8 / 93$ & Pozo Sur & FDA, ofrenda & Cerámica & $091 / 12(1)$ & GE/- & $\begin{array}{l}\text { Cerámica No 2, } \\
\text { mitad. Ítem } 1\end{array}$ \\
\hline $26 / 8 / 93$ & Pozo Sur & FDA, ofrenda & Cerámica & $091 / 12(2)$ & GE/- & $\begin{array}{l}\text { Cerámica No 2, } \\
\text { mitad y fragmento } \\
\text { Ítem } 1\end{array}$ \\
\hline $26 / 8 / 93$ & Pozo Sur & FDA & Tierra & $096 / 17$ & GE/- & $\begin{array}{l}\text { Interior del ceramio } \\
\text { 2. Inventario FDA } \\
\text { 16, Ítem } 24\end{array}$ \\
\hline $26 / 8 / 93$ & Pozo Sur & FDA, ofrenda & Cerámica & $100 / 12$ & GE, JN/- & $\begin{array}{l}\text { Cerámica No. } 3 \text { Ítem } \\
23\end{array}$ \\
\hline $26 / 8 / 93$ & Pozo Sur & FDA & Tierra & $104 / 17$ & JN, GE/- & $\begin{array}{l}\text { Material 8. interior } \\
\text { del Ceramio 3. Ítem } \\
15 .\end{array}$ \\
\hline $26 / 8 / 93$ & SR & Ofrenda FDA & Cerámica & $121 / 7$ & GE, JN/JN & Ítem 12 \\
\hline $26 / 8 / 93$ & Pozo Sur & FDA, ofrenda & Cerámica & $093 / 13$ & GE/- & Ítem 26. No. 5 \\
\hline $26 / 8 / 93$ & SR & $\begin{array}{l}\text { Tierra que cubría el } \\
\text { FDA }\end{array}$ & Cerámica & $092 / 7(1)$ & GE, JN/- & Ítem 21 y 22 \\
\hline $26 / 8 / 93$ & Pozo Sur & FDA & Cerámica & $092 / 7(2)$ & GE/- & Ítem 25 \\
\hline $26 / 8 / 93$ & Pozo 2 & $\begin{array}{l}\text { Tierra que cubría el } \\
\text { FDA }\end{array}$ & Cerámica & $089 / 7$ & GE, JN/JN & Ítem 2 \\
\hline $26 / 8 / 93$ & Pozo Sur & FDA & Botánico & $102 / 8$ & JN, GE/- & Material 24. Ítem 13 \\
\hline $26 / 8 / 93$ & Pozo Sur & $\begin{array}{l}\text { Entierro FDA, ofrenda } \\
\text { funeraria }\end{array}$ & Botánico & $090 / 8$ & JN, GE/- & $\begin{array}{l}\text { 9@. Mate 1a. Ítem } \\
17\end{array}$ \\
\hline $26 / 8 / 93$ & Pozo Sur & Ofrenda FDA, & Botánico & $108 / 8$ & JN, GE/- & $\begin{array}{l}\text { Mate 1b (parte } \\
\text { inferior). Ítem } 18\end{array}$ \\
\hline $26 / 8 / 93$ & Pozo Sur & FDA, Ofrenda & Botánico & $101 / 8$ & JN, GE/- & Mate 2. Ítem 3 \\
\hline $26 / 8 / 93$ & Pozo Sur & SR. & Tierra & 105/17 & JN, GE/- & $\begin{array}{l}\text { Interior del mate } 2 . \\
\text { Material } 30 \text {. Ítem } 16\end{array}$ \\
\hline $26 / 8 / 93$ & Pozo Sur & Ofrenda FDA & Botánico & $098 / 9$ & GE/- & $\begin{array}{l}\text { Mate } 3 \text {. El registro } \\
\text { numérico del Mate } \\
\text { coincide con 098/24, } \\
\text { pero los mates son }\end{array}$ \\
\hline
\end{tabular}

15

\begin{tabular}{|c|c|c|c|c|c|c|}
\hline & & & & & & diferentes \\
\hline 26/8/93 & Pozo Sur & Ofrenda FDA & Botánico & $098 / 24$ & GE/- & Mate 3. Ítem 19 \\
\hline 26/8/93 & Pozo Sur & FDA & Tierra & 118/17 & JN, GE/- & $\begin{array}{l}\text { Interior Mate 3. ítem } \\
7\end{array}$ \\
\hline $26 / 6 / 93$ & Pozo Sur & FDA & Tierra & $097 / 17$ & GE/- & $\begin{array}{l}\text { Dentro y fuera del } \\
\text { Mate 3, cubrió } \\
\text { parcialmente al telar }\end{array}$ \\
\hline $26 / 8 / 93$ & Pozo Sur & Ofrenda del FDA & Botánico & $094 / 8$ & GE/- & $\begin{array}{l}\text { Mate 4. 5b@, ítem } \\
20\end{array}$ \\
\hline $26 / 8 / 93$ & Pozo Sur & FDA & Botánico & $116 / 27$ & JN, GE/- & $\begin{array}{l}\text { Corontas de maíz } 2 \\
\text { y } 3 \text {. Ítem } 10\end{array}$ \\
\hline $26 / 8 / 93$ & Pozo Sur & FDA & Botánico & $115 / 27$ & JN, GE/- & $\begin{array}{l}\text { Corontas de maíz } 4 \\
\text { y } 5 \text {. Ítem } 9\end{array}$ \\
\hline $26 / 8 / 93$ & Pozo Sur & FDA & Botánico & $117 / 27$ & JN, GE/- & $\begin{array}{l}\text { Corontas de maíz. } \\
\text { Ittem } 6\end{array}$ \\
\hline $26 / 8 / 93$ & Pozo Sur & SR & Botánico & $103 / 80$ & JN, GE/- & $\begin{array}{l}\text { 8b@. Cincho de } \\
\text { estera }\end{array}$ \\
\hline $26 / 8 / 93$ & Pozo Sur & FDA & Óseo & $124 / 10$ & JN, GE/- & B(2c). Material 25. \\
\hline $26 / 8 / 93$ C. $12 B$ & Pozo Sur & $\begin{array}{l}\text { Tierra que cubría el } \\
\text { FDA }\end{array}$ & Malacológico & $120 / 30$ & JN, GE/- & Ítem 11 \\
\hline $26 / 8 / 93$ C. $12 C$ & $\begin{array}{l}\text { Pozo Sur, Perfil } \\
\text { Este del FDA }\end{array}$ & Entierro D & Textil & $2584 / \mathrm{SR}$ & GE/GE & $\begin{array}{l}\text { Bolsa de Cemento } 2 \text {. } \\
\text { Textil y algodón } \\
\text { asociado a óseo }\end{array}$ \\
\hline $26 / 8 / 93$ & $\begin{array}{l}\text { Pozo Sur, Perfil } \\
\text { Este, Este del FDA }\end{array}$ & Entierro D, E & Botánico & $2582 / 78(1)$ & GE/- & $\begin{array}{l}\text { Bolsa de Cemento } 1 . \\
\text { Código repetido. }\end{array}$ \\
\hline $26 / 8 / 93$ & $\begin{array}{l}\text { Pozo Sur, Perfil } \\
\text { Este, Este del FDA }\end{array}$ & Entierro D, E & Botánico & $2582 / 78(2)$ & GE/- & Bolsa de Cemento 3 \\
\hline $26 / 8 / 93$ & $\begin{array}{l}\text { Pozo Sur, Perfil } \\
\text { Este del FDA }\end{array}$ & Entierro D, E & Malacológico & $2586 / 83$ & GE/- & Bolsa de Cemento 3 \\
\hline $26 / 8 / 93$ & $\begin{array}{l}\text { Pozo Sur, Perfil } \\
\text { Este, Este del FDA }\end{array}$ & Entierro D, E & Óseo & $2587 / 79(1)$ & GE/- & $\begin{array}{l}\text { Bolsa de Cemento } 3 \text {, } \\
\text { ítem } 55\end{array}$ \\
\hline $26 / 8 / 93$ & $\begin{array}{l}\text { Pozo Sur, Perfil } \\
\text { Este, Este del FDA }\end{array}$ & Entierro D, E & Óseo & $2587 / 33(2)$ & GE/- & $\begin{array}{l}\text { Bolsa de Cemento } 3 \text {, } \\
\text { ítem } 55\end{array}$ \\
\hline $26 / 8 / 93$ & $\begin{array}{l}\text { Pozo Sur, Perfil } \\
\text { Este, Este del FDA }\end{array}$ & Entierro D, E & Óseo & $2587 / 33(3)$ & GE/- & $\begin{array}{l}\text { Bolsa de Cemento } 3 \text {, } \\
\text { ítem } 55\end{array}$ \\
\hline $26 / 8 / 93$ & $\begin{array}{l}\text { Pozo Sur, Perfil } \\
\text { Este, Este del FDA }\end{array}$ & Entierro D, E & Óseo & $2583 / 33(1)$ & GE/- & $\begin{array}{l}\text { Bolsa de Cemento } 2 \text {, } \\
\text { ítem } 54\end{array}$ \\
\hline $26 / 8 / 93$ & $\begin{array}{l}\text { Pozo Sur, Perfil } \\
\text { Este, Este del FDA }\end{array}$ & Entierro D, E & Óseo & 2583/33 (2) & GE/- & $\begin{array}{l}\text { Bolsa de Cemento 2, } \\
\text { ítem } 54\end{array}$ \\
\hline 26/8/93 & Pozo Sur, Perfil & Entierro D, E & Óseo & $2581 / 23(1)$ & GE/- & Bolsa de Cemento 1, \\
\hline
\end{tabular}


Gori Echevarría y Alex Zúñiga / Los contextos funerarios y los materiales arqueológicos de la Huaca Concha

\begin{tabular}{|c|c|c|c|c|c|c|}
\hline & Este, Este del FDA & & & & & ítem 53 \\
\hline $26 / 8 / 93$ & $\begin{array}{l}\text { Pozo Sur, Perfil } \\
\text { Este, Este del FDA }\end{array}$ & Entierro D, E & Óseo & $2581 / 23(2)$ & GE/- & $\begin{array}{l}\text { Bolsa de Cemento 1, } \\
\text { ítem } 53\end{array}$ \\
\hline $26 / 8 / 93$ & $\begin{array}{l}\text { Pozo Sur, Perfil } \\
\text { Este, Este del FDA }\end{array}$ & Entierro D, E & Óseo & $2581 / 23(3)$ & GE/- & $\begin{array}{l}\text { Bolsa de Cemento } 1 \text {, } \\
\text { ítem } 53\end{array}$ \\
\hline $26 / 8 / 93$ & $\begin{array}{l}\text { Pozo Sur, Perfil } \\
\text { Este, Este del FDA }\end{array}$ & Entierro D & Arcilla & $2588 / 84$ & GE/- & $\begin{array}{l}\text { Bolsa de Cemento } \\
\text { No } 3\end{array}$ \\
\hline $26 / 8 / 93$ & $\begin{array}{l}\text { Pozo Sur, Perfil } \\
\text { Este, Este del FDA }\end{array}$ & Entierro D, E & Lítico & $2585 / 81$ & GE/- & Bolsa de Cemento 3 \\
\hline $26 / 8 / 93 \mathrm{C} .12 \mathrm{CH}$ & Pozo Sur & $\begin{array}{l}\text { Material disturbado, } \\
\text { FDA }\end{array}$ & Botánico & $351 / 28$ & $-/ \mathrm{GE}$ & $\begin{array}{l}\text { Bolsa de cemento } 4 . \\
\text { Número } 22\end{array}$ \\
\hline $26 / 8 / 93$ & Pozo Sur & $\begin{array}{l}\text { Material disturbado, } \\
\text { FDA }\end{array}$ & Botánico & $2450 / 28$ & $-/ \mathrm{GE}$ & $\begin{array}{l}\text { Bolsa de Cemento } 5 . \\
\text { Ítem } 57\end{array}$ \\
\hline $26 / 8 / 93$ & $\begin{array}{l}\text { Pozo Sur, Perfil } \\
\text { Este, Este del FDA }\end{array}$ & $\begin{array}{l}\text { Material disturbado, } \\
\text { FDA }\end{array}$ & Botánico & $2582 / 78(3)$ & SR & Bolsa de Cemento 5 \\
\hline $26 / 8 / 93$ & $\begin{array}{l}\text { Pozo Sur, Perfil } \\
\text { Este, Este del FDA }\end{array}$ & Material disturbado & Óseo & $2589 / 33$ & GE/- & Bolsa de cemento 5 \\
\hline $26 / 8 / 93$ C. $12 D$ & Zona A & $\mathrm{SR}$ & Botánico & $128 / 27$ & $\mathrm{SR}$ & Mate 5. Ítem 33 \\
\hline 26/8/93 C. $12 E$ & Pozo Sur & Entierro & Botánico & $112 / 9$ & $\mathrm{SR}$ & Mate \\
\hline $26 / 8 / 93$ C. $12 F$ & Pozo Sur & SR & Cerámica & $113 / 13$ & SR & $\begin{array}{l}\text { Entera. Borde muy } \\
\text { deteriorado y } \\
\text { presencia de hollín }\end{array}$ \\
\hline $26 / 8 / 93$ & Pozo Sur & SR & Botánico & $125 / 27$ & -/LW, GE & $\begin{array}{l}\text { Material } 22 \text { FDA. } \\
\text { Fragmento de tusa. } \\
\text { ¿Ítem } 10 ?\end{array}$ \\
\hline $26 / 8 / 93$ & Pozo Sur & SR & Botánico & $110 / 27$ & SR & $\begin{array}{l}\text { Îtem 19. Base de } \\
\text { una vasija de mate }\end{array}$ \\
\hline $26 / 8 / 93$ & Pozo Sur & SR & Orgánico & $114 / 80$ & SR & $\begin{array}{l}\text { Plumas de color } \\
\text { blanco amarradas }\end{array}$ \\
\hline $27 / 8 / 93$ C. $12 G$ & Pozo Sur & Tumba FDA & Textil & $147 / S R$ & GE/GE & $\begin{array}{l}6 \mathrm{C} @ \text { Material } \\
\text { diverso: soguillas, } \\
\text { textiles, carbones, } \\
\text { vegetales, pequeñas } \\
\text { conchas y huesos }\end{array}$ \\
\hline $27 / 8 / 93$ & Pozo Sur & $\begin{array}{l}\text { Entierro FDA, Fardo } \\
\text { funerario }\end{array}$ & Textil & $137 / S R$ & -/DC, JN, SM, GE & SR \\
\hline $27 / 8 / 93$ & Pozo Sur & Tumba FDA & Textil & $154 / S R$ & $\mathrm{JN}, \mathrm{DC} /-$ & $\begin{array}{l}\text { Bolsa6d@ Textil y } \\
\text { vegetales asociados } \\
\text { a entierro }\end{array}$ \\
\hline
\end{tabular}

17

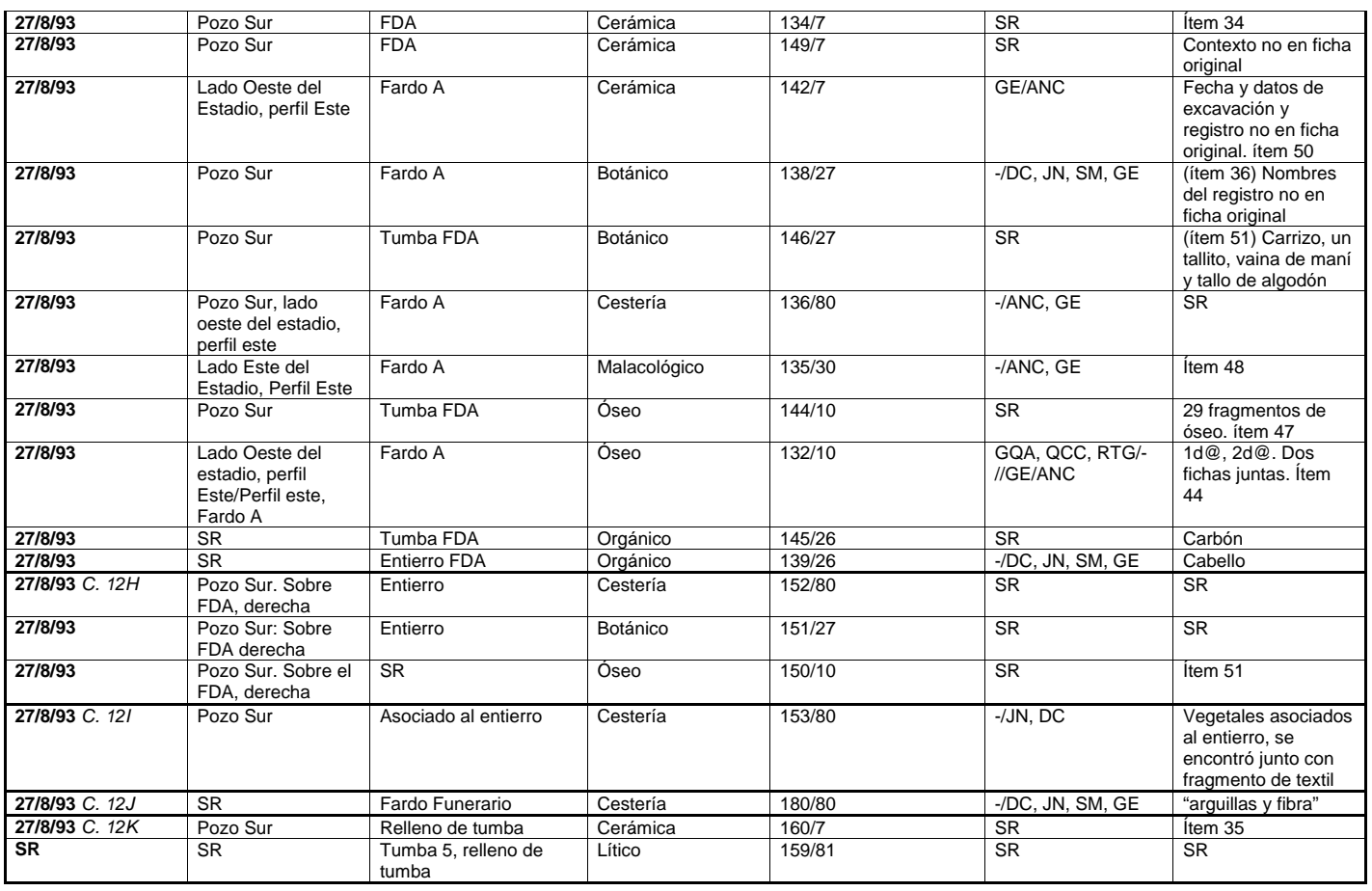


Arqueología y Sociedad 29, 2015: 183 - 231

\begin{tabular}{|c|c|c|c|c|c|c|}
\hline $27 / 8 / 93$ C. $12 L$ & $\mathrm{SR}$ & Recuperación No. 3 & Cerámica & $080 / 7$ & $\mathrm{SR}$ & Ítem 58 \\
\hline $27 / 8 / 93$ C. $12 M$ & Pozo Sur & Disturbado & Lítico & $141 / 81$ & $\mathrm{JN} /-$ & $\begin{array}{l}\text { Piedras, } 9 \text { unidades. } \\
\text { Ítem } 37\end{array}$ \\
\hline $27 / 8 / 93$ C. $12 N$ & $\begin{array}{l}\text { Lado Oeste del } \\
\text { Estadio, Perfil Este. }\end{array}$ & $\mathrm{SR}$ & Cerámica & $126 / 7$ & -/Delia Aponte & Ítem 43 \\
\hline $27 / 8 / 93$ & $\begin{array}{l}\text { Lado Oeste del } \\
\text { estadio, Perfil este }\end{array}$ & SR & Botánico & $130 / 27$ & $\begin{array}{l}\text { GQA, QCC, RTG, } \\
\text { MAS/Andy }\end{array}$ & $\begin{array}{l}\text { 1A@. "Textil, carbón } \\
\text { y otros (vegetal)". }\end{array}$ \\
\hline $27 / 8 / 93$ & $\begin{array}{l}\text { Lado Oeste del } \\
\text { estadio, perfil Este }\end{array}$ & SR & Botánico & $129 / 27$ & GQA, QCC/- & Ítem 7 \\
\hline $27 / 8 / 93$ & Pozo Sur & SR & Cestería & $148 / 80$ & SR & $\begin{array}{l}4 \text { fragmentos de } \\
\text { soguilla }\end{array}$ \\
\hline $27 / 8 / 93$ & $\begin{array}{l}\text { Oeste del estadio, } \\
\text { perfil este }\end{array}$ & SR & Malacológico & $127 / 30$ & GQA, RCT/ANC & 1B@ \\
\hline $27 / 8 / 93$ & SR & SR & Orgánico & $143 / 26$ & GE/ANC & $\begin{array}{l}\text { Un fragmento de } \\
\text { carbón }\end{array}$ \\
\hline $27 / 8 / 93$ & $\begin{array}{l}\text { Lado Oeste del } \\
\text { estadio, Perfil Este }\end{array}$ & SR & Orgánico & $131 / 26$ & $\begin{array}{l}\text { GQA, QCC, RTG, } \\
\text { MAS/Andy }\end{array}$ & Carbón \\
\hline $27 / 8 / 93$ & Pozo Sur & SR & Orgánico & $133 / 26$ & -ISMR, Goy & Carbón \\
\hline $2 / 9 / 93$ C. $13 A$ & $\begin{array}{l}\text { Pozo Sur. Material } \\
\text { del perfil }\end{array}$ & $\begin{array}{l}\text { Parte del entierro } \\
\text { disturbado. Encima del } \\
\text { entierro } 7\end{array}$ & Textil & $334 / \mathrm{SR}$ & $-/ R L$ & SR \\
\hline $2 / 9 / 93$ & Pozo Sur & $\begin{array}{l}\text { Disturbado, asociado a } \\
\text { entierro } 7\end{array}$ & Cerámica & $336 / 14$ & -/CC, EM, JC & SR \\
\hline $2 / 9 / 93$ & SR & Asociado a entierro 7 & Cerámica & $329 / 15$ & $\mathrm{SR}$ & SR \\
\hline $2 / 9 / 93$ & Pozo Sur & Asociado a entierro 7 & Cerámica & $336 / 15$ & -/CC, EM, JC & SR \\
\hline $2 / 9 / 93$ & SR & Asociado a entierro 7 & Botánico & $330 / 27$ & SR & $\begin{array}{l}\text { Fragmento de mate } \\
\text { y otros. Ítem } 67\end{array}$ \\
\hline $2 / 9 / 93$ & SR & Asociado a Entierro 7 & Botánico & $332 / 80$ & SR & Artefacto \\
\hline $2 / 9 / 93$ & $\begin{array}{l}\text { Pozo Sur. Material } \\
\text { del perfil }\end{array}$ & $\begin{array}{l}\text { Parte del entierro } \\
\text { disturbado. Encima del } \\
\text { Entierro } 7\end{array}$ & Botánico & $335 / 27$ & $-/ R L$ & SR \\
\hline 2/9/93 & Pozo Sur & Entierro 7 & Malacológico & $340 / 30$ & -/Juan Paredes & $\mathrm{SR}$ \\
\hline $2 / 9 / 93$ & Pozo Sur. & $\begin{array}{l}\text { Parte del entierro } \\
\text { disturbado. Encima del } \\
\text { entierro } 7\end{array}$ & Óseo & $333 / 25$ & $\mathrm{RL} /-$ & Ítem 63 \\
\hline $2 / 9 / 93$ & SR & Asociado a Entierro 7 & Óseo & $331 / 25$ & SR & SR \\
\hline 2/9/93 & Material del perfil & Asociado a entierro 7 & Óseo & $337 / 29$ & -/ER & $\mathrm{SR}$ \\
\hline 2/9/93 C. 13B & Pozo Sur & Disturbado & Óseo & $341 / 25$ & PRC/- & $\mathrm{SR}$ \\
\hline
\end{tabular}

19

\begin{tabular}{|c|c|c|c|c|c|c|}
\hline $6 / 9 / 93$ C. $14 A$ & $\begin{array}{l}\text { Sitio Ciudad } \\
\text { universitaria, Sector } \\
4, \text { Unidad } 2\end{array}$ & Entierro 8 & Cerámica & $342 / 15$ & SR & SR \\
\hline $6 / 9 / 93$ & $\begin{array}{l}\text { Sitio Ciudad } \\
\text { Universitaria, } \\
\text { Sector 4, Unidad } 2\end{array}$ & Entierro 8 & Botánico & $344 / 26(1)$ & SR & SR \\
\hline $6 / 9 / 93$ & Sector 4 & Entierro 8 & \begin{tabular}{|l} 
Botánico \\
\end{tabular} & $344 / 26(2)$ & SR & SR \\
\hline $6 / 9 / 93$ & \begin{tabular}{|l|} 
Sector 4, Unidad 2 \\
\end{tabular} & Entierro 8 & \begin{tabular}{|l|} 
Botánico \\
\end{tabular} & $344 / 27(1)$ & SR & Ítem 63 \\
\hline 6/9/93 & \begin{tabular}{|l|} 
Sector 4, Unidad 2 \\
\end{tabular} & Entierro 8 & \begin{tabular}{|l|} 
Botánico \\
\end{tabular} & $344 / 27(2)$ & SR & Ítem 62 \\
\hline 6/9/93 & \begin{tabular}{|l|} 
Sector 4, Unidad 2 \\
\end{tabular} & Entierro 8 & \begin{tabular}{|l} 
Cestería \\
\end{tabular} & $345 / 80$ & SR & SR \\
\hline $6 / 9 / 93$ & Sector 4, Unidad 2. & Entierro 8 & Óseo & $346 / 25$ (1) & SR & $\begin{array}{l}\text { Colocado en el ítem } \\
\text { de la caja no } \\
\text { analizada en } 1993 . \\
\text { Ítem } 61 \\
\end{array}$ \\
\hline 6/9/93 & \begin{tabular}{|l|} 
Sector 4, Unidad 2 \\
\end{tabular} & Entierro 8 & Óseo & $346 / 25(2)$ & SR & SR \\
\hline 6/9/93 & \begin{tabular}{|l} 
Sector 4, Unidad 2 \\
\end{tabular} & Entierro 8 & Óseo & $346 / 25(3)$ & SR & Ítem 61 \\
\hline 6/9/93 & \begin{tabular}{|l|} 
Sector 4, Unidad 2 \\
\end{tabular} & Entierro 8 & Óseo & $346 / 24(4)$ & SR & Ítem 62 \\
\hline $6 / 9 / 93$ & Sector 4, Unidad 2 & Entierro 8 & Óseo & $346 / 25(5)$ & SR & Ítem 62 \\
\hline 6/9/93 & Sector 4 , Unidad 2 & Entierro 8 & \begin{tabular}{|l|} 
Orgánico \\
\end{tabular} & $347 / 26$ & SR & Carbón \\
\hline $6 / 9 / 93$ C. $14 B$ & Pozo Sur & $\begin{array}{l}\text { Material removido de } \\
\text { superficie }\end{array}$ & Óseo & $338 / 29$ & $-/ \mathrm{JJ}, \mathrm{JL}$ & ¿ítem 63? \\
\hline $6 / 9 / 93$ C. $14 C$ & $\begin{array}{l}\text { Sector 4, Zona } \\
\text { sur/2-S }\end{array}$ & $\begin{array}{l}\text { Material disturbado, } \\
\text { limpieza }\end{array}$ & Cerámica & $168 / 18(1 a)$ & -/Aldo Lara y otros. & \begin{tabular}{|l|} 
Incluye material de \\
fechas $7 / 9$ y $8 / 9$ \\
\end{tabular} \\
\hline $6 / 9 / 93$ & Sector 4, Zona sur & Disturbado. & Cerámica & $168 / 18(2)$ & SR & $\begin{array}{l}\text { 11@ Contexto no en } \\
\text { ficha original }\end{array}$ \\
\hline 6/9/93 & Sector 4, (ZS) & Disturbado & \begin{tabular}{|l|} 
Botánico \\
\end{tabular} & $170 / 27$ & $-/ H T$ & SR \\
\hline $6 / 9 / 93$ & Sector 4, zona Sur & Disturbado & Malacológico & $169 / 30$ & $-/ \mathrm{JC}$ & SR \\
\hline $6 / 9 / 93$ C. $14 \mathrm{CH}$ & Sector 4, Zona Sur & $\mathrm{SR}$ & Óseo & $161 / 10(a)$ & $\begin{array}{l}\text {-/JQ, AL.//Alberto } \\
\text { Aranda }\end{array}$ & \begin{tabular}{|l} 
(ítem 64 y 66 ) \\
Incluye material de \\
fechas $7 / 9,8 / 9$ \\
\end{tabular} \\
\hline $6 / 9 / 93$ & 4, Zona Sur & SR & Moderno & $163 / 82$ & SR & \begin{tabular}{|l} 
El código se repite \\
en la caja 26
\end{tabular} \\
\hline $7 / 9 / 93$ C. $14 D$ & $\begin{array}{l}\text { Sector 4, Zona } \\
\text { Sur/2-S }\end{array}$ & $\begin{array}{l}\text { Material disturbado, } \\
\text { limpieza }\end{array}$ & Cerámica & $168 / 18(1 b)$ & -/Aldo Lara y otros. & $\begin{array}{l}\text { Se la ha agrupado } \\
\text { en la misma bolsa } \\
\text { de } 168 \text { (1) }\end{array}$ \\
\hline 7/9/93 & 4-Zona Sur & Material disturbado & \begin{tabular}{|l|} 
Botánico \\
\end{tabular} & $167 / 27$ & SR & SR \\
\hline 7/9/93 & Sector 4, Zona Sur & Material disturbado & \begin{tabular}{|l|} 
Botánico \\
\end{tabular} & $165 / 27$ & \begin{tabular}{|l}
-IAA, Narciso \\
\end{tabular} & SR \\
\hline 7/9/93 & Sector 4, Zona Sur & Material disturbado & Cestería & $166 / 80$ & SR & SR \\
\hline
\end{tabular}


Gori Echevarría y Alex Zúñiga / Los contextos funerarios y los materiales arqueológicos de la Huaca Concha

\begin{tabular}{|c|c|c|c|c|c|c|}
\hline 1993 & $\begin{array}{l}\text { 4, Zona Sur. } \\
\text { Estadio }\end{array}$ & Material disturbado & Óseo & $162 / 10$ & SR & SR \\
\hline $7 / 9 / 93$ C. $14 E$ & Sector 4 , Zona Sur & SR & Óseo & $161 / 10(b)$ & $\begin{array}{l}-/ J Q, A L . / / A \text { Alberto } \\
\text { Aranda }\end{array}$ & $\begin{array}{l}\text { Incluye material de } \\
\text { fechas } 6 / 9 \text { y } 8 / 9 \text {. } \\
\text { Ítem } 64 \text { y } 66\end{array}$ \\
\hline $8 / 9 / 93$ C. $14 \mathrm{~F}$ & $\begin{array}{l}\text { Sector 4, Zona } \\
\text { Sur/2-S }\end{array}$ & $\begin{array}{l}\text { Material disturbado, } \\
\text { limpieza }\end{array}$ & Cerámica & $168 / 18(1 \mathrm{c})$ & -/Aldo Lara y otros. & $\begin{array}{l}\text { Se la ha agrupado } \\
\text { en la misma bolsa } \\
\text { de } 168(1 \mathrm{a}, \mathrm{b} \text { y } \mathrm{c})\end{array}$ \\
\hline $8 / 9 / 93$ C. $14 G$ & Sector 4, Zona Sur & SR & Botánico & $164 / 27$ & SR & $\begin{array}{l}\text { Dos fragmentos de } \\
\text { mate }\end{array}$ \\
\hline $8 / 9 / 93$ & Sector 4, Zona Sur & SR & Óseo & $161 / 10$ (c) & $\begin{array}{l}\text {-/JQ, AL.//Alberto } \\
\text { Aranda }\end{array}$ & $\begin{array}{l}\text { Incluye material de } \\
\text { fechas } 6 / 9,7 / 9 \text {. Ítem } \\
64 \text { y } 66\end{array}$ \\
\hline $8 / 9 / 93$ & $\begin{array}{l}\text { Sector 4, Zona Sur. } \\
\text { Estadio }\end{array}$ & SR & Orgánico & $163 / 26$ & $\begin{array}{l}\text {-/Aldo Lara, Jhony } \\
\text { Quispe }\end{array}$ & Carbón \\
\hline $21 / 7 / 94$ C. $15 A$ & Plataforma superior & $\begin{array}{l}\text { Disturbado por } \\
\text { maquinaria }\end{array}$ & Malacológico & $085 / 30$ & SR & SR \\
\hline $21 / 7 / 94$ & $\begin{array}{l}\text { Plataforma } \\
\text { superior, Pozo Sur } \\
2\end{array}$ & SR & Botánico & $088 / 8$ & SR & Fragmento de mate \\
\hline $23 / 7 / 94$ C. $15 B$ & Pozo Sur 2 & SR & Cerámica & $087 / 11(1)$ & $\mathrm{JN} /-$ & $\mathrm{SR}$ \\
\hline $23 / 7 / 94$ & $\begin{array}{l}\text { Unidad Pozo Sur 2, } \\
\text { plataforma superior }\end{array}$ & SR & Cerámica & $087 / 11(2)$ & $-/ J N, P E, S M$ & SR \\
\hline $23 / 7 / 94$ & Pozo Sur 2 & $\begin{array}{l}\text { Asociado a entierros y } \\
\text { esquina con adobitos } \\
\text { reutilizados }\end{array}$ & Cerámica & $087 / 11(3)$ & $\mathrm{JN} /-$ & SR \\
\hline $23 / 7 / 94$ & $\begin{array}{l}\text { Unidad Pozo Sur 2, } \\
\text { plataforma superior }\end{array}$ & SR & Cerámica & $087 / 11(4)$ & $-/ \mathrm{JN}, \mathrm{PE}, \mathrm{SM}$ & SR \\
\hline $23 / 7 / 94$ & $\begin{array}{l}\text { Pozo 2. Entre el } \\
\text { baño sur y cerca } \\
\text { del estadio }\end{array}$ & $\begin{array}{l}\text { Fragmentería mayor } \\
\text { asociada a un entierro }\end{array}$ & Cerámica & $087 / 11(5)$ & $-/ \mathrm{JN}, \mathrm{PE}, \mathrm{SM}$ & SR \\
\hline $23 / 7 / 94$ & $\begin{array}{l}\text { Unidad Pozo Sur 2, } \\
\text { plataforma superior }\end{array}$ & SR & Cerámica & $087 / 11(6)$ & $-/ \mathrm{JN}, \mathrm{PE}, \mathrm{SM}$ & SR \\
\hline $23 / 7 / 94$ & Pozo Sur & $\begin{array}{l}\text { Asociado a entierros y } \\
\text { adobitos reutilizados }\end{array}$ & Botánico & $095 / 8$ & JNL/- & Mate \\
\hline 1/8/94 C. $16 A$ & Pozo Sur 2 & Desmonte del Pozo & Botánico & $084 / 9$ & JN, SM/- & Mate \\
\hline
\end{tabular}

21

\begin{tabular}{|c|c|c|c|c|c|c|}
\hline 1/8/94 C. $16 B$ & Pozo Sur & SR & Óseo & $086 / 10$ & SR & $\begin{array}{l}\text { Cráneo entregado } \\
\text { por personal de } \\
\text { vigilancia del estadio }\end{array}$ \\
\hline 1993 C. $17 A$ & SR & Entierro & Orgánico & $299 / 22$ & $\mathrm{SR}$ & Entierro de infante \\
\hline SR & Pozo Norte & $\begin{array}{l}\text { Material de desmonte } \\
\text { (recolección) }\end{array}$ & Botánico & $177 / 27$ & SR & SR \\
\hline SR & Pozo Norte & $\begin{array}{l}\text { Material de desmonte, } \\
\text { (recolección) }\end{array}$ & Malacológico & $179 / 30$ & SR & SR \\
\hline SR C. 17C & $\begin{array}{l}\text { Pozo 2, Perfil, } \\
\text { Unidad } 2\end{array}$ & Limpieza & Cerámica & $253 / 18$ & $\mathrm{SR}$ & $\mathrm{SR}$ \\
\hline SR C. $17 \mathrm{CH}$ & $\mathrm{SR}$ & SR & Cerámico & $352 / 15$ & $\mathrm{SR}$ & $\mathrm{SR}$ \\
\hline SR & $\begin{array}{l}\text { Maranga, Huaca } \\
\text { Concha }\end{array}$ & SR & Botánico & $353 / 26$ & SR & $\begin{array}{l}\text { Pequeños } \\
\text { fragmentos de } \\
\text { soguillas }\end{array}$ \\
\hline SR & $\begin{array}{l}\text { Maranga, Huaca } \\
\text { Concha }\end{array}$ & SR & Botánico & $355 / 26$ & SR & Mate \\
\hline
\end{tabular}


